Portland State University

PDXScholar

$1-1-2012$

\title{
Engaging Global Service: Organizational Motivations for and Perceived Benefits of Hosting International Volunteers
}

Erin Leslie Barnhart

Portland State University

Follow this and additional works at: https://pdxscholar.library.pdx.edu/open_access_etds Let us know how access to this document benefits you.

\section{Recommended Citation}

Barnhart, Erin Leslie, "Engaging Global Service: Organizational Motivations for and Perceived Benefits of Hosting International Volunteers" (2012). Dissertations and Theses. Paper 372.

https://doi.org/10.15760/etd.372

This Dissertation is brought to you for free and open access. It has been accepted for inclusion in Dissertations and Theses by an authorized administrator of PDXScholar. Please contact us if we can make this document more accessible: pdxscholar@pdx.edu. 
Engaging Global Service: Organizational Motivations for and Perceived Benefits of Hosting International Volunteers

by

Erin Leslie Barnhart

A dissertation submitted in partial fulfillment of the requirements for the degree of

\author{
Doctor of Philosophy \\ in \\ Urban Studies
}

\author{
Dissertation Committee: \\ Ellen Bassett, Chair \\ Carl Abbott \\ Leslie McBride \\ Margaret Sherrard Sherraden \\ Richard White
}

Portland State University

(C) 2012 


\begin{abstract}
An increasingly popular way for global citizens to contribute to communities around the world is through international volunteering. In tandem with this growing trend, academic research in the field has increased to explore the goals, motivations, and impacts of international service on volunteers, host communities, and volunteer-sending organizations. One of the larger gaps in our understanding of global civic engagement though is the specifics of how and why, as well as the overall impact of international service on, host organizations that seek and/or accept international volunteers.

Using an exploratory research design to collect and analyze survey data and openended email inquiry responses from almost 250 organizational representatives in $50+$ countries, this dissertation expands the breadth and depth of knowledge on the relationship between host organizations and international volunteers. Findings include a broad and varied range of potential motivations for hosting international volunteers, from direct benefits to the host organization like leveraging organizational capacity to benefits extended to the broader community and volunteers themselves such as providing opportunities for cross-cultural interaction. In addition, host organization characteristics and opinions were compared between two global regions - Africa and Asia - and statistically significant relationships identified between characteristics and opinions of host organizations and their reported satisfaction with international volunteers.

This study contributes new data on and from organizations that host international volunteers. Research findings also support and expand the field's understanding of international volunteer engagement as it relates specifically to organizational capacity and social capital theory.
\end{abstract}




\section{Dedication}

To Kenneth R. Maupin,

for his unwavering and inestimable support and encouragement. Thank you. 


\section{Acknowledgments}

I would like to express my sincere thanks and appreciation to Action Without Borders/Idealist.org, especially Julia Smith and Jeremy MacKechnie, for their generous and invaluable assistance during the course of this research. I would also like to thank my dissertation committee for their thoughtful guidance with the preparation, research, analysis, and writing of this dissertation, with special acknowledgment of Dr. Carl Abbott for serving as my much-valued advisor throughout my doctoral program.

I am wholeheartedly grateful to my many peers who have provided inspiration throughout my professional and academic career, including Dr. Margaret Sherraden, Dr. Amanda Moore McBride, Dr. Benjamin Lough, Zahara Heckscher, Joe Collins, Stefano DeZerega, Karen Heller Key, Mark Hoelter, Jayne Cravens, Thomas Winston Morgan, Steven Rosenthal, and Carlton Rounds. It is a privilege to consider so many of you to be both my colleagues and my friends. Speaking of colleagues and friends, I would be remiss if I did not extend my deepest gratitude to "Finkel's Team," especially Meg Busse, Steven Joiner, Eric Fichtl, Kyle Dawkins, Ken Maupin, and my treasured friend and mentor Russ Finkelstein; this very special group of professional teammates and dear friends have in no small way helped to shape the direction of my career as well as contributed immeasurable inspiration, laughter, and joy to my life.

Finally, special thanks and love to my family for their resolute encouragement of and confidence in me: my parents Steve and Marilyn Barnhart, my sister and brother-inlaw Elizabeth and Matt Droscher, my niece and nephew Kate and Ben Droscher, and my partner Ken Maupin. Thank you, all. 


\section{Engaging Global Service: \\ Organizational Motivations for and Perceived Benefits of Hosting International Volunteers}

Table of Contents

Abstract.

Dedication. .ii

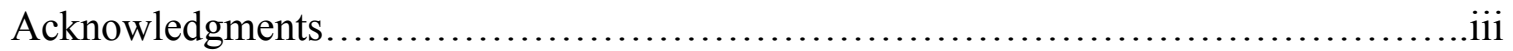

List of Tables........................................................................

Chapter 1: Introduction.....................................................

Chapter 2: Literature Review...............................................4

Theoretical and Empirical Framework................................. 10

Chapter 3: Research Design and Methods........................................ 34

Research Design...................................................... 34

Guiding Research Questions..........................................36

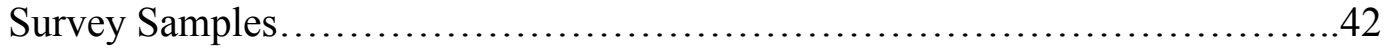

Survey Limitations................................................44

Follow-Up Questions Sample and Limitations............................46

Data Collection...................................................47

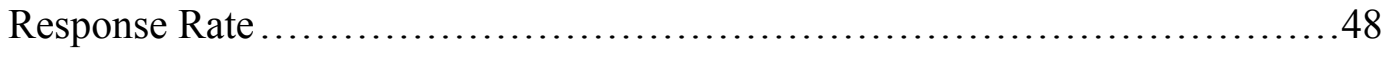

Data Preparation...................................................49

Chapter 4: Research Findings..............................................53

Host Organization Characteristics.....................................53

Host Organization Opinions and Perspectives..............................73

Host Organization Characteristics and Opinions by Geography................99 
Host Organization Characteristics and Opinions by Recruitment Type...........112

Statistically Significant Relationships.................................116

Responses to Follow-Up Questions...................................136

Responses from Organizations That Do Not Host International Volunteers......146

Chapter 5: Conclusions................................................... 148

Research Summary...................................................148

Theoretical Contributions.................................................. 158

Research Significance.............................................172

Limitations......................................................... 174

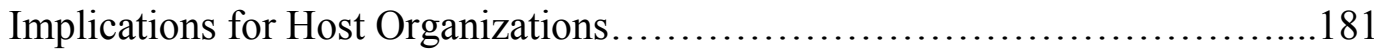

Suggestions for Future Research...................................... 186

References............................................................ 193

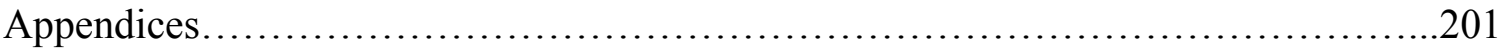

Appendix A: Sample Selection of Idealist.org Areas of Focus..................201

Appendix B: Survey Questions......................................204

Appendix C: Follow-Up Questions...................................215

Appendix D: Distribution of Respondent Countries........................217 


\section{List of Tables}

Table 1. Hypothesized Relationships Between Organization's Volunteer Program Characteristics and Reported Benefits, Challenges, and Satisfaction with Engaging International Volunteers..................................... 38

Table 2. Respondent Statistics per Region..................................54

Table 3. Percentage of Responses to Survey Question "What is your organization's

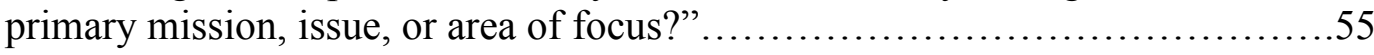

Table 4. Distribution of Each Area of Focus Across Regions........................56

Table 5. Percentage of Respondent Areas of Focus in Each Region....................57

Table 6. Responses to Survey Question "How are international volunteers managed at

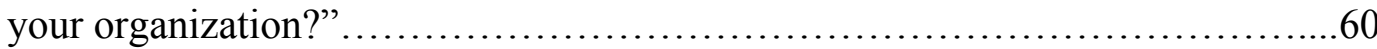

Table 7. Additional International Service Requirements Reported by Respondents......63

Table 8. Responses to Survey Question "How Long Do International Volunteers Serve with Your Organization?" .................................................67

Table 9. Training Methods Shared by Survey Respondents..........................69

Table 10. Reported Organizational Motivations for Deciding to Host International

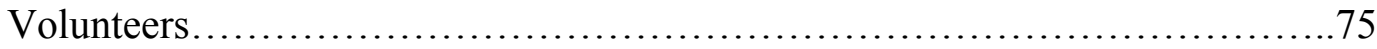

Table 11. Percentage of Responses to "What do you think are the potential benefits of hosting international volunteers? Please mark how much you agree or disagree

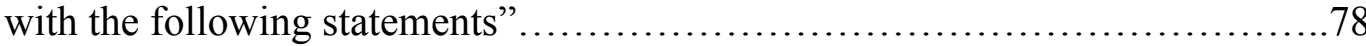

Table 12. Percentage of Responses to "What do you think are the potential challenges of hosting international volunteers? Please mark how much you agree or disagree with the following statements"

Table 13. Responses to "Overall, do you think that it is worthwhile for your organization to host international volunteers?"

Table 14. Percentage of respondents citing common types of projects done by international volunteers

Table 15. Variables Where Difference Between Overall Sample and Specific Recruitment Type Responses was $+/-5.0 \%$ 
Table 16. Statistically Significant Relationships (Dependent Variable: Benefits

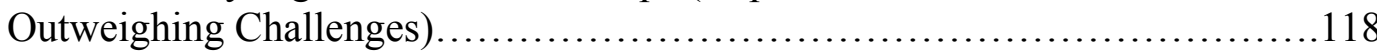

Table 17. Statistically Significant Relationships for Community Development Organizations (Dependent Variable: Benefits Outweighing Challenges)........120

Table 18. Statistically Significant Relationships for Education Organizations (Dependent Variable: Benefits Outweighing Challenges) ..................................121

Table 19. Statistically Significant Relationships (Dependent Variable: Whether Hosting International Volunteers is Worthwhile).... 123

Table 20. Statistically Significant Relationships for Education Organizations (Dependent Variable: Whether Hosting International Volunteers is Worthwhile).

Table 21. Statistically Significant Relationships for Environment Organizations (Dependent Variable: Whether Hosting International Volunteers is Worthwhile)

Table 22. Statistically Significant Relationships Identified via Twelve Hypotheses.....156

Table 23. Statistically Significant Relationships Related to Organizational Capacity...161

Table 24. Statistically Significant Relationships Related to Social Capital.............167 


\section{Chapter 1: Introduction}

On April 15, 2009, I posted the following entry to my personal blog: "So, it's now a few days before departure and I've done my research, read up a bit on history and cultural norms, and talked to a handful of folks who have spent time in Jordan. Still though, I'm prepared to have my eyes opened wide to a whole new world, one I've never experienced, where a call to prayer rings through the hallways of two-thousand-year old buildings five times a day." Two days later, I boarded the first of several planes to travel from Portland, Oregon to Amman, Jordan where I spent two weeks volunteering with a local NGO.

My motivations for volunteering abroad were threefold. The first two were largely about my own personal development and interests: I'd never been to the Middle East and wanted to learn more about this region of the world and, as a woman, was also eager to experience modern gender relations in a vastly different culture than my own. My third reason though was primarily professional. Having built a thriving career studying and implementing strategies for effective civic engagement, up until that point largely in the field of domestic volunteerism, I wanted to learn firsthand about the increasingly popular phenomenon of international service: what it felt like to be a volunteer abroad, how the process of matching volunteers to opportunities might be different when crossing borders (not to mention adding whole new levels of complexity to the exchange), what volunteer management looked like from the other side of the looking glass.

While my experience in Jordan was on the whole overwhelmingly positive, I was surprised and somewhat disappointed to discover that I was in fact a largely ineffective 
volunteer. I knew that staying for only two weeks meant that my contributions would be severely limited and that my lack of Arabic language skills would further hamper my impact, but I'd assumed that coming in with a professional expertise meant that I could make some kind of lasting contribution during my very short tenure. What I discovered though was, despite having gone through a reputable volunteer-sending organization to an organization that regularly hosted international volunteers, the infrastructure to put me to work was minimal and somewhat ad hoc. I came to the Jordanian NGO with a genuine interest in helping out, only to discover that there was in fact little for me to do. While I ended up doing a few independent projects that I'd like to think ended up ultimately being valuable to my host organization, my biggest takeaway from this experience was a sparked interest in the experiences and motivations of host organizations. I knew what my motivations were for seeking to volunteer abroad and had done my research to learn more about the mission and motivations of the volunteer-sending organization that placed me, but was genuinely curious why the local organization - an already busy NGO that did not appear to need short-term English-speaking international volunteers - agreed to serve as my host.

My journey from the Pacific Northwest to the Middle East in the Spring of 2009 served as a flashpoint for my interest in effective international service. In the years following my volunteer abroad experience, I have spent a considerable amount of professional and academic time exploring these very concepts. And while in this process I have discovered a rich body of research and growing understanding of the benefits, challenges, and motivations of international service for the individual volunteer, as well 
as increasingly for volunteer-sending organizations and host communities, my questions about the motivations of host organizations remained unanswered.

This dissertation was designed to begin the process of filling in these gaps, asking questions of and hearing directly from host organizations around the globe in order to learn more about why and how they decided to and host international volunteers.

This paper is structured as follows: the next chapter, Chapter 2, provides context for the overall field of international service studies by offering a synthesis of the current literature as well as laying down a theoretical and empirical foundation for understanding the potential value of international volunteers. The following chapter, Chapter 3, introduces the research design and methodology of this dissertation, as well as five guiding research questions to supplement the central query. Chapter 4 then delves into research results and findings. Finally, Chapter 5 provides a comprehensive analysis of research findings, including a discussion of limitations and how this study's findings are rooted in and expand upon existing theoretical foundations, along with recommendations for future research and potential implications for host organizations in the field. 


\section{Chapter 2: Literature Review}

In 2005, close to one million Americans reported that they volunteered or served internationally. This was an increase of $10 \%$ or 100,000 additional reported international volunteers over 2004 (Lough, 2006). In recent years, public interest in - as well as media, legislative, and organizational attention to - international volunteering ${ }^{1}$ has grown significantly.

Explanations for this growing interest in international service are diverse.

McBride and Daftary (2005) found that increasing globalization and the bridging nature of technologies like media and Internet have led to more individuals becoming invested in situations beyond their own borders, making international service more attractive and increasingly popular. Individual motivations for international service, as identified by Lough, McBride, and Sherraden ${ }^{2}$ (2009), fall primarily into four categories: 1) altruism (making a difference, helping to reduce social or economic inequality), 2) personal transformation (having a meaningful experience, making new friends, seeking personal growth, increasing intercultural awareness and understanding), 3) skill and/or professional development (gaining experience abroad, expanding professional networks, leveraging skills and career development, fulfilling educational requirements, needing a vocation), and 4) simply being asked. Additional motivations include seeking to do something more substantial while traveling (also called vacation volunteering or

\footnotetext{
${ }^{1}$ As defined by Sherraden, Lough, and McBride (2008, p. 397-398), international volunteering and service, or IVS, is "an organized period of engagement and contribution to society by volunteers who work across an international border, in another country, or countries. IVS may be sponsored by public or private organizations, it is recognized and valued by society, and volunteers receive little or no monetary compensation (Sherraden 2001). This definition excludes volunteering within national boundaries, as well as mutual aid and military service."

${ }^{2}$ Please note that these three scholars in particular are responsible for a significant proportion of recent research on international service and volunteerism. Their names, in various combinations, appear throughout the literature.
} 
voluntourism) and self-identification with global citizenship and perceptions of shared responsibility for worldwide social and environmental change.

From an organizational or institutional perspective, Sherraden, Stringham, Sow, and McBride (2006) cited that the primary goals for international voluntary service are to foster cross-cultural understanding, promote peace, and advance a shared global citizenship. An additional motivation for promoting global service is what Rieffel (2005) considers to be soft mechanisms of global power, including citizen diplomacy, e.g. improving the image of the United States internationally as well as the dissemination of American culture, politics, and economics through the positive actions of citizen volunteers.

International volunteers have long been engaged as actors in social and environmental change, particularly in the interest of community development, by structures ranging from global missionary efforts ${ }^{3}$ to government aid and assistance. For

\footnotetext{
${ }^{3}$ In seeking studies to inform the research questions and hypotheses of this dissertation, the literature on missionary and international faith-based voluntary service was explored. What followed was the discovery that, while there have been several studies of the impact of international missions and faith-motivated service on the lives of individual missionaries and volunteers (as well as practitioner accounts and suggestions for more effective engagement), the findings largely mirrored those of the research on broader international service. For example, criticisms emerged that the primary recipients of benefits within international mission trips are the volunteers themselves (Krabill 1998, Eby 1998, Van Engen 2000). Similarly, scholars of international missions have highlighted the perceived importance of providing pre and post-service organizational support and training to individuals, explored the efficacy of short-term trips, and expressed concern over issues of paternalism and colonialism (Priest \& Dischinger n.d., Slate n.d., VanRheenen n.d., Ferris 2005, Friesen 2005, Dohn \& Dohn 2006).

However, while there are many similarities in the literature, there are also a few key differences, including, in some cases, service delivery methods as well as volunteer motivations. For example, Ferris (2005, p. 316) found that "Faith-based humanitarian organizations share many characteristics with their secular counterparts and are influenced by the same political, social and economic contexts. However, there are two characteristics which set faith-based humanitarian organizations apart from most secular humanitarian organizations: they are motivated by their faith and they have a constituency which is broader than humanitarian concerns."
} 
example, in the recent era of neoliberalism, as many government entities outsource human services to external parties, international volunteers have increasingly been sought as delivery agents for services previously provided by the state (McBride \& Daftary, 2005; Rieffel, 2005; Lacey \& Ilcan, 2006).

The models for international voluntary service are diverse and dependent upon several factors (Sherraden, Stringham, Sow, \& McBride, 2006). First, the length of service may be anywhere from short-term to long-term, ranging from one day service projects to several year long commitments. Illustrating this distinction, Lough (2006) found that $65 \%$ of Americans who volunteered abroad in 2005 served for two or fewer weeks while only $15 \%$ volunteered for longer than two months.

Second, the type of volunteer project or role may be direct service - where volunteers are likely on the front lines of service delivery and in direct contact with the population or environment served - or focused more on organizational capacity building - generally more behind the scenes work to help a foreign group, organization, or agency better serve their audience, operate more effectively, or make progress towards their mission.

Third, the direction of service can range from unilateral to bilateral or even multilateral, though most current models of international service remain unilateral exchanges of volunteers from industrialized nations to communities in developing countries. In addition, the organizational type engaging the volunteer can range from government agencies (e.g. the U.S. Peace Corps) to nonprofit or nongovernmental

Given the largely parallel findings and a lack of available research on the perceptions and/or measures of benefit for organizations engaging international missionaries/volunteers - the latter being the focus of this dissertation - this footnote serves as a synthesis of the comparative review of this literature. 
organizations (NGOs) to for-profit entities. These organizations can also be secular or faith-based; indeed, Lough (2006) found that 50\% of Americans who volunteered abroad in 2005 did so with a faith-based organization.

Requirements for a volunteer to participate can range from age - several international service programs are focused on youth engagement while others target older volunteers - to specific skill sets and expertise, while volunteer abroad projects and roles can address issues along an enormous spectrum of potential opportunities and causes from building infrastructure post-disaster to teaching and assisting local entrepreneurs with micro-finance.

Finally, a seventh factor in models of international service - the structure and goals of the organization - bears singling out for the purposes of this dissertation. Specifically, most international volunteers contribute their time and expertise via one of two organizational structures: volunteer-sending organizations and host organizations. Volunteer-sending organizations exist primarily to coordinate and facilitate international exchange; individuals volunteer either directly with and through the volunteer-sending program or with one of their partner organizations in the host community.

Conversely, host organizations are those local entities that seek and/or accept international volunteers - either independently or via a partnership with a volunteersending organization or agency - to assist with local programs, service delivery, and organizational capacity building. Additional albeit less common structures supporting international service include volunteering via a corporate engagement effort and service as part of a study abroad or work abroad program. 
Organizational practices supporting international volunteers also vary widely. Many volunteer-sending, and to a lesser extent, host organizations provide services such as housing, meals, transportation, language support, training and orientation, and/or structured cultural excursions, while others may be unable to provide anything beyond a place for the volunteer to work. The responsibility for recruiting, screening, matching/placing, training, and supervising international volunteers can fall to volunteersending and/or host organizations, and the subsequent costs of engaging an international volunteer can be borne primarily by one or both parties, as well as in many cases passed on to the volunteer.

Several identified societal benefits have been associated with international volunteerism (see the Theoretical and Empirical Framework section of this chapter for potential benefits identified specifically for international volunteers, organizations, and communities), particularly where employed as a method of international aid and assistance. For example, Sherraden et al $(2005$, p. 172) found that volunteerism as a mechanism for community development can advance foreign policy using a different resource: instead of providing traditional financial assistance, international voluntary service focuses on "skill and technology transfer." The United Nations body of UN Volunteers (UNV) seeks specifically to address development goals through international NGO and global volunteer efforts as UNV participants provide direct service and leverage community level voluntary efforts by helping to build local capacity to address social problems (2001). At the same time, by virtue of affiliation with the United Nations, these service efforts benefit from diverse resources, both financial and knowledge-based. Finally, as stated by Lewis (2005): 
As an arena of development activity, international volunteering is important because it can humanize what is often left as a technical or managerial process. It can bridge the gap between the professionalized world of development experts and organisations and the 'non-specialised publics' who engage with the ideas and practices of development...international volunteering can provide tangible contributions to development in the form of skills and other resource transfers, but also - and perhaps more importantly - it can promote international understanding and solidarity. (p. 15-16).

There are also significant criticisms of international service and volunteering.

Lewis (2005) outlined several concerns including a) international volunteers being too closely linked to political objectives, b) international volunteers dismissing ideological differences (raising the question of whether or not international volunteerism can in fact serve as a form of colonialism or paternalism), c) an increasing professionalism - and subsequent potentially exclusive nature - to international volunteering, and d) exclusion of local actors from community development planning and implementation processes.

The latter point was also raised by Lacey and Ilcan (2006) as the authors explored the effect international volunteers and NGOs have on power dynamics when they determine community development activities for, rather than with, local communities. With such potentially skewed power structures, and a rise in skilled/professionalized international volunteer engagement, the import of traditionally Western market-oriented skills may be considered by some to be more valuable than local cultural knowledge - at the expense of community ownership, local involvement, cultural sensitivity and appropriateness, and sustainability of both local and international volunteer efforts. In the same vein, McBride and Daftary (2005) also discussed the potential of international service to explicitly or implicitly exacerbate colonial or imperial power dynamics as well as a troubling lack of accessibility and inclusivity in international service. 
Lewis (2005) also questioned to what extent international volunteers $c a n$ be effective, given their lack of local cultural knowledge and the seemingly disproportionate granting of benefits to the volunteer rather than the community served. Indeed, it is a widespread concern in the field that inexperienced international volunteers may not receive adequate training, resulting in a lack of the skills or knowledge required to successfully complete community development objectives, thus potentially serving as a well-intentioned hindrance to real progress. Similarly, Rockcliffe (2005) discussed some of the flaws inherent to some international exchange programs, including problems with effective, mutual skill transfer and the aforementioned issues of imbalanced partnerships and paternalism.

Finally some question the cost efficiency of engaging international volunteers. For example, in a 2005 study of a national UN volunteer program in Mongolia, Erdenechimeg, Bulganzaya and Gantumut (2005) found that engaging international volunteers would have cost 10 times more than working with national volunteers. Similarly, country experts in sub-Saharan Africa interviewed by Laleman, et al (2007, p. 6) argued that foreign volunteers were "considerably less cost-effective than locally hired staff," a concern that was amplified by an awareness of unemployed and sub-employed local health workers and the seemingly paradoxical phenomena of "the co-existence of the brain drain of African doctors and nurses to the North with programmes to recruit young volunteers in the North to work in sub-Saharan Africa."

\section{Theoretical and Empirical Framework}

While evidence on the scale, scope, and effectiveness of international service continues to be debated, there is consensus among scholars that the current body of 
research on international volunteerism is extremely limited (McBride, Sherraden, Benitez, \& Johnson, 2004; Lewis, 2005; McBride \& Daftary, 2005; Sherraden, Stringham, Sow, \& McBride, 2006; Sherraden, Lough, \& McBride, 2008). Two primary reasons for the scarcity of formal research are: a) civic service is itself still an emerging field of academic inquiry (McBride et al., 2004), and b) the growth and expansion of international service outside of faith-based and government programs is a relatively recent phenomenon. The following theoretical and empirical framework provides an overview of existing research on measured and perceived benefits of international volunteering, all within the context of and grounded by research on measured and perceived benefits of domestic service.

Over the past several decades, a body of research on the cultural practices of civic service and volunteerism as a social phenomena has accumulated, ranging from explorations of volunteer motivations to the psychological and physical health benefits and impacts of service on individual volunteers (Horton Smith, 1994; Putnam, 1995; Clary et al., 1998; Anheier \& Salamon, 1999; Brown, 1999; Wilson \& Musick, 1999; Arai, 2000; Putnam, 2000; Fien \& Sokien, 2002; Hays, 2002; Price, 2002; Brooks, 2003; de Raad, 2003; Unstead-Joss, 2008.) To establish a theoretical and empirical framework for this dissertation, the following section offers an overview of the literature on measured and perceived benefits of domestic and international volunteerism and service for volunteers, communities, and organizations. Given this dissertation's exploration of organizational perspectives, this section of the literature review is focused most intensively on the benefits of volunteers for organizations. 


\section{The benefits of volunteering for individuals.}

Research has identified that volunteerism generates a number of diverse benefits for individual community actors. For example, identified individual benefits include greater participation in the community (Anheier \& Salamon, 1999; Brown, 1999; Arai, 2000), establishing new social ties (Arai, 2000), learning about diversity and tolerance (Brown, 1999), and experiencing group accomplishment and a greater appreciation for civic affairs (Smith, 1999; Arai, 2000). Additional individual benefits include personal enrichment (Brown, 1999; Smith, 1999; Wilson \& Musick, 1999; Arai, 2000), recreation (Arai, 2000), and development of new knowledge and skills (Smith, 1999; Arai, 2000; Fien \& Skoien, 2002; de Raad, 2003). Finally, studies have found significant links between volunteering and good physical and mental health (Smith, 1999; Wilson \& Musick, 1999), as well as job attainment and other career-related benefits (Smith, 1999).

While the literature on international volunteerism is still emerging, research thus far has focused largely on the impact of international service on the individual volunteer, rather than the impact of voluntary service on the community or organizations (Lewis, 2005; Sherraden, Lough, \& McBride, 2008). Potential benefits for individual actors include increased intercultural understanding, personal and professional transformation and skill development, greater and more nuanced understanding of global issues, greater cultural competency, broader social and professional networks, continued and/or strengthened commitment to civic involvement, greater employability and/or increased effectiveness at current jobs, broader world view and global context, and ability to assist with increasing understanding of and interaction with foreign cultures and global interdependence in home communities (Campbell and Smith, 2006; Davis Smith, 2004; 
Lough, McBride, and Sherraden, 2009; McBride, Sherraden, \& Lough, 2007; McGehee, 2002; Sherraden, Lough, \& McBride, 2008; Unstead-Joss, 2008). McBride and Lough (2008, p. 1) also found that "disadvantaged volunteers often develop a strong sense of self-reliance and autonomy, disassociate themselves with negative labels and stereotypes in their home country context, and experience 'role- reversal' that helps them gain a greater sense of participation and contribution by serving abroad (IVR 2006).”

\section{The benefits of volunteers for the community.}

In addition to personal rewards gained by the volunteer, the overall community benefits from volunteer engagement can include economic growth and impact (Wolozin, 1975; Brown, 1999, Independent Sector 2009), greater social cohesion (Anheier \& Salamon, 1999; Baron et al., 2000) and maintenance of accessible democracy (Arai, 2000; Dekker \& Uslaner, 2001), as well as greater cultural capital (Jeannotte, 2003), better governmental performance (Knack, 2002) and contributions towards reductions in poverty (de Raad, 2003). There has also been significant research indicating that volunteerism is a critical element in the development and maintenance of social capital (Wilson \& Musick, 1998; Smith, 1999; Putnam, 2000; Brown \& Ferris, 2002; Fien \& Skoien, 2002; Hays, 2002; de Raad, 2003; van Deth, 2003; Isham, Kolodinsky, \& Kimberly, 2006) As stated by Smith, "Voluntarism can create social capital—that is, social networks of trust and cooperation — that can then promote greater political involvement and citizen participation in public affairs. The civic infrastructure, broadly defined, will be stronger" (1999, p 169). 
Exploring the impact of international volunteers on host communities ${ }^{4}$ has been one of the more difficult research agendas in the field to advance. Given the enormous variance in cultural, social, environmental, political, and economic norms and realities among global communities, developing replicable measurable indices and benchmarks has been daunting. Therefore, most of the research on international volunteerism benefits for host communities has thus far utilized individual case studies. McBride, Sherraden, and Lough synthesize some of these findings in the following:

case studies suggest that [international volunteering and service] also makes a contribution to the communities they serve by promoting public education and health, enhancing community relations and social capital, and encouraging economic development (Greenwood et al., 2005; IVR, 2002; Lopes \& Theisohn, 2003; Mayer, 2003; Peace Corps, 2007a; Pratt, 2002; Raad, 2007; Salomon, Anheier, List, Toepler, \& Sokolowski, 1999; UNV, 2004). A short survey of experts representing corporate volunteer programs indicates that nearly half of the benefits derived from international corporate service are perceived to have direct social or community impacts (Hills \& Mahmud, 2007). Likewise, 40 percent of volunteers in another study agreed that long-term service is useful as a tool for community development (Cook \& Jackson, 2006). (2007, p. 6).

Sherraden, Lough, and McBride (2008) also found that international volunteers may affect, positively and/or negatively, a community's social, economic, environmental, civic, and political development as well as intercultural and international relations. However, the authors also noted that the direction, strength, relationships among, and positive/negative orientation of these impacts are still relatively unknown.

There have also been efforts to measure if and how international volunteering contributes to and/or affects community levels of social capital. Randel, German, Cordiero, and Baker (2004) argued that international volunteering has contributed to an

\footnotetext{
${ }^{4}$ While a scholarly definition is still emerging, for the purpose of this dissertation, host communities are defined as those geographic locales where international volunteers serve in conjunction with nonprofit and nongovernmental organizations (NGOs), government agencies, and/or other formal or informal partners.
} 
increase in social capital for both developed and developing nation societies via such factors as the following:

- greater international understanding and solidarity,

- stronger links between organizations and communities,

- promoting partnership among volunteers and local citizens,

- modeling community engagement,

- greater public understanding of globalization and development,

- opportunities for personal and professional development (particularly for young people),

- organizational capacity building,

- incorporation of developing world issues into developed world policy agendas,

- increased access to information,

- greater interaction between and among global cultures,

- expanded community and global networks, and

- decreased racism and xenophobia.

Finally, Lough, McBride, and Sherraden (2007) explored the economic impact of volunteers abroad by estimating the value of a US volunteer hour, applying it to the overseas service hours reported by Americans in the 2005 Current Population Survey, and comparing it to accepted economic estimates of the value of a domestic volunteer hour, finding that - by these standards - US volunteers abroad contributed $\$ 2.92$ billion to the global economy. However, the authors also discussed at length the numerous variables, from assumptions of volunteer value to wage parity from country to country, that could potentially skew these figures.

\section{The benefits of volunteers for the organization: Domestic service.}

There are relatively few studies on the impacts and contributions of volunteers for those organizations who engage them, at least in comparison with the body of research focused on benefits to the individual and service value to the community. Of those explorations of the benefits of domestic volunteers for organizations, most have 
concentrated on the economic savings and benefits of voluntary labor (Gamm \& Kassab, 1983; Brudney, 1990; Brown, 1999; Brudney \& Gazley, 2002; Handy \& Srinivasan, 2005; Independent Sector, 2009).

However, authors like Gamm and Kassab acknowledge that this time/cost-benefit analysis is limited in its conclusions as it ignores additional benefits to the organization such as volunteers amplifying what an often smaller paid staff can accomplish, volunteers complementing and/or filling existing skill gaps, emotional support provided by volunteers to the population served by the organization, and the value of demonstrated volunteer investment when seeking political and economic support. Similarly, as discussed by Brown (1999, p. 7), assessing the value of volunteers using strictly economic measures like the willingness to pay can be problematic given that "volunteer labor and philanthropic nonprofit organizations are generally dedicated to filling in gaps in service provision that markets do not reach. They exist, in other words, because their supporters are not satisfied with the market outcomes that reflect people's willingness to pay." In short, economic measures of volunteer impact, while certainly a potentially significant part of assessing volunteer contribution, do not take into account mission and social impact, two factors that define and significantly drive the work of most charitable organizations.

It is interesting to note that there is in fact a basis for this proliferation of research on the economic value of volunteers; as stated by Brudney and Gazley (2002, p. 526), in a survey of governmental human resource administrators, "the most common perceived advantage of volunteerism is cost savings," an assumption that has been supported by media attention and general promotion of voluntary service. However, Brudney and 
Gazley also found that this perception is more often an assumption than a reality, in part due to the pervasive myth of volunteers being a free resource and the accompanying underestimating of costs inherent to developing and maintaining a healthy volunteer program. Instead, in earlier research, Brudney (1990) identified a perhaps more reasonable measure for the benefits of engaging volunteers: greater potential for increased cost-effectiveness.

Given these limitations, and the recognition that there are also additional, more intangible impacts of volunteer service, several scholars have focused on other measures of benefits derived by organizations engaging volunteers, including establishing trust and bridging ties with new communities and populations, extending the breadth and depth of service delivery, leveraging organizational capacity and skill sets to address needs and reach objectives, inspiring greater accountability where engaged at public agencies, providing a tangible way for citizens to inform and/or lobby for specific services and future organizational direction, injecting fresh perspective and innovative approaches, providing opportunities for positive public relations and greater community awareness of organizational programs and services, becoming financial contributors, and for those that are already donors, giving significantly more than non-volunteers (Brudney, 1990; Sundeen, 1990; Brown, 1999, Independent Sector, 2001, Brudney \& Gazley, 2002; UN Volunteers, 2002; ServiceLeader, 2010).

However, as pointed out by Handy and Srinivasan (2005), there is still largely an assumption that all organizations want or are at least ready and willing to accept all or most volunteers who approach them to serve, despite the reality that engaging volunteers requires a significant time as well as human and financial resource investment. In short, 
there is an assumed demand for volunteers when, in reality, this may vary considerably depending on the organization. Delving into this assumption, Brudney and Kellough (2000) explored variables that might lead state government agencies to engage volunteers, from the types of services provided or issue areas addressed, to the size of the agency, to the presence of employee unions. The authors also explored measures of volunteer effectiveness experienced by those agencies that engaged volunteers, focusing primarily on accepted volunteer resource management practices and the size of the volunteer workforce, as well as perceived organizational benefits of and motivations for engaging volunteers.

There is also a broader issue of how volunteers interact with staff members as well as whether volunteers in fact replace paid staff (or vice versa). While the field of volunteer resource management has several mechanisms in place to prevent or discourage organizations from replacing paid positions with unpaid labor, it is a common fear and persistent barrier to successful volunteer-staff partnerships. Handy, Mook, and Quarter (2008) explored this issue in depth, identifying some of the factors that might lead an organization to assign a role or project to a paid staff person or volunteer, including costeffectiveness, importance and/or centrality of volunteers to the organizational mission, and legal barriers and guidelines (e.g. in a clinical setting, volunteers may legally be barred access to confidential medical files or providing certain services, while conversely, nonprofit boards are in many countries required by law to be unpaid.) The authors also explored shifting trends in the balance of and organizational determinations for paid staff and volunteer engagement in order to more wholly understand the interchangeability of paid and unpaid labor. 
However, to insert these findings into the context of this dissertation, much of the research on the benefits of volunteers for organizations thus far has been specific to domestic engagement. There is still a significant gap in the literature on organizational benefits of international volunteers; for example, Handy and Srinivasan's study was specific to hospital volunteers in Canada and thus the demand for volunteer labor model they developed would likely be ill-suited for the sheer breadth of organizational structures, volunteer roles/projects, causes and issues addressed, and cultural norms and expectations surrounding voluntary service inherent to international engagement. Without a comprehensive baseline understanding of organizational motivations for seeking or accepting international volunteers, there is currently no way to assess whether Handy and Srinivasan's model of volunteer supply outpacing volunteer demand also applies to a cross-national service paradigm.

Similarly, given the range of staffing models, labor laws, and differing expectations of volunteers and paid staff, using Handy, Mook, and Quarter's research to explore whether international volunteers replace and/or supplement local staff would be at best challenging and at worst misleading. Instead, taking a lesson from Handy and Srinivasan's analysis - specifically their recognition of the subjectivity of determining volunteer value and subsequent decision to use organizational perceptions, in this case of hospital CEOs, as a proxy for measuring productivity - this dissertation seeks to identify organizational perceptions unique to international engagement and establish a foundation of understanding from which to develop robust measurements of international volunteer impact on global organizations. 


\section{The benefit of volunteers for the organization: International service.}

Within the overall body of research on international civic engagement, one of the largest remaining gaps exists in understanding the impacts, perceived benefits, and volunteer resource management practices of the volunteer-sending and host organizations that engage international volunteers. In addition, what research does exist has thus far largely focused on the role of volunteer-sending organizations rather than local host entities.

One of the more comprehensive explorations of international volunteer impact on volunteer-sending organizations was conducted by Sherraden, Lough, and McBride (2008), in which the authors found that organizations are central actors in determining what international civic engagement will look like for individuals, communities, and organizations. Specifically, the authors cited the matching process - determining the fit of a volunteer for an organization based on both individual and organizational goals and objectives - as potentially being "a key to predicting outcomes" (p. 399). Similarly, they found that "the ability of sending, host, and intermediary organizations to cover costs and coordinate IVS activities may shape volunteer effectiveness and outcomes of service (SOS 1999b)" (p. 401).

Sherraden, Lough, and McBride also explored issues of institutional capacity for engaging international volunteers, focusing specifically on such areas as:

- financial and human resources to fund and manage international volunteers,

- accessibility and attracting and/or recruiting diverse volunteers,

- internationality, or the direction and flow of volunteers (e.g. unilateral, bilateral, etc.),

- information,

- financial incentives and/or assistance to increase access for and diversity of volunteers, 
- facilitation,

- volunteer resource management (specifically training, support, and supervision),

- organizational networks, and

- accountability.

On this latter point, the authors stated that host organizations have the potential "to play a minor or major role in determining objectives, selecting volunteers, choosing [international volunteer] activity, or supervising volunteers," citing that those volunteersending organizations and programs that are accountable to local community members and organizations may more successfully meet community needs as well as provide a model where "volunteers do not act as managers and experts, but colleagues and team members, thereby encouraging mutual learning and reciprocity in skill sharing, while minimizing paternalism and reducing competition (Daley and Winter 1978; Rockliffe 2005)." (2008, p. 403).

Sherraden, Lough, and McBride (2008) also determined that there appear to be both positive and negative relationships between engaging international volunteers and organizational capacity. On the positive side, international volunteers could potentially leverage the impact of local staff and volunteers by providing new skills and perspectives (or even just an extra set of hands), offering opportunities for host organizations to become more internationally and culturally competent, and helping to expand connections to local and global individual and partner networks. Alternatively though, the time and resources required for engaging international volunteers could potentially become a drain on the organization. Similarly, without effective volunteer resource management, international volunteers could end up serving as ineffective partners, hindering an organization's ability to achieve its mission as well as potentially damaging 
its reputation. While Sherraden, Lough, and McBride (2008) focused primarily on volunteer-sending entities rather than host organizations, their research does bolster the call for a better understanding of host organization capacity and how that relates to individual motivations, volunteer-sending organization goals, and the overall impact of international service on global volunteers, organizations, and communities.

In another study involving volunteer-sending organizations, Laleman, et al (2007) conducted research designed to quantify the impacts of international health volunteers in sub-Saharan Africa. Positive outcomes mentioned by the volunteer-sending organizations and medical officers interviewed included the willingness and/or ability of some international volunteers to work in conditions where local health professionals were unable or unwilling to work, innovation and management capacity, skill transfer (particularly via highly skilled international volunteers), and improved quality of teaching. Respondents also noted that international volunteers served as "a concrete expression of international solidarity, international human relations, and cultural exchange. Moreover, [respondents] recognized the contributions of international health volunteers as advocates in their home society, ensuring public support for international solidarity and development aid in donor countries.” (p. 5).

At the same time, however, Laleman, et al discovered significant critiques of international health volunteers and preferences were expressed by medical officers for particular types of volunteers - e.g., those with specific skill sets and experience, those working in mission hospitals and government facilities rather than on NGO projects, those with longer term service commitments - who were perceived as "fitting well within - and strengthening - existing structures and having more appropriate qualifications." 
(2007, p. 8). To bolster the impacts of international health volunteers, medical officers suggested the following conditions for more successful engagement: clear identification of healthcare needs prior to volunteer recruitment, a preference for experienced volunteers with a focus on knowledge and skill transfer, adequate training and preparation (especially for younger volunteers) as well as pairing volunteers with local health professionals during the first few months of service, selecting volunteers prepared for and willing to work in the local cultural and organizational environment, and seeking volunteers who could commit to a more significant period of service (with the exception of specialists where shorter service projects could be equally as effective.)

An alternative approach to exploring the impact of international volunteerism on organizations has been to gather external or volunteer-based perceptions of impact such as the study conducted by Lough, McBride, and Sherraden (2009) where the authors found that most alumni of two international service programs believed their international service efforts to be effective, primarily in terms of promoting cross-cultural exchange, but also in accomplishing their specific tasks and project goals. Over three-quarters of respondents believed they had made a lasting contribution to the host organization or community, with nearly $70 \%$ believing they had a skill that was needed by the host organization and $70 \%$ citing their ability to transfer their skill effectively. A majority of respondents also believed that they shared similar goals with local staff and perceived their effectiveness as volunteers to be highest when they were contributing a skill not possessed by local staff. However, some volunteers also expressed concern that their volunteer role served as a replacement for paid staff and perceived that by participating they were contributing to local unemployment. Along these same lines, Sherraden, 
Lough, and McBride (2008) cautioned that success with international volunteers could potentially encourage some host organizations to see them as replacements for paid staff and local volunteers.

There have also been a few studies that shed light on the volunteer resource management and recruitment practices of host organizations. For example, Lough's (2006) study of Americans serving abroad identified that half of those volunteering abroad sought out and contacted host and volunteer-sending organizations themselves, while another third were asked by someone at the organization to volunteer. Lough also found that less than $1 \%$ of Americans volunteering internationally in 2005 found their service opportunity through common domestic volunteer recruitment mediums like media or the Internet. McBride, Sherraden, and Lough (2007) also outlined some of the existing research findings on volunteer resource management practices specific to engaging international volunteers, including the importance of crafting and implementing comprehensive application, screening, training and orientation, cultural and language support, and supervisory methods and processes for managing foreign volunteers.

There is also growing evidence of the importance of simultaneously engaging local citizens. McBride, Sherraden, and Lough (2007) stated that where local organizations and community members actively collaborated with international volunteer-sending organizations - again, those entities that coordinate international volunteerism projects and/or serve as a bridge between interested volunteers and foreign host communities - to determine how international volunteers are engaged, more effective programs, both for the volunteers and their hosts, were developed and implemented. The authors also found partnerships between local and international volunteers to be central to 
community capacity development; these local-international volunteer collaborations were shown to be effective for assessing community need as they helped to ensure that international volunteer roles and projects were wanted and needed by the local community and did not intentionally or unintentionally replace jobs or volunteer roles that could have effectively been filled by local citizens.

However, we still have very little understanding of, and evidence as to, why an organization might proactively seek or positively accept the placement of or respond to the request from an interested international volunteer. One study by Vian, Feeley, MacLeod, Richards, and McCoy (2007), while focused specifically on international corporate volunteers, explored these types of perceptions by assessing pre- and postvolunteer capacity of organizations that partnered with international corporate engagement programs, finding that in most cases, organizations perceived their capacity levels to have stayed the same or improved.

Another study shedding some light on organizational goals and objectives for engaging foreign volunteers was conducted by Keesbury (2003) who found that some of the benefits for an organization in hosting international volunteers - specifically in this case, professionals volunteering overseas - included access to an otherwise unaffordable consultant, establishing peer-to-peer relationships between organizational staff and skilled volunteers, and greater trust given the perceived institutional and financial independence of international volunteers. Keesbury also found that demand-driven development of volunteer roles and programs by host organizations, as well as greater responsibility and program direction by local staff members, led to more successful international volunteer engagement. 
There is also very little evidence on the economic costs and returns for host organizations of engaging international volunteers. For example, McBride, Sherraden, and Lough (2007) found that despite evidence that host and volunteer-sending organizations often share program costs, engaging international volunteers often still results in a significant investment of time and resources for the host organization. Also, given that volunteer-sending organizations may potentially focus primarily on providing experiences that meet their volunteers' personal goals while host organizations might focus more intensively on the outcomes of service for their organization and community, there are concerns that organizational biases might influence program development. Where this might occur, international service could potentially play out as volunteers being placed in unsatisfying roles and projects and host organizations and communities not being most effectively served by foreign volunteers. However, again, there is little to no baseline data to put these concerns into context from an organizational perspective.

What the field does know is that thousands of organizations worldwide are actively seeking and/or accepting foreign volunteers to assist with their program delivery and capacity development, yet there is still a paucity of research on why organizations might bother seeking or accepting international volunteers in the first place. Similarly, it has been a significant challenge for the field to establish a clear theoretical foundation for overall research on international volunteer engagement. As Sherraden, Lough, and McBride (2008, p. 412) wrote, "Formal theory is largely absent from existing research on [international volunteer engagement], but ask practitioners and they will give you their theory of change and ideas about how and why the program affects community members and volunteers." With this in mind, I will now outline two theoretical foundations to 
anchor this paper's inquiries in existing literature and theory as well as to best explain how this study's findings offer significant contributions to the field.

\section{Theoretical foundation \#1: Organizational capacity.}

The first of these two theoretical foundations uses an organizational capacity lens from within the greater family of organizational theory to assess the value and impact of international volunteers for host organizations. As defined by the authors of "Historical Perspectives on Organizational Theory" (Gakushuu.org, 2011), organizational theory explores and studies formal and informal organizations in order "to provide people with ways to understand, predict, and influence behavior in organizations (McShane \& Von Glinow, 2005) by adapting flexible frameworks that can explain dynamic organizations in dynamic environments." Scott and Davis (2007) offered the following complementary description of the types of topics and issues explored by organizational theory:

Most analysts have conceived of organizations as social structures created by individuals to support the collaborative pursuit of specified goals. Given this conception, all organizations confront a number of common problems: all must define (and redefine) their objectives; all must induce participants to contribute services; all must control and coordinate these contributions; resources must be garnered from the environment and products or services dispensed; participants must be selected, trained, and replaced...In addition to these common operational requirements, some analysts have also emphasized that all organizations are beset by a common curse. All resources cannot be devoted directly to goal attainment; some - in some cases a high proportion - of the resources utilized by any organization must be expended to maintain the organization itself...And, organizations must find ways of combining and harmonizing features associated with the work flow - technologies, equipment, skills, know-how, communication of task information - with features associated with the human/social features motivation, dealing with differing interests, authority and status matters, equity and distribution issues. (p. 11).

While the broader field of organizational theory contains a multitude of definitions, subgenres, and systems to describe and analyze such factors as how 
organizational entities are structured, motivated, and influenced by their environments, this dissertation is best rooted in one aspect of organizational theory: organizational capacity.

In their exploration of nonprofit organizational capacity, Schuh and Leviton (2006, p. 172) define organizational capacity as "the ability to successfully implement and complete a new project or to expand an existing one successfully." They explain:

An organization's 'projects' are not limited to service delivery, but can include a fund raising drive, public relations program, and other non-program, non-service delivery efforts. When agencies are out of equilibrium (i.e. expanding or spiraling down), need quick response to volatile environments, take on new work, or expand their missions, organizational capacity and capacity building become issues. An organization is analogous to a glass of water, and its capacity is analogous - not to the size of the glass - but to how much more water the glass can carry without spilling some...The research literature to date suggests two levels of organizational capacity that, when enhanced or more fully developed, tend to improve the likelihood of successful program implementation (Letts, Ryan, \& Grossman, 1999): [1)] Individual expertise that includes the skills, knowledge, and experience that employees and volunteers bring to the organization (in this framework 'leadership', is a type of expertise, to be expressed in a particular organizational context) [and 2)] Organizational resources and procedures that permit agencies to use individual expertise productively. ( $\mathrm{p}$. 172).

Throughout existing literature, connections between domestic and international volunteer engagement and organizational capacity have already been established. For example, scholars like Brudney and Gazley (2002, p. 527-528) suggest viewing volunteers "as supplementary resources...valued for their ability not so much to stretch a thin budget but to improve an organization's efficiency, that is, its capacity to do more with its existing resources." Gamm and Kassab (1983) cited additional elements of organizational capacity that can potentially be expanded by volunteer engagement, 
including the potential for volunteers to augment existing staff skill sets and the emotional support provided by volunteers to both staff and the population served alike.

Looking specifically at the literature on international volunteer engagement, several scholars cite the potential of international volunteers to increase or otherwise enhance organizational capacity by lending new skills and perspectives, providing training to local staff and volunteers as well as facilitating other methods of skill and knowledge transfer, offering opportunities for host organizations to become more internationally and culturally competent, and even simply providing more people to do the work at hand (UNV, 2001; Keesbury, 2003; Randel et al., 2004; Lewis, 2005; Sherraden et al., 2006; Laleman et al., 2007; Plewes and Stuart, 2007; Sherraden et al., 2008; Lough, McBride, Sherraden, \& O’Hara, 2011). In a recently published study, Lough et al (2011) found that organizational hosts of short-term international volunteers identified four main ways in which international volunteers helped to develop organizational capacity, including leveraging the size of staff to complete additional work, contributing ideas and skills (including skill transfer to local staff) as well as tangible resources, and increasing the cultural competence of both staff and local citizens. At the same time, the authors found that there were several challenges which could potentially limit the development of this capacity, including international volunteer language abilities, the length of a volunteer's stay, and how well the volunteer was trained and integrated into the staff.

With these definitions of organizational theory and capacity, as well as already identified connections between organizational capacity development and domestic/international volunteer engagement, in mind, this dissertation seeks to draw 
new and clearer connections between motivations for and potential benefits/challenges of hosting international volunteers and how host organizations might effectively build and sustain their organizational capacity.

\section{Theoretical foundation \#2: Social capital.}

The second foundation offered to root this study's findings in pre-existing theory is that of social capital. While several definitions of social capital exist, developed within theoretical families ranging from sociology to economics to political science, perhaps the most relevant definition for this study is provided by Schneider (2009). Acknowledging several of the primary proponents of social capital theory - including Putnam, Coleman, and Bourdieu - Schneider (2009, p. 644) defines social capital as "relationships based in patterns of reciprocal, enforceable trust that enable people and institutions to gain access to resources like social services, volunteers, or funding." And while social capital is most frequently discussed as a phenomenon existing among, between, and within individuals and communities, Schneider (2009, p. 644) also offers a definition for organizational social capital: "established, trust based networks among organizations or communities supporting a particular nonprofit, that an organization can use to further its goals."

As was discussed previously in this chapter, there has been significant research indicating that volunteerism is a critical element in the development and maintenance of social capital (Wilson \& Musick, 1998; Smith, 1999; Putnam, 2000; Brown \& Ferris, 2002; Brudney \& Gazley, 2002; Fien \& Skoien, 2002; Hays, 2002; de Raad, 2003; van Deth, 2003; Isham, Kolodinsky, \& Kimberly, 2006). Social capital has also been identified specifically as an outcome of international service and volunteer engagement (Randel et al., 2004; McBride et al., 2007; Plewes \& Stuart, 2007); for example, Randel 
et al (2004) identified several elements of social capital developed or enhanced by international volunteerism including greater international understanding and solidarity, stronger links between organizations and communities, promoting partnership among volunteers and local citizens, modeling community engagement, organizational capacity building, greater interaction between and among global cultures, and expanded community and global networks.

Within the broader concept of social capital, there are varying types of social, community, and organizational ties that have been identified, including bonding, bridging, and linking social capital. As defined by Schneider (1999), bonding social capital is generally considered to be the relationships and interactions within closed communities - for example, within specific racial or immigrant groups - while bridging social capital is the ties and relationships developed between individuals of different groups or communities, often crossing social, economic, political, and/or other boundaries. However, where Schneider (2007, p. 578) defines bridging social capital as "horizontal ties among different communities, for example, connections among faith communities to promote interfaith understanding or engage in civil activities," linking social capital is defined as vertical relationships "between people or groups where a clear power differential exists, for example, relationships between an organization and its funders."

It is these latter two types of social capital - bridging and linking social capital that have been tied most specifically to international volunteer engagement outcomes, for example the ties host organizations can potentially develop with individuals, organizations, and communities on both a local and international scale. As stated by 
Randel et al (2004, p. 13), "International volunteers provide a common denominator between different groups of people - and can be a catalyst for bridging social capital.” Indeed, several scholars have cited the opportunity for organizations to expand their network of supporters - advocates, volunteers, interns, researchers, donors, funding organizations, partner organizations, etc. - via the relationships developed with and by international volunteers, both while the volunteer is still in-country as well as upon their return home (Laleman et al., 2007; Sherraden et al., 2008; Lough et al., 2009; McBride et al., 2010; Lough et al., 2011). The benefits of fostering these international networks, especially in terms of developing and sustaining potential fundraising sources, can be significant for host organizations. Lough et al (2009) explained:

[former international volunteers]...engaged in fundraising activities during and after their international service that brought sizable resources into the organization. During their service, volunteers often raised donations from the local or international community to buy supplies and improve facilities... Others helped the organizations write grants to fund current and new programs. Some [former volunteers] continued to be involved with fundraising efforts and support years after they returned home. (p. 26).

International volunteers, advocates, and donors not living full-time within the community supported may also not be relevant; as Schneider (2007, p. 575) writes, "networks can use their social capital to support people different from themselves without expanding their networks to include the people who benefit from their largesse...[volunteers do not always] expand their social networks to develop long-term resource-sharing relationships with the recipients of their aid."

Additional benefits stemming from the development of bridging and linking social capital via international volunteers can be garnering political support from international groups and organizations, developing new connections and relationships 
with political leaders and other decision makers, and entering into new networks with peer organizations, both locally and internationally (Ihlen, 2007; Sherraden et al., 2008; Schneider, 2009). In short, Schneider (2009, p. 646-647) notes that social capital networks "are more than simply connections; they are ties that people and organizations use over time to get access to the resources they need."

Based on this chapter's review of existing literature on domestic and international volunteer engagement, as well as the two theoretical foundations - organizational capacity and social capital theory - presented here, this dissertation seeks to address gaps and broaden understanding of international volunteer engagement by exploring organizational motivations for and perceived benefits and challenges of hosting international volunteers, all while building on and rooting empirical findings within these existing theoretical constructs. 


\section{Chapter 3: Research Design and Methods}

In order to better understand how and why organizations might host international volunteers, including what benefits they might receive and/or challenges they might experience, I designed a largely exploratory study of international hosting entities to answer the following central research question: What motivates nonprofit/ nongovernmental or government organizations to host international volunteers?

\section{Research Design}

To begin answering this question, I sought a descriptive, observational research design that would capture a first-time snapshot of data from this broad, diverse, and thus far largely unstudied group of subjects. I also wanted a design that would allow for the collection of both quantitative and qualitative elements, providing comparative data while also allowing for open-ended responses; the latter was determined to be especially important given the overwhelming lack of knowledge on host organizations and the fact that no previous study of host organization perceptions could serve as a baseline for predetermining such things as multiple choice answer options. Given these parameters, I determined that the most appropriate framework was a cross-sectional research study of international host organizations.

In order to gather this mix of closed-ended and open-ended data, I decided to seek opinions and information from participating host organizations via a two-pronged methodology. First, a web-based survey (Appendix B) was conducted of non-U.S.-based nonprofit/nongovernmental organizations and government agencies that host international volunteers; this survey was distributed to two primary groups of potential respondents: a convenience sample provided by the organization Action Without Borders 
and organizations receiving the survey through snowball sampling within the field. Additional details on sampling will be outlined later in this chapter.

I chose a web-based survey as the primary method of data collection for this dissertation for three reasons. First, given that there is no baseline understanding of organizational motivations for or perceived benefits and challenges of engaging international volunteers, a survey allowed for a broad and varied snapshot of opinions to be gathered simultaneously and with relative ease. Second, by collecting data from such a diverse cross-section of global organizations - organizations solicited for participation varied widely not only in geographic location, social and cultural norms, and community traditions of civic service but also in size, mission, cause or issue addressed, organizational structure, volunteer program infrastructure, and volunteer resource management practices - an accessible web-based survey could help identify commonalities and trends within and across disparate types of international host organizations. Third, web-based surveys offer a relatively easy way to gather both openand closed-ended data, allowing for tests of statistical significance as well as opportunities to identify new variables that might be missing from current theory.

On this last point, while several of the survey questions did seek quantitative data using prescribed answer options for analysis, a majority of the questions asked offered open text boxes to gather responses. This was determined to be the best method of data capture both due to the previously mentioned lack of baseline data to craft appropriate answer options as well as to more easily accommodate those respondents for whom English was not their first language. 
The second data collection effort followed completion of the survey. Based on initial analysis to identify themes in and relationships among variables in the data, I developed a series of open-ended follow-up questions (Appendix C). These questions were designed to gather primarily qualitative data from a sub-sample of respondents in the interest of providing further illumination to the survey data.

Overall, it is important to note that given the global scope of inquiry and significant logistical challenges to crafting culturally appropriate evaluative and economic metrics for measuring quantitative value, this study was limited to organizational perceptions.

\section{Guiding Research Questions}

To further understand organizational motivations for and perceived benefits and challenges of hosting international volunteers, particularly within the context of how international volunteers might contribute to organizational capacity and/or the development of social capital within the organization and/or local community, I crafted five guiding research questions:

1. What are the primary motivations for an organization to seek and/or accept international volunteers?

2. What are the primary reported benefits of engaging international volunteers?

3. What are the primary reported challenges of engaging international volunteers?

4. What is the relationship between an organization's area of focus and reported benefits of, challenges of, and satisfaction with engaging international volunteers? Specifically, are there variations in the perceptions among host organizations doing different kinds of charitable work? 
5. What is the relationship between an organization's volunteer program characteristics and reported benefits of, perceived challenges of, and satisfaction with engaging international volunteers?

I explored the first three guiding research questions using similarly worded questions in the survey; the fourth question was explored primarily through data analysis comparing responses received from different organizational areas of focus. For the fifth guiding research question, I developed a table of hypothesized relationships between dependent and independent variables (Table 1). For example, research on domestic volunteer management has shown that more effective volunteer engagement occurs where there is a dedicated paid volunteer management position (Urban Institute, 2004). Similarly, Sherraden, Lough, and McBride (2008) found that where organizations engaged in effective volunteer management practices such as determining appropriate projects, selecting volunteers, and providing supervision, a more collaborative model of volunteers serving with community members emerged, potentially resulting in more positive perceptions of international volunteers overall. Therefore, I hypothesized that a significant relationship would exist between having a dedicated staff person managing international volunteers and more positive perceptions of international volunteers. 
Table 1

Hypothesized Relationships Between Organization's Volunteer Program

Characteristics and Reported Benefits, Challenges, and Satisfaction with Engaging International Volunteers ${ }^{\text {a }}$

\begin{tabular}{|c|c|c|c|}
\hline $\begin{array}{c}\text { Independent } \\
\text { Variable }\end{array}$ & $\begin{array}{l}\text { Hypothesized } \\
\text { Relationship }\end{array}$ & $\begin{array}{c}\text { Source(s) } \\
\text { of Data }\end{array}$ & Rationale \\
\hline $\begin{array}{l}\text { Age of } \\
\text { international } \\
\text { volunteers }\end{array}$ & Unsure & $\begin{array}{l}\text { Survey } \\
\text { Question } \\
\# 16\end{array}$ & $\begin{array}{l}\text { On one hand, older volunteers might offer } \\
\text { an organization more relevant skills and } \\
\text { experience than a younger volunteer. } \\
\text { Alternatively, a younger volunteer might } \\
\text { be more open to new ways of doing things } \\
\text { and/or a wider variety of potential tasks. } \\
\text { However, there is no current evidence to } \\
\text { support these assertions. }\end{array}$ \\
\hline $\begin{array}{l}\text { Collaboration } \\
\text { with partner } \\
\text { organization } \\
\text { or funder to } \\
\text { host } \\
\text { international } \\
\text { volunteers }\end{array}$ & Unsure & $\begin{array}{l}\text { Survey } \\
\text { Question } \\
\text { s \#1, 12, } \\
19,21\end{array}$ & $\begin{array}{l}\text { McBride, Sherraden, and Lough (2007) } \\
\text { found that where local organizations } \\
\text { partnered with volunteer-sending } \\
\text { organizations to determine how volunteers } \\
\text { were engaged, more effective programs } \\
\text { were developed. It can perhaps therefore } \\
\text { be extrapolated that those partnerships } \\
\text { where host organizations have a } \\
\text { significant voice in planning and } \\
\text { implementation might result in more } \\
\text { positive perceptions. However, those host } \\
\text { organizations that have no little to no } \\
\text { voice in whether and/or how to engage } \\
\text { international volunteers might harbor } \\
\text { more negative perceptions. }\end{array}$ \\
\hline $\begin{array}{l}\text { Length of } \\
\text { time } \\
\text { international } \\
\text { volunteers } \\
\text { stay with } \\
\text { organization }\end{array}$ & $\begin{array}{l}\uparrow \text { Time }= \\
\uparrow \text { Perceptions }\end{array}$ & $\begin{array}{l}\text { Survey } \\
\text { Question } \\
\# 17\end{array}$ & $\begin{array}{l}\text { While scholars like Laleman et al (2007) } \\
\text { have explored the benefits of longer-term } \\
\text { service, this hypothesis is based largely on } \\
\text { anecdotal evidence from practitioners in } \\
\text { both domestic and international service. } \\
\text { Experience from these fields dictates that } \\
\text { one longer-term volunteer often requires } \\
\text { less supervision and training than multiple } \\
\text { short-term volunteers doing the same } \\
\text { work. Therefore, where an international } \\
\text { volunteer requires less hands-on support, } \\
\text { there might be more positive perceptions } \\
\text { of engaging them. }\end{array}$ \\
\hline
\end{tabular}




\begin{tabular}{|c|c|c|c|}
\hline $\begin{array}{l}\text { Method of } \\
\text { connecting } \\
\text { volunteers } \\
\text { with } \\
\text { organization }\end{array}$ & Unsure & $\begin{array}{l}\text { Survey } \\
\text { Question } \\
\# 12\end{array}$ & $\begin{array}{l}\text { It is unclear what, if any, effect how } \\
\text { international volunteers connect with an } \\
\text { organization might have on perceptions. }\end{array}$ \\
\hline $\begin{array}{l}\text { Number of } \\
\text { international } \\
\text { volunteers } \\
\text { engaged in } \\
2010\end{array}$ & Unsure & $\begin{array}{l}\text { Survey } \\
\text { Question } \\
\# 15\end{array}$ & $\begin{array}{l}\text { It is unclear what, if any, effect hosting } \\
\text { more or fewer international volunteers } \\
\text { might have on perceptions. While } \\
\text { engaging more international volunteers } \\
\text { might indicate an enthusiasm for the role } \\
\text { of host organization, based on positive } \\
\text { experiences and perceptions, there may be } \\
\text { other, potentially negative, factors for why } \\
\text { an organization hosts more than fewer. }\end{array}$ \\
\hline $\begin{array}{l}\text { Number of } \\
\text { years } \\
\text { organization } \\
\text { has hosted } \\
\text { international } \\
\text { volunteers }\end{array}$ & $\begin{array}{l}\uparrow \text { Time }= \\
\uparrow \text { Perceptions }\end{array}$ & $\begin{array}{l}\text { Survey } \\
\text { Question } \\
\# 10\end{array}$ & $\begin{array}{l}\text { It is possible that the more experience an } \\
\text { organization has had with international } \\
\text { volunteers - including time to develop } \\
\text { and shape their international engagement } \\
\text { program - the more positive their } \\
\text { perceptions will be of international } \\
\text { volunteers. However, there is no current } \\
\text { evidence to support this assertion. }\end{array}$ \\
\hline $\begin{array}{l}\text { Person } \\
\text { responsible } \\
\text { for managing } \\
\text { international } \\
\text { volunteers }\end{array}$ & $\begin{array}{l}\uparrow \text { Paid Staff } \\
\text { Person }=\uparrow \\
\text { Perceptions }\end{array}$ & $\begin{array}{l}\text { Survey } \\
\text { Question } \\
\# 11\end{array}$ & $\begin{array}{l}\text { Research on domestic volunteer } \\
\text { management has shown that more } \\
\text { effective volunteer engagement occurs } \\
\text { where there is a dedicated paid volunteer } \\
\text { management position (Urban Institute, } \\
\text { 2004). Similarly, Sherraden, Lough, and } \\
\text { McBride (2008) found that where } \\
\text { organizations engaged in effective } \\
\text { volunteer management practices such as } \\
\text { determining appropriate projects, } \\
\text { selecting volunteers, and providing } \\
\text { supervision, a more collaborative model } \\
\text { of volunteers serving with community } \\
\text { members emerged, potentially resulting in } \\
\text { more positive perceptions of international } \\
\text { volunteers overall. }\end{array}$ \\
\hline
\end{tabular}




\begin{tabular}{|c|c|c|c|}
\hline $\begin{array}{l}\text { Process for } \\
\text { determining } \\
\text { fit of } \\
\text { international } \\
\text { volunteer }\end{array}$ & $\begin{array}{l}\text { Matching } \\
\text { Process = } \\
\uparrow \text { Perceptions }\end{array}$ & $\begin{array}{l}\text { Survey } \\
\text { Question } \\
\# 14\end{array}$ & $\begin{array}{l}\text { Sherraden, Lough, and McBride (2008) } \\
\text { cited the matching process - determining } \\
\text { the fit of a volunteer for an organization } \\
\text { based on both individual and } \\
\text { organizational goals and objectives - as } \\
\text { potentially being "a key to predicting } \\
\text { outcomes" (p. 399). Similarly, McBride, } \\
\text { Sherraden, and Lough (2007) raised } \\
\text { concerns that, where there was not } \\
\text { attention paid to appropriately matching } \\
\text { international volunteers, the result could } \\
\text { be volunteers being placed in unsatisfying } \\
\text { roles and projects and host organizations } \\
\text { and communities not being most } \\
\text { effectively served. }\end{array}$ \\
\hline $\begin{array}{l}\text { Revenue } \\
\text { generated by } \\
\text { international } \\
\text { volunteers }\end{array}$ & Unsure & $\begin{array}{l}\text { Survey } \\
\text { Question } \\
\# 21\end{array}$ & $\begin{array}{l}\text { It is unclear what, if any, effect revenue } \\
\text { generated by international volunteers } \\
\text { might have on perceptions. On one hand, } \\
\text { if program fees or other revenue generated } \\
\text { by international volunteers have a } \\
\text { significant impact on an organization's } \\
\text { financial well-being, then one might } \\
\text { expect perceptions to be more positive. } \\
\text { However, several scholars have also } \\
\text { explored concerns over the costs of } \\
\text { hosting international volunteers } \\
\text { (Erdenechimeg, et al., 2005; Laleman, et } \\
\text { al., } 2007 \text {; McBride, et al., 2007; } \\
\text { Sherraden, et al., 2008); it is feasible that } \\
\text { where costs appear to be greater than any } \\
\text { revenue received, a more negative } \\
\text { perception could be formed. }\end{array}$ \\
\hline $\begin{array}{l}\text { Skill or } \\
\text { language } \\
\text { requirements } \\
\text { for } \\
\text { international } \\
\text { volunteers }\end{array}$ & $\begin{array}{l}\uparrow \text { Skills/ } \\
\text { Language }=\uparrow \\
\text { Perceptions }\end{array}$ & $\begin{array}{l}\text { Survey } \\
\text { Question } \\
\# 14\end{array}$ & $\begin{array}{l}\text { There is still considerable debate about } \\
\text { how effective skill transfer via } \\
\text { international service may actually be but } \\
\text { many scholars are exploring the pros and } \\
\text { cons of engaging skilled vs. general } \\
\text { international volunteers (Keesbury, 2003; } \\
\text { Lewis, 2005; Rockcliffe, 2005; Sherraden, } \\
\text { et al., 2005; Laleman, et al., 2007; } \\
\text { Sherraden, et al. 2008). Thus far, the } \\
\text { consensus appears to be that skilled } \\
\text { volunteers have overall greater impact } \\
\text { (although type and measures of impact are }\end{array}$ \\
\hline
\end{tabular}


still largely open to interpretation).

Similarly, while it is unclear what if any

impact language ability might have on the

efficacy of an international volunteer, it is

possible that those volunteers with greater fluency in one or more of the local languages might generate more positive perceptions from host organizations.

$\begin{array}{lll}\text { Staff input } & \text { Staff Input }= & \text { Survey } \\ \text { into projects } & \uparrow \text { Perceptions } & \text { Question } \\ \text { for } & & \# 19 \\ \text { international } & & \\ \text { volunteers } & & \end{array}$

Sherraden, Lough, and McBride (2008)

found that where organizations play an active role in determining community needs and crafting appropriate volunteer roles and projects, more effective international service is likely to occur. The same authors found in 2007 that where local organizations collaborated with volunteer-sending organizations to determine how international volunteers were engaged, more effective programs were developed (McBride, et al, 2007). It may also be that more organizational control over determining projects for international volunteers might minimize concerns over international volunteers replacing local jobs.

$\begin{array}{lll}\text { Training } & \uparrow \text { Training }= & \text { Survey } \\ \text { provided to } & \uparrow \text { Perceptions } & \text { Question } \\ \text { international } & & \# 20 \\ \text { volunteers } & & \end{array}$

Several scholars have cited the importance of adequate training for international volunteers (Lewis, 2005; Laleman, et al., 2007; McBride, et al., 2007; Sherraden, et al., 2008). It is therefore possible that those volunteers with more access to training might also be more effective, leading to a more positive organizational perception. However, without assessing the effectiveness of available trainings, this will likely still be a speculative conclusion.

Notes: ${ }^{\mathrm{a}}$ Dependent Variables $=$ Positive and Negative Perceptions of International Volunteers Reported via Survey Questions \#4-5 


\section{Survey Samples}

Survey data was sought from two primary samples. The first and larger of these samples consisted of organizations with online profiles in English on the website Idealist.org. These organizations were part of a very large convenience sample provided by the hosts of Idealist.org, Action Without Borders, an international nonprofit organization that seeks to connect individuals, organizations, and resources worldwide in order to help people move from good intentions to action (Action Without Borders, 2010).

In addition to having an English language profile on the Idealist.org website, organizations included in the Idealist.org sample frame must have identified themselves to be working in at least one of the following mission, cause or issue areas: Agriculture, Arts, Community Development, Disability Issues, Economic Development, Education, Environment, Family, Health and Medicine, Human Rights and Civil Liberties, International Cooperation, International Relations, Philanthropy, Poverty and Hunger, Rural Issues, Technology, Volunteering, Women, or Youth.

These areas of focus were selected for three reasons. First, they represented a diverse cross-section of organization types. Second, as of January 2011, they represented the most popular areas of focus on Idealist.org for non-U.S.-based organizations; each area of focus (with the exception of International Cooperation and International Relations, which were chosen for their explicitly international focus) was indicated on a minimum of 1,000 non-U.S.-based organizational profiles and/or a minimum of 300 nonU.S.-based volunteer opportunities. Finally, these areas of focus also correlated with popular focus areas for international service projects. Please note that faith groups were 
excluded as a specific typology as there was no way to definitively differentiate them from other nonprofit or nongovernmental organizations on Idealist.org. However, many faith organizations were included in the sample by virtue of their identification with one or more of the selected areas of focus. In addition, respondents were asked in the survey if their organization had a faith affiliation. For further information on the selected areas of focus, see Appendix A.

The Idealist.org sample was an ideal, very large convenience sample to include in this study as it provided access to a broad-based snapshot of organizational perspectives as well as offered a unique opportunity to potentially reach a significant number of international host organizations. Indeed, the Idealist.org website hosts some of the largest databases of nonprofit/non-governmental organizations and international volunteer opportunities in the world. For example, as of January 2011, Idealist.org hosted online profiles in English for over 9,000 non-U.S.-based nonprofit/nongovernmental organizations and government agencies. In addition, any volunteer-sending organizations in the sample were asked to pass the web-based survey along to local partner host organizations doing work in one or more of the specified areas of focus.

While this convenience sample likely excluded smaller grassroots groups that may have had limited or no Internet or bilingual capacity, it was intended to help minimize or avoid language, technology, or digital divide barriers; the sample provided by Action Without Borders included host organizations that 1) voluntarily created profiles in English on the Idealist.org website, 2) used the Internet to increase global awareness of their organization, 3) used the Internet to recruit and/or accept international volunteers, and/or 4) used English as the, or a, primary language for recruiting and communicating 
with potential international volunteers. Finally, because the survey was sent to host organizations with online profiles in English - as well as via English-language international service websites and listservs - concerns over survey delivery, digital divide issues, and language barriers were significantly minimized.

The second, albeit smaller, sample for this web-based survey was sought using snowball sampling. Specifically, a link to the survey was posted to several international service field websites and listservs. Those host organizations that received the survey and met the criteria for eligibility - again, non-U.S.-based, currently engaging international volunteers, and working in one of the aforementioned areas of focus - were then invited to participate in the study. Ineligible organizations receiving the link were encouraged to send the survey link to any host organizations that met these criteria.

\section{Survey Limitations}

It is important to note that there were significant limitations to this research design. First, while most of the organizations in the sample had English language profiles on Idealist.org and/or participated in or on English-language listservs or websites, it was not guaranteed that the recipient of the survey would have sufficient language proficiency to respond. Second, there was also the concern that Internet access could be inconsistent for many potential respondents, resulting in fewer and/or incomplete survey responses.

Third, there was no way to guarantee - beyond asking respondents to confirm in the eligibility section of the survey - that the person responding to the survey was the person most familiar with an organization's international volunteer program and over the age of 18. Fourth, there was no way to guarantee that more than one response from an organization would not be received. This was ideally minimized though using the survey 
platform's option for establishing unique respondent parameters in which cookies were sent to the respondent's computer when the first survey submit was received; this then prevented additional surveys from being submitted from the same computer. Fifth, there was some concern that significant self-selection bias might occur, especially among host organizations that are actively recruiting and/or have had positive experiences with international volunteers; this potential issue will be discussed in greater detail in Chapter 5. Finally, given that there is no existing database of all international host organizations, it was impossible to ensure that the sample was in fact representative of the overall field. Another challenge of the survey design was determining the actual size of the survey sample. Because Idealist.org allows organizations to identify three or more areas of focus for their profiles, it was difficult to accurately estimate how many of the $9,000+$ non-U.S. based organizations with English-language profiles on the site would also meet the area of focus criteria. However, Idealist.org confirmed that the survey text and link was sent to 6,010 organization representatives when they distributed it on April 11, 2011; after removing the $10-12 \%$ of emails that bounced on April 11, a reminder email was sent to 5,253 organization representatives on April 19,2011. An important clarification, though, is that these numbers corresponded with the number of individuals who received the email, rather than the number of organizations contacted; this was because some organizations in the Idealist.org database listed more than one contact person on their account. Thus the definitive number of organizations contacted within the Idealist.org sample is still unclear. However, given the similar lack of clear parameters on the number of organizations contacted via snowball sampling, a conclusive sample size has been determined to simply be unavailable. 
Because an accurate response rate, calculated by comparing the number of survey responses received to the total sample size contacted, was not available for this study, an arbitrary overall response of 270 organizations (or $3 \%$ of the 9,000 non-U.S.-based nonprofit/ nongovernmental organizations and government agencies with Englishlanguage profiles on Idealist.org) was targeted. At the same time, in order to ensure that a minimally representative sample was collected, at least twenty organizations from each area of focus typology were also sought.

\section{Follow-Up Questions Sample and Limitations}

The sample of respondents that received the set of follow-up questions was determined via self-selection. Specifically, survey respondents were asked if they would be willing to respond to additional questions and, if so, to include their name and email address in the last survey question text box. Upon receipt, this information was separated from survey responses and moved to another document in order to preserve anonymity.

Because follow-up question responses were not intended to be representative of the broader field nor the full survey sample - the primary objective of these questions was to collect individualized examples and insights in order to complement survey responsesthere was no predetermined ideal sample size or characteristics; instead sample size and characteristics were determined by the self-selecting survey respondents who agreed to participate.

There were two significant limitations to this sample and methodology. First, relying on self-selection to determine the sample meant that responses were extremely vulnerable to self-selection bias. With no clear sense of a larger representative sample, either for the overall study or the follow-up questions component, this further limits 
conclusions that can be drawn from the data. Second, because follow-up question responses could not be tied back to survey responses - and no identifying details were collected from follow-up question respondents - there was no way to tie specific responses to, nor explore potential relationships with, other organizational perceptions and/or characteristics. While this represents a lost opportunity to connect follow-up responses to individual survey answers, the decision was made to sever this tie in order to preserve the anonymity of survey respondents, thus ideally facilitating a high response rate from survey participants.

\section{Data Collection}

Data collection took place in Spring/Summer 2011. First, on April 7 and 11,2011, a link to the web-based survey, built on the web-based platform QuestionPro, was sent to organizations in the Idealist.org sample. This text provided an overview of the study, my role in the study (I am a former employee of Action Without Borders but given that survey responses were anonymous and there were no questions evaluating the efficacy of Idealist.org, it was determined that there would be no to minimal researcher or data source bias; introductory language was included to make this distinction clear), and a link to and attachment of an informed consent letter per Portland State University's Human Subjects Research Review Committee. Then, on April 19, 2011, a reminder email was sent to encourage organizations in this sample to complete the survey.

On April 21 and 22, 2011, a link to the web-based survey and introductory text was also posted to field-specific websites and listservs, including the Building Bridges Coalition, OzVPM, UKVPM, European Volunteer Center (CEV), Forum on Education Abroad, NAFSA Association of International Educators, Alliance of European Voluntary 
Organisations, Association of Voluntary Service Organisations (AVSO), International Association for Volunteer Effort (IAVE), TransitionsAbroad.com, Voluntourism.org, World Volunteer Web, and via individual thought and organization leaders in the field of international service.

All potential respondent host organizations were asked to have only one person their international volunteer coordinator or, where this position did not exist, the staff person or volunteer who was most responsible for managing international volunteers complete the survey. Respondents were also asked if they would be willing to receive the follow-up questions and, if so, to provide their name and email address at the end of the survey.

On Monday, May 2, 2011, three weeks after the initial email was sent to organizations in the Idealist.org sample, the survey was closed to new responses.

On June 29, 2011, follow-up questions were emailed to those survey respondents who agreed to participate.

\section{Response Rate}

The web-based survey was viewed by 1,153 individuals; 547 of these individuals started the survey while 301 submitted the completed survey. Of these 301 respondents, 53 were determine to be ineligible for inclusion due to one of more of the following reasons: not agreeing to informed consent, not including any answers in the submitted report, not engaging international volunteers (including those who have not yet started hosting international volunteers but plan to in the future), being located in the United States, and/or serving as a volunteer-sending organization rather than a host organization. Once these responses were excluded, the adjusted total for web-based survey responses 
eligible for analysis became 248 .

In addition, 165 survey respondents agreed to be contacted with follow-up questions; 31 respondents or $18.8 \%$ of the follow-up question sample size submitted answers to these questions via email.

\section{Data Preparation}

After closing the survey to new responses, data was transferred from QuestionPro to SPSS software via Excel spreadsheets. While initial survey questions were designed so that collected data would have no identifying characteristics and responses to the surveys would be anonymous, as part of preliminary coding of the survey data, any inadvertent identification - individual names, organizational names, etc. - was removed. The exception to this was where respondents indicated a willingness to participate in the follow-up interview portion of the research; this data was separated from the survey data upon receipt and kept in a separate file with no identifying information to link it back to survey responses. While QuestionPro did gather IP addresses by default - and it was confirmed that this feature could not be turned off - this data was also immediately deleted once downloaded from QuestionPro.

Once ineligible responses were removed from the sample, open-ended responses were then reviewed to identify themes and answer categories. This was done manually by examining each open-ended response, identifying reoccurring themes, and, where appropriate, collapsing theme categories where significant overlapping similarities were discovered; for example, when creating the categories for most important challenges as shared by respondents via an open text box, the characteristics that international volunteers can be "unmotivated" and "unreliable" were combined into one category 
while the characteristic "untrustworthy" was left as its own standalone category. A codebook was then developed and open-ended responses coded for statistical analysis.

Following coding, preliminary analysis was conducted to clean up and clarify the data. First, frequency analysis and descriptive statistics were run using SPSS software to confirm that the maximum and minimum values were within the appropriate range of answer options. Second, adjustments to the data were made for two questions where the respondent could choose more than one answer option and conflicting answers were selected; where this occurred, specifically in the variables concerning volunteer requirements (19 responses) and revenue generation (16 responses), the response was then excluded from analysis (for example, if in answer to the survey question "Does your organization receive or earn any money from hosting international volunteers? Please choose all that apply," a respondent selected both "Yes, international volunteers pay us a fee to volunteer with our organization" and "No, we do not receive any money from hosting international volunteers," that respondent's answer was then excluded from analysis of those variables. The exception to this was where the respondent used the "Other" option to explain why they did not receive funding and/or exceptions to their usual policy or circumstance. This occurred in thirteen of the sixteen conflicting responses to this question and was thus coded as though those respondents had only selected "No, we do not receive any money from hosting international volunteers.") Third, to allow for more accurate analysis as an independent variable, answers to the question "Overall, do you think that it is worthwhile for your organization to host international volunteers?" were collapsed from five categories - "Yes," "Yes, but if...", 
"No," "No, but/if...", and "Not sure" - into three categories: "Yes/Yes, but/if...", "No/No, but/if...", and "Not sure".

Before appropriate tests for exploring statistically significant relationships between variables could be identified, the nature of the data required determination. First, the data was determined to be non-parametric as there was no evidence to suggest that the respondent sample was in fact representative of the overall population. This was both because there are no known parameters to the total population as well as the significant variance that likely occurred due to differences by country, area of focus, etc. Second, all variables in the survey were determined to be categorical - either nominal or ordinal - as there was no clear evidence to suggest that respondents considered and/or weighted the differences between ranked answers to be of equal distance or weight.

Most of the variables were considered to be nominal as coding of open-ended questions was done primarily by establishing answer categories drawn from the survey responses; each respondent's open-ended answers were then determined to either fit or not fit into each of these answer categories. However, a few variables were determined to be ordinal in nature; these questions were those that used a Likert or similar scale where answer options had a rank or order. Again though, these were considered to be categorical variables due to the lack of clear evidence that respondents considered the ranks or orders to be of equal distance or weight.

Once the data had been classified, appropriate tests for identifying statistically significant relationships were explored. Because the data was identified as categorical and non-parametrical, the most appropriate test for exploring these relationships was determined to be Pearson's chi-square. In addition, because many of the variables had 
answer options with response frequencies of fewer than five (a violation of chi-square assumptions for validity in SPSS), Fisher's Exact Test was used as a complementary metric where available. In these cases, SPSS was instructed to recognize answers coded as "not applicable" and "unclear response" as missing to allow for the 2 × 2 field required of Fisher's Exact Test. Potential limitations associated with the use of these specific analytical tests are discussed in Chapter 5. 


\section{Chapter 4: Research Findings}

Receiving responses from different types and structures of host organizations from around the globe provided an opportunity to identify commonalities, conduct initial comparative analysis, and offer a first glimpse into what may be some universal experiences of serving as a host organization. To review these findings, this chapter is organized in five sections.

First, descriptive statistics are explored; these findings are categorized by host organization characteristics and host organization opinions. Second, these same statistics are explored for just those respondents in Africa and Asia, the two global regions represented by the greatest number of respondents. Third, chi-square tests run to identify significant relationships between host organization opinions and characteristics are outlined; these are offered both for the overall sample and for the three area of focus typologies affiliated with twenty or more survey respondents each: Community Development, Education, and Environment. Fourth, tests run to explore guiding research question hypotheses are explained. Finally, responses to follow-up questions - as well as explanations provided by respondents that do not currently host international volunteers are offered to provide additional perspectives.

\section{Host Organization Characteristics}

A primary goal of this dissertation was to capture a current snapshot of host organization perspectives and opinions on hosting international volunteers. However, before these findings can be explored, it is important to offer a snapshot of survey respondents and their organizations. This section provides details on the characteristics of responding host organizations and their international volunteer programs. 


\section{Country.}

Eligible survey responses were received from 248 individuals representing at least 57 countries in seven global regions (Table 2). For respondent statistics by country, please see Appendix D.

Table 2

Respondent Statistics per Region

Region

Number of Number of Percentage of

Countries Respondents Total

Africa

\begin{tabular}{ccc} 
& & Respondents \\
\hline $15^{\mathrm{a}}$ & 103 & $41.5 \%$ \\
5 & 72 & $29.0 \%$ \\
13 & 25 & $10.1 \%$ \\
7 & 19 & $7.7 \%$ \\
2 & 18 & $7.3 \%$ \\
1 & 8 & $3.2 \%$ \\
$57^{\mathrm{a}}$ & 3 & $1.2 \%$
\end{tabular}

Notes: ${ }^{a}$ One respondent specified a region name rather than country, so this figure may be in fact be +1 if the respondent represented a country not already listed.

\section{Area of focus.}

The most commonly identified primary missions, causes, or issue areas of focus were Education (26.6\%), Community Development (23.8\%), and Environment (8.9\%). However, an additional 16 areas of focus were also identified per Table 3. Tables 4 and 5 provide two additional perspectives on area of focus results: first on the distribution of each area of focus across regions and then on the percentage of respondents per region. 
Table 3

Percentage of Responses to Survey Question “What is your organization's primary mission, issue, or area of focus?"

\begin{tabular}{|c|c|c|}
\hline Area of Focus & $\begin{array}{l}\text { Number of } \\
\text { Respondents }\end{array}$ & $\begin{array}{l}\text { Percentage of Total } \\
\text { Respondents }\end{array}$ \\
\hline Education & 66 & $26.6 \%$ \\
\hline Community Development & 59 & $23.8 \%$ \\
\hline Environment & 22 & $8.9 \%$ \\
\hline Youth & 17 & $6.9 \%$ \\
\hline Health and Medicine & 13 & $5.2 \%$ \\
\hline Volunteering & 13 & $5.2 \%$ \\
\hline Economic Development & 7 & $2.8 \%$ \\
\hline Philanthropy & 7 & $2.8 \%$ \\
\hline Women & 7 & $2.8 \%$ \\
\hline Agriculture & 6 & $2.4 \%$ \\
\hline Disability Issues & 6 & $2.4 \%$ \\
\hline Poverty and Hunger & 6 & $2.4 \%$ \\
\hline Human Rights and Civil Liberties & 5 & $2.0 \%$ \\
\hline Arts & 4 & $1.6 \%$ \\
\hline Rural Issues & 3 & $1.2 \%$ \\
\hline Technology & 3 & $1.2 \%$ \\
\hline Family & 2 & $0.8 \%$ \\
\hline International Cooperation & 1 & $0.4 \%$ \\
\hline International Relations & 1 & $0.4 \%$ \\
\hline
\end{tabular}


Table 4

Distribution of Each Area of Focus Across Regions ${ }^{\mathrm{a}, \mathrm{b}}$

\begin{tabular}{|c|c|c|c|c|c|c|c|}
\hline Area of Focus & Africa & Asia & $\begin{array}{l}\text { Central } \\
\text { America }\end{array}$ & Europe & $\begin{array}{l}\text { North } \\
\text { America }\end{array}$ & Oceania & $\begin{array}{l}\text { South } \\
\text { America }\end{array}$ \\
\hline Agriculture & $66.7 \%$ & $16.7 \%$ & - & - & - & - & $16.7 \%$ \\
\hline Arts & $50.0 \%$ & $25.0 \%$ & - & $25.0 \%$ & - & - & - \\
\hline $\begin{array}{l}\text { Community } \\
\text { Development }\end{array}$ & $64.4 \%$ & $18.6 \%$ & $5.1 \%$ & $3.4 \%$ & $1.7 \%$ & $5.1 \%$ & $1.7 \%$ \\
\hline $\begin{array}{l}\text { Disability } \\
\text { Issues }\end{array}$ & $50.0 \%$ & $50.0 \%$ & - & - & - & - & - \\
\hline $\begin{array}{l}\text { Economic } \\
\text { Development }\end{array}$ & $57.1 \%$ & $14.3 \%$ & - & $14.3 \%$ & - & - & $14.3 \%$ \\
\hline Education & $36.4 \%$ & $31.8 \%$ & $20.0 \%$ & $3.0 \%$ & $1.5 \%$ & - & $7.6 \%$ \\
\hline Environment & $9.1 \%$ & $31.8 \%$ & $22.7 \%$ & $13.6 \%$ & $9.1 \%$ & - & $13.6 \%$ \\
\hline Family & - & $50.0 \%$ & - & - & $50.0 \%$ & - & - \\
\hline $\begin{array}{l}\text { Health and } \\
\text { Medicine }\end{array}$ & $53.8 \%$ & $30.8 \%$ & - & - & $7.7 \%$ & - & $7.7 \%$ \\
\hline $\begin{array}{l}\text { Human Rights/ } \\
\text { Civil Liberties }\end{array}$ & $60.0 \%$ & $20.0 \%$ & - & - & - & - & $20.0 \%$ \\
\hline $\begin{array}{l}\text { International } \\
\text { Cooperation }\end{array}$ & - & - & - & $100 \%$ & - & - & - \\
\hline $\begin{array}{l}\text { International } \\
\text { Relations }\end{array}$ & - & - & - & $100 \%$ & - & - & - \\
\hline Philanthropy & $71.4 \%$ & $14.3 \%$ & - & $14.3 \%$ & - & - & - \\
\hline $\begin{array}{l}\text { Poverty and } \\
\text { Hunger }\end{array}$ & - & $50.0 \%$ & - & $33.3 \%$ & $16.7 \%$ & - & - \\
\hline Rural Issues & $33.3 \%$ & $33.3 \%$ & - & - & $33.3 \%$ & - & - \\
\hline Technology & - & $66.7 \%$ & - & $33.3 \%$ & - & - & - \\
\hline Volunteering & $15.4 \%$ & $38.5 \%$ & $7.7 \%$ & $15.4 \%$ & - & - & $23.1 \%$ \\
\hline Women & - & $71.4 \%$ & $28.6 \%$ & - & - & - & - \\
\hline Youth & $47.1 \%$ & $23.5 \%$ & $5.9 \%$ & $11.8 \%$ & - & - & $11.8 \%$ \\
\hline
\end{tabular}


Table 5

Percentage of Respondent Areas of Focus in Each Region ${ }^{\mathrm{a}, \mathrm{b}}$

\begin{tabular}{|c|c|c|c|c|c|c|c|}
\hline Area of Focus & Africa & Asia & $\begin{array}{l}\text { Central } \\
\text { America }\end{array}$ & Europe & $\begin{array}{c}\text { North } \\
\text { America }\end{array}$ & Oceania & $\begin{array}{c}\text { South } \\
\text { America }\end{array}$ \\
\hline Agriculture & $3.9 \%$ & $1.4 \%$ & - & - & - & - & $5.6 \%$ \\
\hline Arts & $1.9 \%$ & $1.4 \%$ & - & $5.3 \%$ & - & - & - \\
\hline $\begin{array}{l}\text { Community } \\
\text { Development }\end{array}$ & $36.9 \%$ & $15.3 \%$ & $12.0 \%$ & $10.5 \%$ & $12.5 \%$ & $100 \%$ & $5.6 \%$ \\
\hline $\begin{array}{l}\text { Disability } \\
\text { Issues }\end{array}$ & $2.9 \%$ & $4.2 \%$ & - & - & - & - & - \\
\hline $\begin{array}{l}\text { Economic } \\
\text { Development }\end{array}$ & $3.9 \%$ & $1.4 \%$ & - & $5.3 \%$ & - & - & $5.6 \%$ \\
\hline Education & $23.3 \%$ & $29.2 \%$ & $52.0 \%$ & $10.5 \%$ & $12.5 \%$ & - & $27.8 \%$ \\
\hline Environment & $1.9 \%$ & $9.7 \%$ & $20.0 \%$ & $15.8 \%$ & $25.0 \%$ & - & $16.7 \%$ \\
\hline Family & - & $1.4 \%$ & - & - & $12.5 \%$ & - & - \\
\hline $\begin{array}{l}\text { Health and } \\
\text { Medicine }\end{array}$ & $6.8 \%$ & $5.6 \%$ & - & - & $12.5 \%$ & - & $5.6 \%$ \\
\hline $\begin{array}{l}\text { Human Rights/ } \\
\text { Civil Liberties }\end{array}$ & $2.9 \%$ & $1.4 \%$ & - & - & - & - & $5.6 \%$ \\
\hline $\begin{array}{l}\text { International } \\
\text { Cooperation }\end{array}$ & - & - & - & $5.3 \%$ & - & - & - \\
\hline $\begin{array}{l}\text { International } \\
\text { Relations }\end{array}$ & - & - & - & $5.3 \%$ & - & - & - \\
\hline Philanthropy & $4.9 \%$ & $1.4 \%$ & - & $5.3 \%$ & - & - & - \\
\hline $\begin{array}{l}\text { Poverty and } \\
\text { Hunger }\end{array}$ & - & $4.2 \%$ & - & $10.5 \%$ & $12.5 \%$ & - & - \\
\hline Rural Issues & $1.0 \%$ & $1.4 \%$ & - & - & $12.5 \%$ & - & - \\
\hline Technology & - & $2.8 \%$ & - & $5.3 \%$ & - & - & - \\
\hline Volunteering & $1.9 \%$ & $6.9 \%$ & $4.0 \%$ & $10.5 \%$ & - & - & $16.7 \%$ \\
\hline Women & - & $6.9 \%$ & $8.0 \%$ & - & - & - & - \\
\hline Youth & $7.8 \%$ & $5.6 \%$ & $4.0 \%$ & $10.5 \%$ & - & - & $11.1 \%$ \\
\hline
\end{tabular}

Notes: ${ }^{\mathrm{a}}$ The sum of each column is $100 \%{ }^{\mathrm{b}}$ Highest percentage per column is in bold. 


\section{Faith affiliation.}

Perhaps despite the significant role faith organizations have played in both historical and modern day international service and development, a vast majority of respondents $-85.5 \%$ - indicated that their organization was not affiliated with a faith group or institution like a church, temple, or mosque. Of the 35 respondents that did indicate a faith affiliation, the most commonly mentioned type was Christian with 15 respondents; four of these specifically mentioned Catholicism. Three respondents were affiliated with Buddhist organizations with an additional one organization each affiliated with Muslim and Ananda Marga faiths. Most respondents with a faith affiliation were not specific with their theology or denomination though, instead describing the affiliation using such terms as "faith based," "church," and "evangelical." In addition, the term "affiliation" was interpreted several different ways, including direct partnerships with a specific church, an adherence to a particular ideology or related philosophy, receiving funds from a faith-based entity, and partnering regularly with faith-based organizations.

\section{Age of international volunteer program.}

While a small handful of organizations reported having hosted international volunteers for over twenty-five years, the vast majority of responding organizations reported relatively young international volunteer programs. Specifically, just over half $50.4 \%$ - of respondents reported that they began hosting international volunteers only within the past five years, while $78.3 \%$ of respondents began hosting international volunteers within the past decade. 


\section{Volunteer management infrastructure.}

Survey respondents reported a broad range of volunteer management models for hosting and engaging their international volunteers (Table 6). The most common of these were those with a staff volunteer coordinator $(16.0 \%)$ or one staff person - whose role was not specifically identified as volunteer coordination or management - most responsible for engaging international volunteers (18.3\%); for example, survey respondent \#1510925 wrote: “Usually our project manager manages the volunteer - we don't take more than one at a time because we are small."

Volunteers managing volunteers was also somewhat common, with $10.8 \%$ of respondents relying on volunteers to manage international volunteers; as survey respondent \#1480202 explained, while they had a volunteer coordinator, "this is not a permanent or paid position and usually current volunteers fill in for this position. Many past volunteers have brought up the need for a permanent volunteer coordinator but it is currently outside of our budget." Finally, $6.6 \%$ of respondents indicated that they expected international volunteers to manage themselves. "There is nothing like managing volunteers at our organization," wrote survey respondent \#1428438. "We all work as a team following the usual daily routine."

It is worth noting that the process of categorizing and comparing responses proved to be a challenging task because of ambiguous, oft difficult to understand responses. Further details on this challenge, including potential limitations and future opportunities for exploration of this topic, can be found in Chapter 5. 
Table 6

Responses to Survey Question "How are international volunteers managed at your organization?"

Volunteer Management Model(s)

Support provided by one or more persons but type (staff, volunteer, etc.) unspecified

One non-volunteer coordinator staff person

responsible

One volunteer coordinator responsible

One or more volunteers responsible

More than one non-volunteer coordinator staff responsible

One or more staff people responsible, but other staff also involved

International volunteers manage themselves

More than one volunteer coordinator responsible

Committee or board responsible

All staff responsible

Other

Host family member(s) responsible

Partner organization responsible

\begin{tabular}{cc}
$\begin{array}{c}\text { Number of } \\
\text { Respondents }\end{array}$ & $\begin{array}{c}\text { Percentage of Total } \\
\text { Respondents }\end{array}$ \\
\hline 97 & $45.5 \%$ \\
39 & $18.3 \%$ \\
34 & $16.0 \%$ \\
23 & $10.8 \%$ \\
20 & $9.4 \%$ \\
15 & $7.0 \%$ \\
14 & $6.6 \%$ \\
9 & $4.2 \%$ \\
6 & $2.8 \%$ \\
4 & $1.9 \%$ \\
4 & $1.9 \%$ \\
1 & $0.5 \%$ \\
1 & $0.5 \%$
\end{tabular}

\section{Recruitment methods.}

The most commonly reported method for connecting with potential international volunteers was organization-led recruitment with $45.6 \%$ of respondents actively seeking international volunteers. Of reported recruitment methods, the types deemed most effective by respondents were recruiting via their own website $(50.9 \%)$, recruiting via partner organizations like universities (37.9\%), posting on Idealist.org (26.2\%), recruiting via Facebook (15.4\%), posting on other websites (13.6\%), and word of mouth $(10.3 \%)$. 
For nearly $20 \%$ of respondents, international volunteers generally found their organization independently while $13.3 \%$ partnered with a volunteer-sending organization and $8.5 \%$ had international volunteers placed with them by other kinds of partner organizations such as universities and faith groups.

\section{International service requirements.}

While $11.9 \%$ of respondents reported that they had no prerequisites for someone to become an international volunteer with their organization, a majority of respondents specified requirements ranging from education and skills to language ability and application procedures. Of these potential qualifications and processes, the most commonly required were that international volunteers be a certain age (54.0\%), have specific skills (such as being qualified to provide medical care) (51.3\%), and have a certain level of education (46.9\%). In addition, $67.3 \%$ of respondents required that potential international volunteers submit an application, with an additional $35.4 \%$ requiring an interview as well, while $24.3 \%$ reported requiring volunteers to speak one or more local languages.

When asked to explain or share examples to illuminate their survey responses, an additional collection of international service requirements and pre-requisites emerged (Table 7). For example, some respondents reported fairly stringent acceptance procedures and requirements. As survey respondent \#1394574 explained, "Volunteers must be 18 years old, available to volunteer [for] at least 4 weeks, and speak an intermediate level of Spanish (or have the availibilty [sic] to take intense Spanish lessons for 4 weeks before beginning work in the school)." Survey respondent \#1413065 wrote, "Our interviews are through emails. They must have a specific task to complete after 
coming here. Without any specific agenda we do not entertain any volunteers." Survey respondent \#1514544 offered the following:

"We look for senior retired level experienced volunteers with background [sic] both in social and entrepreneurial field [sic], specific skills like finance, social investment banking and business planning, have [sic] education and experience of atleast [sic] 15 years and up. The key is to get senior people possible couple [sic] who can come for atleast [sic] 1 year to train the younger members of our organizations by parting [sic] their longtime life skills to our people. We lack management and training [and] so look for these skills."

Some respondents reported guidelines that served less as requirements and more as preferred international volunteer characteristics. For example, survey respondent \#1413981 stated "They must have a good work ethic, be able to work independently and as part of a team, be independent personally, able to follow instructions and understand the overall mission of our charity." Survey respondent \#1411572 wrote, "Volunteers must also have the maturity to cope with the stress of volunteering and have a support network back home." Survey respondent \#1505049 wrote, "They must posses the desire to really work, not just come and party. They must be a 'fit' for the project they want to work with," while survey respondent \#1564513 shared "Our only requirement is that the volunteer be self-directed and able to care for themselves in the community." Survey respondent \#1403123 explained:

Vols [sic] must be able to stay with us for at least three months in order to get the most out of their experience. They must be old enough to be self sufficient, we provide accommodation but they are expected to look after themselves. They must also need this experience either to kick start their career, get some specific instruction...or be passionate about what we are doing and want to learn more. We don't take volunteers who are 'looking for something to do'. I reserve the right to give my placements to people (generally newly qualified graduates) who will be able to use the experience to their maximum advantage. 
Table 7

Additional International Service Requirements Reported by Respondents

Additional Service Requirements

Number of Percentage of Total

Other

\begin{tabular}{cc} 
Respondents & Respondents \\
\hline 26 & $41.9 \%$
\end{tabular}

Be over the age of 18

15

$24.2 \%$

Be able to stay for a certain period of time

9

$14.5 \%$

Have awareness of and/or a commitment to the

8

$12.9 \%$

issue

Provide a $\mathrm{CV}$ or resume

8

$12.9 \%$

Agree to program rules, policies, code of

6

$9.7 \%$

conduct, etc.

Provide references or be recommended

6

$9.7 \%$

Have experience working with children or

$6.5 \%$ young people

Be able to work independently

Pass a criminal background screening

Be financially self-sufficient

Have experience living in another country

Have relevant certifications per the field

Meet maturity requirements

Agree with the organization's philosophical or religious tenets

Other respondents reported more open acceptance policies. For example, survey respondent \#1395294 stated, "We welcome all volunteers and try to find a placement based on their education, work experience, skills and interests. There is always something they can do to benefit our work. Most volunteers, who approach us, are however well 
educated and posses certain skills." Similarly, survey respondent \#1451347 shared "Each potential volunteer is looked at on an individual basis to see if his/her background/knowledge/skills/interests could be used at the school. So far, we have not refused anyone interested in working at the school.” Survey respondent \#1415489 explained, "We just need people than [sic] want to help in the community, no matter how much education or age," while survey respondent \#1394214 shared, "We are welcoming [sic] everyone that wants to bring a smile to the faces of my people." Or, as survey respondent \#1507247 simply stated, "Everyone has a usable skill.”

It is potentially worth noting here the connections that emerged from the data between an organization's area of focus and reported international service requirements. For example, $84.6 \%$ of organizations focused on health and medicine, as well as $80.0 \%$ of organizations focused on disability issues, required that their international volunteers have specific skill sets; this was also required by $75 \%$ of arts organizations, $66.7 \%$ of technology organizations, and $64.3 \%$ of youth-focused organizations. Specific education levels were required by $80.0 \%$ of agriculture organizations, $69.2 \%$ of health and medicine organizations, $60 \%$ of organizations focused on human rights and civil liberties, and $60.0 \%$ of organizations focused on disability issues. Education and skill requirements were also indicated by approximately half of all community development and education organizations. International volunteers being a certain age was also a very common requirement among respondents; nearly two-thirds of all areas of focus had $50 \%$ or more of their respondents report age requirements. By comparison, only one area of focus organizations focused on rural issues - had more than half of its reporting organizations indicate a language requirement. 
For almost every area of focus - with the exception of arts and rural issues organizations $-50 \%$ or more respondents indicated that they required an application from potential international volunteers. However, the areas of focus where $50 \%$ or more organizations required an interview was limited to international cooperation, international relations, poverty and hunger, technology, and youth organizations (the first four of which had very small overall response totals.)

Trends between international volunteer recruitment methods and international service requirements were also identified in the data. Specifically, of those organizations that required specific skills, the most commonly identified recruitment method was having international volunteers placed with them by a partner organization like a university or faith group (76.5\%), followed by placement by a partner volunteer-sending organization (51.6\%), active recruitment by the organization (49.5\%), and international volunteers finding the organization on their own (48.8\%). A similar pattern emerged where the requirement was a certain level of education, with $76.5 \%$ placed by a partner organization, $61.3 \%$ placed by a volunteer-sending organization, $44.9 \%$ active recruitment by the organization, and $39.0 \%$ finding the organization on their own. Where the requirement was age, however, a slight shift occurred, with the predominant recruitment method becoming international volunteers finding the organization on their own (58.5\%), followed by placement by a volunteer-sending organization (58.1\%), active recruitment $(55.1 \%)$, and placement by a partner organization like a university or faith group (47.1\%). 


\section{Number and age of international volunteers.}

The vast majority of responding organizations reported relatively small international volunteer programs; for example, $64.8 \%$ of respondent organizations hosted fewer than 10 international volunteers in 2010 while only $12.6 \%$ hosted more than 50 international volunteers that year.

Survey respondents were also asked to identify the age of most of their international volunteers. The most common age group - reported by $86.2 \%$ of respondents - was international volunteers in their twenties, followed by volunteers in their thirties (39.7\%), forties (24.3\%), fifties (20.9\%), and under twenty (17.2\%). Older volunteers, over the age of 60 , were identified as being common for $20.9 \%$ of respondents, while $6.3 \%$ of respondents reported that all ages of international volunteers were hosted by their organization.

\section{Length of international service.}

Respondents were then asked to consider various lengths of international service (Table 8 ). The most frequently cited length of international service - by almost $85 \%$ of the 169 respondents who answered this question - was one to three months: $46.4 \%$ of respondents indicated that international volunteers almost always serve for that length of time with an additional $38.5 \%$ reporting that international volunteers occasionally serve for that length of time.

Overall, respondents reported that shorter terms of service were more common for their international volunteers than longer terms. For example, while $69.2 \%$ of respondents reported that international volunteers almost always or occasionally served for between 
two weeks and one month, just over half as many reported having international

volunteers almost always or occasionally stay for over one year.

Table 8

Responses to Survey Question "How Long Do International Volunteers Serve with Your Organization?",

Length of Service

1 to 3 months

Between 2 weeks and 1 month

3 to 6 months

2 weeks or less

6 to 12 months

Over 1 year

\begin{tabular}{ccc}
$\begin{array}{c}\text { Almost } \\
\text { Always }\end{array}$ & Occasionally & $\begin{array}{c}\text { Rarely or } \\
\text { Never }\end{array}$ \\
\hline $46.4 \%(89)$ & $38.5 \%(74)$ & $15.1 \%(29)$ \\
$32.5 \%(55)$ & $36.7 \%(62)$ & $30.8 \%(52)$ \\
$27.5 \%(49)$ & $41.6 \%(74)$ & $30.9 \%(55)$ \\
$23.1 \%(39)$ & $34.3 \%(58)$ & $42.6 \%(72)$ \\
$18.3 \%(31)$ & $33.1 \%(56)$ & $48.5 \%(82)$ \\
$9.1 \%(15)$ & $26.2 \%(43)$ & $64.6 \%(106)$
\end{tabular}

Notes: ${ }^{\text {a }}$ Number in parentheses is the number of respondents that selected answer. Type of international service project.

The most common location where international service projects take place, according to $46.7 \%$ of respondents, was in the local community. Conversely, $4.0 \%$ of host organizations reported most commonly offering international volunteer roles within their own organization. Just over one-fifth of respondents reported offering volunteer projects both in the community as well as internally within their organization.

Types of volunteer projects and roles varied widely with, by far, the most common type being teaching, classroom assistance, tutoring, and/or community education (61.3\%). This presumably included the frequently mentioned international service project of providing English language assistance. The next most common types of volunteer projects were construction and/or infrastructure development or 
improvement like painting, installations, etc. (17.8\%), technology tasks like building websites (15.6\%), and research, data collection, and reporting (12.4\%).

Survey respondent \#1393500 explained, "Longer term volunteers, those arriving as individuals, are working directly with children in the local schools. Short term volunteers coming in groups are more often working at construction, school repairs, etc." A second respondent, \#1414403, offered the following: "Most volunteers work directly with the community through several community based organizations that we partner with: schools, orphanages etc. A smaller number work within our organization in areas like website development and in our core projects like training in the community." Survey respondent \#1390909 described their international volunteer projects as follows:

Last year it was building [a] trek path along a narrow ledge in a pristine...forest (with the villagers). This year it will be building a lodge mid way along the trail, installing flush toilets at intervals, [a] thatch roof rest area that [is] handy with brief showers, culverts over dips to level the path, and swinging bridges.

Sometimes they teach English to have a break from walking up to the site daily.

\section{International service project determination.}

Overall, a majority of organizations reported being responsible for determining appropriate roles and projects for their international volunteers: $72.2 \%$ of respondents indicated that "projects for international volunteers are created by our staff based on what our organization needs" and 59.8\% cited that "projects for international volunteers are created by our staff based on community feedback and what our community needs". Just over $40 \%$ of respondents allowed "projects for international volunteers [to be] suggested or proposed by international volunteers themselves." Lastly, just over one-fifth of respondents selected the answer option "projects for international volunteers are suggested or proposed by our partner organizations." 


\section{Training methods.}

Almost $80 \%$ of respondents reported offering some type of training to their international volunteers. Based on examples shared in open-ended responses, six different types of potential training methods were identified and categorized (Table 9); a category was also created for where respondents indicated that they offer training but the type or method of training was unclear.

Table 9

Training Methods Shared by Survey Respondents

Training Methods

Materials, orientation, and/or training provided upon arrival

Other or unspecified type of training and/or orientation provided or offered after arrival Training provided on-the-job after arrival

Training available as needed after arrival

Materials provided before international volunteers arrive

Ongoing training provided after arrival

Partner organization responsible for training and/or orientation

\begin{tabular}{cc}
$\begin{array}{c}\text { Number of } \\
\text { Respondents }\end{array}$ & $\begin{array}{c}\text { Percentage of Total } \\
\text { Respondents }\end{array}$ \\
\hline 79 & $45.9 \%$ \\
71 & $41.3 \%$ \\
27 & $15.7 \%$ \\
12 & $7.0 \%$ \\
10 & $5.8 \%$ \\
9 & $5.2 \%$ \\
4 & $2.3 \%$
\end{tabular}

Nearly half of respondents reported offering some kind of training and/or orientation upon arrival of international volunteers. For some respondents, this is structured as a formal, comprehensive introductory exercise that takes place over the course of one or more days; for example, survey respondent \#1550946 wrote that "Upon arrival, new international volunteers partake in a ten-day orientation program which focuses on building cultural literacy and assimilation, setting work expectations, schedule, policies and procedures and providing a clear overview of mission, vision, 
approach, programs, beneficiaries and local needs." For others, it is dependent on the type of volunteer; as survey respondent \#1510109 explained, "as most of our volunteers are unskilled in the project work, our training is very structured, including manuals and 4 days of induction and supervision. for [sic] our skilled volunteers...there is little to no training, only a [sic] induction to the project set-up and needs."

Several respondents reported offering training on-the-job, on an ongoing basis, and/or as needed; as survey respondent \#1395541 explained, "The training is not too formal as we need to engage them as soon as we can. During the first two weeks they accompany staff and observe, ask questions and are provided with guidance to begin their own activity with staff support."

Finally, nearly one-fifth of respondents stated that they do not offer any kind of training to their international volunteers. As survey respondent \#1505421 explained, "[B]ecause volunteer roles are to provide training to local staff themselves, we do not train our volunteers." Survey respondent \#1512965 wrote, "It's all training. They do real work and get incredibly valuable international experience that they couldn't even pay for."

One potential finding of interest is that $100 \%$ of those host organizations that responded to this question and have international volunteer programs established prior to 1990 indicated that they currently offer training; by contrast, less than $20 \%$ of responding organizations with programs established after 2000 currently offer training.

\section{Revenue generation.}

Survey respondents were next asked to share if and how they receive or earn any money from hosting international volunteers, to which approximately half reported 
receiving funding. Specifically, $37.1 \%$ of responding organizations reported that international volunteers pay them a fee to volunteer with their organization while an additional $10.9 \%$ receive funding from a partner organization for hosting international volunteers.

Some respondents reported that they require fees from some but not all international volunteers, depending on such factors as length of service or skill sets; as survey respondent \#1409606 explained, "They pay according to their capacity and interests and we pay if we have funded projects that need their skills. Payments are low either way, and supervising them can require unpaid staff time." Survey respondent \#1505415 wrote, "Short term volunteers require a small fee and long term volunteers (3 months or more) require no fee.”

Among those that do receive funding from hosting international volunteers, how and how much - they receive appears to vary widely. For some, fee amounts are designed to only cover the core costs of hosting - for example, accommodations, meals, etc. - and not the materials needed and/or staff time required to train and supervise international volunteers. Others build into their fees funding for administrative overhead of the volunteer program and/or costs associated with the organization's broader community projects and services. Fee amounts were similarly varied. Survey respondent \#1451143 wrote: "Volunteers pay a one time USD\$100 administration fee. It supports operation of office, volunteer support, support for projects. The volunteer pays this if they are here for two weeks or two years." Survey respondent \#1504769 stated:

[A] $\$ 650$ donation is requested. $\$ 250$ goes toward running the volunteer program (orientation, management, recruiting, etc.), \$150 goes to a partner organization or project materials (for example, our health volunteers work in the health clinic, so 
we donate this portion to the clinic), and $\$ 250$ goes directly to a homestay [sic] family that the volunteer lives with for the first month (includes bedding, private room, three meals, and drinking water).

Some respondents did not initially charge any type of fee but changed their policies over time: as survey respondent \#1411572 shared:

Initially volunteers didn't have to pay anything, but we realised after a while that this was limiting the organisation in terms of how many volunteers we could host as we couldn't meet their costs. Volunteers now have to pay a small contribution to the accommodation that they stay in (this doesn't actually cover the full costs and is far less than rent in their own country), and a one off contribution that goes towards the costs of recruiting and hosting them $(\$ 100)$.

For the $48.0 \%$ of respondents that reported not receiving any money for hosting international volunteers, the reasons for not requiring or receiving financial benefits were varied. For example, for some, a conscious decision was made to not seek funding from international volunteers. As survey respondent \#1413065 wrote, "NO. We do not charge any [international volunteer] any fees. Neither we [sic] expect any donation from them. This is our policy." Survey respondent \#1472549 wrote, "our [sic] policy is to receive no money from our volunteers. we [sic] believe in the skills of volunteers and we also believe that this creates responsibilities for the volunteers who come to us." Others do not require a fee from volunteers but leave the door open for them to provide financial support or request voluntary support for specific services; as survey respondent \#1391702 stated, "We do not receive a tuition fee for hosting volunteers, but if they choose to stay in our dorm space, we ask for a nominal donation ( $\$ 25 /$ week) to help defray the cost of renting the space.” Survey respondent \#1514800 shared:

It's not really a 'formal' fee - what we ask for is that they help contribute towards the cost of their stay (accommodation, fuel, transport, food, etc) and that they contribute something towards the cost of the materials that they use (for example, if we build something in community...we might ask for contributions towards the 
cost.) We are a faith-based organization, so we don't always ask for anything and we often let people decide what they want to pay us.

\section{Host Organization Opinions and Perspectives}

Having introduced the broader characteristics of responding host organizations and their international volunteer programs, this section will now delve into their reported opinions of and perspectives on engaging international volunteers, from organizational motivations for hosting international volunteers to the potential benefits and challenges of facilitating international service.

\section{Motivation to host international volunteers.}

Based on the open-ended responses received from survey respondents, 16 categories of motivation were identified and tabulated (Table 10). Of these, the most commonly cited motivation - by $43.2 \%$ of respondents - was that international volunteers could contribute needed skills, languages, and perspectives. As survey respondent \#1391170 wrote, "We believe International Volunteers [sic] can bring in skills, experience and knowledge that we might not be able to have locally." Survey respondent \#1411800 shared, "Because the schools asked us to help by bringing native english [sic] speakers to support [local] english [sic] teachers in the classroom."

The second most commonly cited motivation - indicated by $31.0 \%$ of respondents - was that hosting international volunteers provided opportunities for cross-cultural connections, learning, and understanding, both for international volunteers and the community. For international volunteers, serving abroad provides a chance to learn more about life and work in another part of the world; as survey respondent \#1394068 wrote, "We wanted to give as wide a range of people as possible the chance to live in a village, 
learn about development work and help out." This cultural exchange may also generate benefits for the community at large. As survey respondent \#1391049 wrote, "Our organisation is based in an isolated, rural, cross-border region which needs to open up to different ideas, cultures and mentalities. The contact with international volunteers make [sic] a change in how the community develops.” Survey respondent \#1391324 explained,

My NGO is based in a poor postwar area in [country]. People here do not travel much, [sic] the children have limited resources and oportunities [sic]. Volunteering brings in individuals from other cultures and opens up this closed area. Volunteers contribute their time and skills and have a great influence on people that have suffered through war and often have learned to become helpless and inert in their own communities. Volunteers help us kick start the community, individuals from the local community get involved and we learn from one another.

Similarly, survey respondent \#1611001 shared the following: "We appreciate and value the diversity of experiences of international volunteers. The local community enjoys working with them and having an opportunity to practice their English etc."

The third most common (25.4\%) motivation reported was that volunteers were needed to help fill gaps and leverage staff capacity. For some, this was due to the relatively inexpensive nature of engaging international volunteers while, for others, it was in response to a lack of local volunteer engagement; survey respondent \#1506211 wrote that "...local youth do not understand why they should volunteer in community development. Whereas, so far my interactions with international volunteers [sic], they are very committed and understand volunteerism and willing [sic] to assist.” For several respondents, international volunteer skills provided a way to expand internal organizational capacity; for example, survey respondent \#1428438 wrote that "Apart from getting an extra helping hand we get to understand how things could be done 
differently." Survey respondent \#1505421 explained, "As with most NGOs many of our local staff have had limited education but are committed to learning. Thus we utilize international volunteers in training and working on staff development issues...the role of the volunteer is mainly focused on training and developoing [sic] sustainable systems of operation." Survey respondent \#1433073 wrote, "For diversity in our organization, providing training and coaching, to grow our activities which could not be funded or managed immediately with internal resources."

Finally, the fourth most common motivation - cited by $14.6 \%$ of respondents was that international volunteers could potentially contribute financial resources, assist with fundraising, and/or become donors. "Volnteers [sic] are agentss [sic] of fundraising," wrote survey respondent \#1511864. "When the volunteering period ends they in most cases acts as agents or links between donor and the project." Survey respondent \#1410782 shared, "International Volunteers [sic] have been abasis [sic] of moblising [sic] some funds for our project. Especially so when they return to their home coutry [sic],They [sic] are in position [sic] to explain properly the work we do with children."

Table 10

Reported Organizational Motivations for Deciding to Host International Volunteers

Organizational Motivations

International volunteers contribute needed skills, languages, and perspectives

Hosting international volunteers provides opportunities for cross-cultural connections, learning, and understanding for international volunteers and the community

\begin{tabular}{cc}
$\begin{array}{c}\text { Number of } \\
\text { Respondents }\end{array}$ & $\begin{array}{c}\text { Percentage of } \\
\text { Respondents }\end{array}$ \\
\hline 92 & $43.2 \%$
\end{tabular}

66

$31.0 \%$ 

opportunities

Other reasons

International volunteers are committed and/or

effective

International volunteers support local efforts and 
Overall, many respondents cited more than one, if not several, of the above identified motivations for engaging international volunteers. For example, as survey respondent \#1395541 wrote: "Widen the horizons of beneficiaries, especially in remote areas. Introduce new experiences and skill sets to the current workforce. Add an interesting new member to the staff for a short period of time."

\section{Potential benefits of hosting international volunteers.}

In order to gauge perceptions on the potential benefits of hosting international volunteers, survey respondents were asked to consider thirteen benefits statements and rank how much they agreed or disagreed with each using a six-point Likert Scale; their

answers options were, in order, "strongly agree," "agree," "neutral," "disagree," "strongly disagree," and "not sure."

Overall, respondents appeared to be overwhelmingly positive regarding the benefits of hosting international volunteers (Table 11). For example, a majority of respondents agreed or strongly agreed with all but three of the suggested benefits statements; in fact, the only statements where less than $50 \%$ of respondents agreed or strongly agreed were where international volunteers 1) "help us attract local volunteers" (48.1\%), 2) "are inexpensive" (44.0\%), and 3) "became financial donors" (38.2\%). The most commonly agreed with statements were that international volunteers 1) "contribute needed skills" (91.4\% agreed or strongly agreed; 53.7\% strongly agreed), 2) "provide an opportunity for local people to learn more about other nations and cultures" $(88.0 \%$ agreed or strongly agreed; $60.3 \%$ strongly agreed), and 3) "provide a new viewpoint or perspective" (89.1\% agreed or strongly agreed; $49.8 \%$ strongly agreed). 
Just over half of respondents agreed or strongly agreed with statements regarding financial gains; $54.4 \%$ of respondents agreed or strongly agreed that international volunteers "help our economy by spending money locally" while $51.5 \%$ agreed or strongly agreed that international volunteers "generate revenue for our organization."

Table 11

Percentage of Responses to "What do you think are the potential benefits of hosting international volunteers? Please mark how much you agree or disagree with the following statements: " a, b

International volunteers... Strongly Agree Neutral Disagree Strongly Not Agree ...provide an opportunity for local people to learn more about other nations

$60.3 \%$

(146) and cultures

...contribute needed skills

...provide a new

viewpoint or perspective

...bring international attention to our work

...provide more people to get our work done

...bring credibility to our work

...become advocates upon

return home

...are effective

...help us attract local

volunteers

...generate revenue for our organization

...are inexpensive

$\begin{array}{cccccc}\mathbf{5 3 . 7 \%} & 37.7 \% & 7.4 \% & 0.8 \% & 0.4 \% & 0.0 \% \\ \mathbf{( 1 3 1 )} & (92) & (18) & (2) & (1) & (0)\end{array}$

49.8\% $\quad 39.3 \% \quad 8.4 \% \quad 1.7 \% \quad 0.4 \% \quad 0.4 \%$ (119) (94) (20) (4) (1)

(1)

$\begin{array}{llllll}\mathbf{3 9 . 8} \% & 39.4 \% & 14.8 \% & 4.7 \% & 0.4 \% & 0.8 \%\end{array}$

(94) (93) (35) (11) (1)

$\begin{array}{cccccc}37.1 \% & \mathbf{4 0 . 6 \%} & 15.2 \% & 5.4 \% & 1.3 \% & 0.4 \% \\ (83) & (91) & (34) & (12) & (3) & (1)\end{array}$

$\begin{array}{llllll}\mathbf{3 6 . 2} \% & 34.2 \% & 21.0 \% & 6.2 \% & 1.2 \% & 1.2 \%\end{array}$

$\begin{array}{lllll}\text { (88) } & (83) & (51) & (15) & \text { (3) }\end{array}$

$\begin{array}{llllll}35.6 \% & \mathbf{4 0 . 6} \% & 18.0 \% & 4.6 \% & 0.8 \% & 0.4 \%\end{array}$

$\begin{array}{lllll}(85) & \text { (97) (43) (11) } \quad \text { (2) }\end{array}$

$\begin{array}{llllll}25.8 \% & \mathbf{4 6 . 3} \% & 25.3 \% & 1.7 \% & 0.0 \% & 0.9 \%\end{array}$

$\begin{array}{llllll}(59) & \text { (106) (58) } & \text { (4) } & \text { (4) }\end{array}$

$22.8 \% \quad 25.3 \% \quad \mathbf{2 8 . 6 \%} \quad 15.8 \% \quad 5.0 \% \quad 2.5 \%$

$\begin{array}{llllll}(55) & (61) \quad \text { (69) } \quad(38) \quad \text { (12) }\end{array}$

$20.6 \% \quad 30.9 \% \quad 23.5 \% \quad 15.6 \% \quad 7.0 \% \quad 2.5 \%$

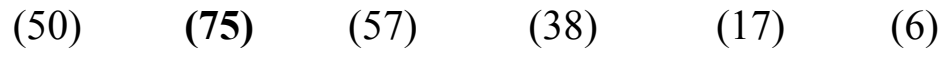

$19.2 \% \quad 24.8 \% \quad \mathbf{3 0 . 8} \% \quad 18.8 \% \quad 3.8 \% \quad 2.6 \%$

$\begin{array}{lllll}(45) & (58) & \text { (72) } & \text { (44) } & \text { (9) }\end{array}$ 
...help our economy by

spending money locally

...become financial

donors
$19.1 \%$

$13.0 \%$

(31)
35.3\% $\quad 26.8 \%$

(83)

(63)

$25.2 \%$

(60)
31.9\% $20.2 \%$

(76)
$12.3 \%$

(48)
$4.3 \%$

(10)

$6.7 \%$
$2.1 \%$

Notes: ${ }^{a}$ Most frequently selected answer options are in bold. ${ }^{b}$ Number in parentheses is the number of respondents that selected answer.

In addition, of the five answer options where more than $10 \%$ of respondents disagreed or strongly disagreed with the statement, four were related to potential financial benefits of hosting international volunteers.

\section{Most important benefits of hosting international volunteers.}

Respondents were next asked to share - in an open text box - what they felt were the most important benefits of hosting international volunteers. The answers to this open question varied broadly, resulting in over 20 categories of answers; while several of these were equivalent to potential benefits suggested in the previous question, many new potential benefits were also identified.

The potential benefit listed as being most important by the greatest number of respondents $-55.2 \%$ - was that international volunteers contribute needed skills, languages, ideas, energy, and perspectives. As survey respondent \#1409517 wrote, "By having a native English speaker teaching English students at our partner organizations [we] are able to reach a higher level of English and therefore write proposals and interact with foreign donors on a higher level." Survey respondent \#1440184 wrote, "Visiting doctors assist in upgrading skills, adding new protocols, etc. Last year, a visiting doctor added new procedures that our laboratory could undertake... so now our lab can do it rather than outsource." Survey respondent \#1395186 shared that international volunteers 
"set an example of concentrated effort and dedication among our staff many a time. Their skills and new perspectives help the organisation develop a broader vision.” A fourth individual, survey respondent \#1411572, wrote:

The local communities we work in have benefitted massively from the wide range of skills our [international] volunteers offer (and I'm not just 'selling' my organization here - we have stringent evaluation processes in place to make sure that we are meeting the needs of the local communities). A specific example could be the...classes that we ran where skilled first aid trainers came and did intensive classes with local women. Not only did this provide the women with vital skills to help their families and communities (and women are the main caregivers meaning more people benefit from them knowing first aid - e.g. the women had up to 15 children), it also improved their position within what is a very partiarchial [sic] society and gave them peer support.

The next most frequently listed important benefit of hosting international volunteers - suggested by $25.2 \%$ of respondents - was the ability to provide opportunities for cross-cultural connections, learning, and understanding for both international volunteers and the community. Survey respondent $\# 1584241$ shared the benefit of this for the international volunteer as the following:

By far the most important aspect is the connection and increased understanding between cultures. Many of our volunteers have never traveled outside of their home country and have never seen people truly living in poverty. Through their work, they're able to grow in their understanding of how billions of people live on a daily basis, while also forming a personal relationship with the beneficiaries. The volunteers also realize the people they are helping are very self-sufficient, intelligent and hard-working - the volunteers act as partners and often assistants to the local beneficiaries. This helps develop both groups' perspective.

Similarly, survey respondent \#1504769 wrote,

It is important for (typically) financially privileged Westerners to explore the world in order to better understand the factors contributing to the major misdistribution [sic] of resources throughout the world. It is one thing to write a check in order to donate to a good cause, but often there is a much more meaningful and long-term effect when an individual spends quality time visiting a new community. 
When citing the most important benefits to the community, respondents offered such evidence as an introduction - especially for young people - to other personal and professional possibilities (for example, going to college), international volunteers making programs and classes more interesting for local participants, friendships forming between international volunteers and community members that are often sustained beyond the term of service, and providing a source of pride for local citizens; to this latter point, survey respondent \#1423385 wrote "Locals are very proud to host and to attract such a great number of foreign people in such a small community." In addition, some respondents suggested that international volunteers can, over time, help to demonstrate other ways of life in relatively isolated areas; survey respondent \#1474134 explained the importance of this as follows:

The [local] community is very restrictive of women's behavior, movement, and rights. When we had women volunteers from the US and Europe, they respected local culture but also showed many people in our community that women can be independent, travel alone, be professional and strong, and that these do not necessary entail improper behavior on their part, or a threat to 'family honor.' The fact that our volunteers have been multicultural... also helped a little to foster a more tolerant attitude in our community.

Survey respondent \#1411572 wrote:

The communities we work in feel highly isolated from the outside world due to ongoing occupation and conflict, they [sic] often feel they are forgotten and noone [sic] cares about them which adds to the psychological impact they already experience. The presence of international volunteers helps break down that barrier and makes the students we work with (and their families) feel part of a global community and realise that some people really do care.

The third most frequently listed benefit - suggested by $24.3 \%$ of respondents was the potential for international volunteers to contribute financial resources, assist with fundraising and/or become donors. As survey respondent \#1428758 wrote, "Our 
relationships with our international volunteers have helped expand our networks and fundraising avenues. When we began an online fundraising drive, these networks were vital in making it a success." Survey respondent \#1505049 stated:

It's really a tie between seeing the positive impacts our volunteers have on our work and communities here - and knowing how we only exist to continue our work because of the exposure they provide us upon return to their home countries and the continued support they give us. An example would be seeing a person return home, join our board of directors and lead fundraising efforts.

Survey respondent \#1515659 wrote, "Besides being a key to achieve [sic] our mission, our organization is financed by the fees they pay for the services they receive (pick up, lodging, assistance, Spanish classes, etc.)”

Several additional, including a handful of newly suggested, potential benefits for hosting international volunteers were also cited as being most important. For example, some of the most important benefits mentioned by respondents were related to how international volunteers (and, in some cases, the host organization) were perceived in and/or directly benefited the community: $7.1 \%$ of respondents cited that international volunteers can be beneficial, inspiring, and/or serve as role models for the organization and/or community; $5.2 \%$ noted that international volunteers bring credibility and respect to the organization's work; $4.8 \%$ offered that international volunteers help to support local efforts, including promoting volunteerism and/or attracting local volunteers; $4.3 \%$ indicated that international volunteers help to make organizational programs more interesting to the population being served; $3.8 \%$ noted that international volunteers can open doors and/or improve relations with other organizations; $1.4 \%$ indicated that international volunteers help the economy by spending money locally; and $1.0 \%$ noted 
that international volunteers are central to the organization's mission and/or demonstrate a commitment to international values.

Other most important benefits cited related more to the host organization's capacity to do its work both currently and in the future: $22.9 \%$ of respondents noted that international volunteers help to raise awareness of the organization and/or the organization's mission either individually or internationally; $18.6 \%$ indicated that international volunteers help to train staff and develop staff capacity; $15.7 \%$ mentioned that international volunteers provide more people to get work done; an additional $15.7 \%$ cited international volunteers becoming advocates upon return home; $5.2 \%$ noted that international volunteers can be inexpensive; $1.9 \%$ mentioned international volunteers making the overall volunteer program more sustainable by staying for longer periods of time and/or volunteering more hours per day; and $1.4 \%$ indicated that international volunteers can increase diversity within the organization and/or community.

A third category of most important benefits mentioned provided opinions primarily on the qualities and characteristics of international volunteers engaged and included such things as international volunteers being committed and/or effective (mentioned by $11.4 \%$ of respondents). Finally, $6.2 \%$ of respondents noted that international volunteers themselves benefited by gaining experience and learning new skills through international service; in fact, $1.4 \%$ of respondents stated that the benefits of hosting international volunteers went primarily to the volunteers themselves rather than the organization or community. As survey respondent \#1511176 wrote, "It's more a [sic] personal satisfaction and involvement rather than benefits to the organisation. Most 
volunteers are young and inexperienced and therefore the benefits of gaining knowledge and experience are actually to the volunteers."

\section{Potential challenges of hosting international volunteers.}

Using identically structured questions to those regarding benefits, survey respondents were next asked to consider thirteen statements listing potential challenges of hosting international volunteers and rank how much they agreed or disagreed with each using the six-point Likert Scale (Table 12).

However, in contrast to the question regarding potential benefits, where a majority of respondents agreed or strongly agreed with all but three of the suggested statements, here a majority of respondents agreed or strongly agreed with only five of the 13 potential challenges suggested: where international volunteers 1) “don’t stay long enough" $(60.8 \%), 2)$ "can be difficult to find" $(57.2 \%), 3)$ "are accustomed to different ways of doing things" (56.4\%), 4) "may not have the language abilities needed" $(53.8 \%)$, and 5) "require a lot of supervision" (50.0\%). In fact, less than $10 \%$ of respondents agreed or strongly agreed with three of the challenge statements: where international volunteers 1) "take the place of local volunteers" $(6.2 \%), 2)$ "are not effective" $(6.3 \%)$, and 3) "take the place of local jobs" $(8.0 \%)$.

\section{Table 12}

Percentage of Responses to "What do you think are the potential challenges of hosting international volunteers? Please mark how much you agree or disagree with the following statements: " a, b

International volunteers... Strongly Agree Neutral Disagree Strongly Not \begin{tabular}{lcccccc} 
& Agree & & & & Disagree & Sure \\
\cline { 2 - 7 } ...can be difficult to find & $20.7 \%$ & $\mathbf{3 6 . 5 \%}$ & $17.8 \%$ & $19.5 \%$ & $4.1 \%$ & $1.2 \%$
\end{tabular}

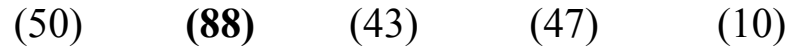




\begin{tabular}{|c|c|c|c|c|c|c|}
\hline $\begin{array}{l}\text {...are accustomed to } \\
\text { different ways of doing } \\
\text { things }\end{array}$ & $\begin{array}{c}19.5 \% \\
(47)\end{array}$ & $\begin{array}{l}36.9 \% \\
(89)\end{array}$ & $\begin{array}{c}26.6 \% \\
(64)\end{array}$ & $\begin{array}{c}14.1 \% \\
(34)\end{array}$ & $\begin{array}{l}1.2 \% \\
(3)\end{array}$ & $\begin{array}{c}1.7 \% \\
(4)\end{array}$ \\
\hline ...don't stay long enough & $\begin{array}{c}17.4 \% \\
(42)\end{array}$ & $\begin{array}{c}43.4 \% \\
(105)\end{array}$ & $\begin{array}{l}20.7 \% \\
(50)\end{array}$ & $\begin{array}{l}16.1 \% \\
(39)\end{array}$ & $\begin{array}{c}2.5 \% \\
(6)\end{array}$ & $\begin{array}{l}0.0 \% \\
(0)\end{array}$ \\
\hline $\begin{array}{l}\text {...require a lot of } \\
\text { supervision }\end{array}$ & $\begin{array}{c}17.4 \% \\
(41)\end{array}$ & $\begin{array}{c}32.6 \% \\
(77)\end{array}$ & $\begin{array}{c}22.9 \% \\
(54)\end{array}$ & $\begin{array}{l}22.9 \% \\
(54)\end{array}$ & $\begin{array}{l}3.8 \% \\
(9)\end{array}$ & $\begin{array}{l}0.4 \% \\
(1)\end{array}$ \\
\hline $\begin{array}{l}\text {...may not have the } \\
\text { language abilities needed }\end{array}$ & $\begin{array}{l}15.0 \% \\
(36)\end{array}$ & $\begin{array}{l}38.8 \% \\
(93)\end{array}$ & $\begin{array}{l}23.8 \% \\
(57)\end{array}$ & $\begin{array}{c}18.3 \% \\
(44)\end{array}$ & $\begin{array}{c}3.3 \% \\
(8)\end{array}$ & $\begin{array}{l}0.8 \% \\
(2)\end{array}$ \\
\hline ...require a lot of training & $\begin{array}{c}14.0 \% \\
(34)\end{array}$ & $\begin{array}{c}28.9 \% \\
(70)\end{array}$ & $\begin{array}{c}24.8 \% \\
(60)\end{array}$ & $\begin{array}{c}28.5 \% \\
(69)\end{array}$ & $\begin{array}{c}3.3 \% \\
(8)\end{array}$ & $\begin{array}{l}0.4 \% \\
(1)\end{array}$ \\
\hline $\begin{array}{l}\text {...may not have the skills } \\
\text { needed }\end{array}$ & $\begin{array}{l}5.8 \% \\
(14)\end{array}$ & $\begin{array}{c}\mathbf{3 5 . 3 \%} \\
(\mathbf{8 5})\end{array}$ & $\begin{array}{c}23.7 \% \\
(57)\end{array}$ & $\begin{array}{c}27.0 \% \\
(65)\end{array}$ & $\begin{array}{c}7.5 \% \\
(18)\end{array}$ & $\begin{array}{l}0.8 \% \\
(2)\end{array}$ \\
\hline ... are expensive & $\begin{array}{l}4.6 \% \\
(11)\end{array}$ & $\begin{array}{c}10.8 \% \\
(26)\end{array}$ & $\begin{array}{c}25.8 \% \\
(62)\end{array}$ & $\begin{array}{l}39.2 \% \\
(94)\end{array}$ & $\begin{array}{c}17.5 \% \\
(42)\end{array}$ & $\begin{array}{l}2.1 \% \\
(5)\end{array}$ \\
\hline $\begin{array}{l}\text {...distract staff and local } \\
\text { volunteers from the work }\end{array}$ & $\begin{array}{l}4.6 \% \\
(11)\end{array}$ & $\begin{array}{c}15.5 \% \\
(37)\end{array}$ & $\begin{array}{l}25.2 \% \\
(60)\end{array}$ & $\begin{array}{l}39.9 \% \\
(95)\end{array}$ & $\begin{array}{c}13.9 \% \\
(33)\end{array}$ & $\begin{array}{c}0.8 \% \\
(2)\end{array}$ \\
\hline $\begin{array}{l}\text {...take the place of local } \\
\text { jobs }\end{array}$ & $\begin{array}{l}3.8 \% \\
(9)\end{array}$ & $\begin{array}{c}4.2 \% \\
(10)\end{array}$ & $\begin{array}{l}10.9 \% \\
(26)\end{array}$ & $\begin{array}{l}45.6 \% \\
(109)\end{array}$ & $\begin{array}{l}33.1 \% \\
(79)\end{array}$ & $\begin{array}{l}2.5 \% \\
(6)\end{array}$ \\
\hline $\begin{array}{l}\text {... are not always welcome } \\
\text { in our community }\end{array}$ & $\begin{array}{c}3.3 \% \\
(8)\end{array}$ & $\begin{array}{l}7.9 \% \\
(19)\end{array}$ & $\begin{array}{l}11.3 \% \\
(27)\end{array}$ & $\begin{array}{c}44.4 \% \\
(106)\end{array}$ & $\begin{array}{l}32.2 \% \\
(77)\end{array}$ & $\begin{array}{l}0.8 \% \\
(2)\end{array}$ \\
\hline $\begin{array}{l}\text {...take the place of local } \\
\text { volunteers }\end{array}$ & $\begin{array}{l}2.5 \% \\
(6)\end{array}$ & $\begin{array}{l}3.7 \% \\
(9)\end{array}$ & $\begin{array}{c}14.5 \% \\
(35)\end{array}$ & $\begin{array}{l}49.8 \% \\
(120)\end{array}$ & $\begin{array}{c}26.6 \% \\
(64)\end{array}$ & $\begin{array}{c}2.9 \% \\
(7)\end{array}$ \\
\hline ....are not effective & $\begin{array}{l}1.7 \% \\
(4)\end{array}$ & $\begin{array}{l}4.6 \% \\
(11)\end{array}$ & $\begin{array}{c}16.9 \% \\
(40)\end{array}$ & $\begin{array}{l}49.8 \% \\
(118)\end{array}$ & $\begin{array}{c}24.5 \% \\
(58)\end{array}$ & $\begin{array}{l}2.5 \% \\
(6)\end{array}$ \\
\hline
\end{tabular}

Instead, most respondents disagreed or strongly disagreed with many of the challenges suggested in the survey. Those statements where the highest percentage of respondents disagreed or strongly disagreed were where international volunteers 1) "take the place of local jobs" (78.7\%), 2) "are not always welcome in our community" (76.6\%), 
3) "take the place of local volunteers" (76.4\%), and 4) "are not effective" (74.3\%). Two additional statements elicited responses of "disagree" or "strongly disagree" from over half of respondents: international volunteers "are expensive" (56.7\%) and "distract staff and local volunteers from the work" (53.8\%).

A handful of statements displayed more divided opinions among respondents. For example, when asked to agree or disagree with the statement that international volunteers "may not have the skills needed," $41.1 \%$ agreed or strongly agreed while $34.5 \%$ disagreed or strongly disagreed. Similarly, regarding the statements that international volunteers "require a lot of training" and "require a lot of supervision," $42.9 \%$ and $50.0 \%$ of respondents agreed or strongly agreed while $31.8 \%$ and $26.7 \%$ disagreed or strongly disagreed, respectively. Finally, for eight of the 13 statements, 20$30 \%$ of respondents chose the answer option "neutral" or "not sure," while for four of the remaining five questions - where the percentage of "neutral" or "not sure" answers was less than $20 \%$ - respondents overwhelmingly disagreed with the statement, with over $70 \%$ responding "disagree" or "strongly disagree."

\section{Most important challenges of hosting international volunteers.}

Again similar to potential benefits, after rating the potential challenge statements listed on the survey, respondents were asked to share what they felt were the most important challenges of hosting international volunteers. Once again, answers varied widely, resulting in over 22 identified kinds of challenges. Again, several were equivalent to those suggested in the potential challenges statements while other new potential challenges were also identified. However, unlike the most important benefits suggested by respondents, most important challenges were more spread out with fewer 
percentages of respondents in each category; in addition, an "other" category that was created for highly individualized responses was the most appropriate for $23.8 \%$ of respondents.

Of the most important challenges identified by respondents, the most frequently cited was that international volunteers "can have difficulty accepting, adjusting, and/or adhering to local cultural and/or professional norms," suggested by $18.5 \%$ of respondents. As survey respondent \#1510925 explained:

The main challenge is for volunteers to adjust to the local culture. We work with students from somewhat conservative and traditional communities and it's not always easy for our volunteers to understand that to avoid offending people they need to modify their dress and even certain subjects of conversation. There is also a complete lack of privacy and personal space which is difficult for volunteers to adjust to.

Survey respondent \#1391049 wrote:

International volunteers have often [sic] difficulties to adapt to the lack of professionalism, commitment, interest and infrastructure of local [sic] community and especially to slow procedures in decision making and implementation by local authorities and other structures.

Survey respondent \#1505421 shared:

Volunteers expect a certain standard and expect standards to be replicated here. They want to change the systems to Western ways of doing things, which do not always work. This makes local staff feel uncomfortable and can somtimes [sic] create an adversarial working environment. Volunteers do need to understand cultural differences and how things operate within local context.

The second most frequently suggested challenge, by $16.1 \%$ of respondents, was that international volunteers "can have unrealistic expectations about what they can or should accomplish and/or how things should be done." Survey respondent \#1513219 offered, "The biggest challenge is encouraging the volunteers that their ideas etc are not always the most effective in our given environment. Volunteers have read and studied 
thories [sic] on what 'helps' local communities and are unwilling to drop those ideas in favour of experience in the field." Survey respondent \#1409578 shared the following example: "We had a situation wherein a volunteer thought that actions should be rapid. Volunteers need to understand that every business decision has financial implications. Much valuable work done by volunteers has remained as a waste, given that there are usually no accompanying resources to implement." Survey respondent \#1403123 wrote, "International volunteers have certain expectations. Invariably different to our own and often high. They want to 'make a difference' and it is hard to convince them that big changes come from small efforts," while survey respondent \#1391575 explained:

This work has a tendency to attract people who want to 'save the world' but have little idea or training in international development and social work nor for the specific community that they are working in AND then they only stay 3-4 months. This leads to a huge amount of time being wasted with people making the same suggestions over and over again, working on projects that are not original and doomed to fail and resistance towards suggestions of those who have been here longer simply because people need to see this for themselves before they will believe it is true - it takes A LOT of patience sometimes. :)

The third and fourth most frequently suggested important challenges were that international volunteers "may not have the language abilities needed" (11.7\%) and "don't stay long enough" (10.1\%). For example, survey respondent \#1390842 wrote "The language barrier is often a huge challenge to their effectiveness as they are often reliant on our staff, taking us away from our work. They also often need a lot of guidance in their work and their free time and even just daily living stuff."

The remaining 17 categories of most important challenges were each cited by less than $10 \%$ of total respondents (note: $0.8 \%$ of respondents reported that they did not experience any challenges in hosting international volunteers). Similarly to the most 
important benefits noted by respondents, most important challenges cited could generally be categorized into a few types of challenges. For example, many of the most important challenges mentioned by respondents related to the host organization's capacity to effectively and efficiently engage international volunteers: $8.5 \%$ noted that international volunteers can require a lot of supervision and assistance; $7.7 \%$ indicated that international volunteers can require a lot or too much time, orientation, and/or training to get started; $6.0 \%$ found that international volunteers can be difficult to find; $5.6 \%$ noted that international volunteers can be expensive; $3.6 \%$ indicated that international volunteers can be difficult to assess, vet, and/or match from afar; $1.2 \%$ noted that international volunteers can be or feel underutilized, sometimes leading to frustration; and $0.4 \%$ cited that international volunteers can require resources or tools that are unavailable or too expensive.

A second category of most important challenges mentioned related primarily to characteristics of and accommodations needed for international volunteers and included such things as international volunteers being unmotivated and/or unreliable (noted by $9.3 \%$ of respondents); having difficulty with local accommodations, food, transportation, climate, etc. (8.1\%); requiring accommodations, transportation, meals, etc. that are difficult to find or very different from local standards (6.0\%); not having the skills required (4.0\%); requiring precautions for health and physical safety or security $(4.0 \%)$; being unprepared for the work, cultural norms, climate, etc. (2.8\%); being difficult to manage (2.0\%); being untrustworthy (2.0\%); and often not being effective (1.6\%). 
The following five quotes offer additional insights into several of the above listed challenges:

Most challenging is that each volunteer has a different work ethic and different need for levels of project guidance. It can be very challenging to lead many volunteers from different ethnicities, educational backgrounds, ages and levels of experience. (Survey Respondent \#1412180)

The most important challenge of hosting international volunteers is the selection process before they arrive. The majority of the problems that have been listed above can be avoided if you have the right volunteer for the wrong position. The biggest challenge is when a volunteer arrives who is not capable of the task they wish to volunteer for and then have to be managed very carefully. (Survey Respondent \#1413981)

Oftentimes, volunteers have good intentions, but because they do not have any relevant skills or language abilities, they end up being disgruntled with their experience, which can have a negative ripple effect. Our staff does not have the time to hold volunteers hands, so it is a real burden to us when a volunteer needs a lot of direction, especially because we try to emphasize the need to an independent, take charge attitude. Of course, we do our best to offer support and language classes when necessary, but our priority is community development, not babysitting. (Survey Respondent \#1504769)

The benefits vastly overweigh the challenges when it comes to long-term volunteers. But short-term volunteers require a lot of training and supervision and don't stay around long enough to begin to apply what they have learned, and sometimes they represent a net loss of productivity. (Survey Respondent \#1415919)

They leave. This is undoubtedly the biggest challenge. They leave and if there is no well developed framework to translate their knowledge to the local community, then it is lost. (Survey Respondent \#1611001)

\section{Comparing benefits to challenges.}

Survey respondents were then asked the first of two questions designed to gauge overall perceived satisfaction with international volunteers: "In your opinion, based on your answers above, do the benefits of hosting international volunteers outweigh the challenges?" In response, $94.2 \%$ of respondents chose the answer option "Yes, I think 
international volunteers generally provide more benefits than challenges for our organization."

When asked to elaborate on their answer choice, some respondents stated that the benefits of hosting international volunteers outweighed the challenges primarily because of the positive changes they have inspired in their communities. Survey respondent \#1391049 explained, "We have hosted more than 60 long term (12 months) volunteers from 20 different countries. The local community has changed in these 8 years. People are more open-minded, optimistic, extravert [sic], interested in what is going on in the rest of the world, don't feel so strong [sic] the isolation and exclusion." "The children in the school adore the volunteers and gain something very special by working with people from so many different cultures and countries," wrote survey respondent \#1394574. Sometimes this translated into benefits for the organization as well, as explained by survey respondent \#1451347: "Even if a volunteer is only around for a brief time, the school gets a reputation for having an 'international presence' which contributes to a belief that it is more well-off/has more credibility."

Other respondents stated that they simply would not be able to get as many things done without international volunteers; survey respondent $\# 1480202$ wrote, "There are definitely challenges to having international volunteers, but over 30 years, volunteers have contributed greatly to the organization. When there are not volunteers, our staff have too much work to do; volunteers help to lessen their load." Respondents also cited such benefits as economic impacts - both while the volunteer is in-country as well as by serving as donors and fundraisers upon return home - and the ability of international volunteers to contribute much-needed new energy and skills; as survey respondent 
\#1504769 explained, "I love the enthusiasm new volunteers bring to our organization. It helps keep me motivated more long term." Survey respondent \#1421575 wrote, "Despite the challenges, volunteers act as catalysts on our projects, they [sic] help motivate local participation, provoke local initiatives/contributions, attract public attention to our work." Still others saw benefit not only in the immediate actions of the volunteers but also in the long-term relationships and roles they transitioned into as they "become advocates, donors, trainers for local volunteers and sometimes role models" (survey respondent \#1571022).

Some respondents qualified their answers as depending on such factors as how well they recruited the "right" volunteers for their organizational and community needs; "Volunteers provide more benefits than challenges if the organisation takes the time to develop criteria for accepting volunteers and vets them individually. We are a very small organisation so it's necessary for our volunteers to have specific skills and be willing to work within our framework," wrote survey respondent \#1510925. For others like survey respondent \#1415919, it depended on how long the volunteer stayed:

Yes, without a question, with long-term volunteers (at least 1-2 months). But when it comes to short-term volunteers, like people who stay less than a week, the answer is less definite. Some short-term volunteers have an ability to quickly adapt and come with ready-made skills and are hard workers, and this type of person helps. But other short-term people require too much supervision and training and actually detract from work.

Some also acknowledged that it was often a mixed bag experience; as survey respondent \#1390868 explained:

I am in the middle on this question. International volunteers require a lot more work on our part, they frequently cancel and when they do come there are extra financial and time costs on our part (picking them up at the airport, housing them before/after they start). On the other hand, we have had many international 
volunteers who come out, do an amazing job and work hard and make a huge impact.

Finally, several respondents expressed their appreciation for the contributions of international volunteers while at the same time stating that their ultimate goal was to engage more local volunteers. Survey respondent \#1391575 explained:

We would not be able to operate without volunteers and they bring motivation and enthusiasm for their work and new perspectives to what we are doing. That said, as the organisation changes and hopefully establishes new financing, we will decrease the number of international volunteers, in particular short term [sic] placements. Hopefully we will set up more local volunteering.

Survey respondent \#1505415 wrote:

Ideally, all volunteers would be local. However, long term [sic] international volunteers that can fill administrative roles provide great benefits to an organization. Unless a volunteer cost is significant (which is a question apart in itself), short term volunteers are generally less beneficial...In general, I am more inclined to accept short term volunteers if they are local and not international - this way, there is no need to train as per lifestyle, cultural awareness, language et al.

\section{Is hosting international volunteers worthwhile?}

To provide further insight into their perceived value of and satisfaction with international volunteers, respondents were then asked if, overall, they thought that it was worthwhile for their organization to host international volunteers. In addition to explaining why or why not, they were asked to select one of five answer options: "Yes," "Yes, but/if...", “No," "No, but/if...”, or "Not sure."

In response, over $88 \%$ of the respondents who answered this question selected the answer option "Yes"; when "Yes, but/if..." responses were included, then $98.0 \%$ of respondents agreed that it was worthwhile to host international volunteers. Overall, only two of 248 respondents selected the answer options "No" or "No, but/if..." (Table 13). 
Table 13

Responses to "Overall, do you think that it is worthwhile for your organization to host international volunteers?"

\begin{tabular}{lcc} 
Answer Options & $\begin{array}{c}\text { Number of } \\
\text { Respondents }\end{array}$ & $\begin{array}{c}\text { Percentage of } \\
\text { Respondents }\end{array}$ \\
\cline { 2 - 3 } Yes & 181 & $88.7 \%$ \\
Yes, but/if... & 19 & $9.3 \%$ \\
No & 1 & $0.5 \%$ \\
No, but/if... & 1 & $0.5 \%$ \\
Not sure & 2 & $1.0 \%$
\end{tabular}

In terms of explanatory statements, some were almost exuberant in their praise for engaging international volunteers. As survey respondent \#1505049 explained,

"Absolutely! The positive things we see come out of this experience for both the volunteers and communities is quite impressive!" Survey respondent \#1391324 wrote:

Absolutely, it is extremely important to our community that they get to experience and work with international educated and motivated volunteers. It means the world to our kids and youth that sorely need role models...the volunteers give them an alternative role model, a positive and motivating role model. In addition, our kids english langauge [sic] skills have greatly improved and they cannot wait for the next batch of volunteers to arrive.

"Very worthwhile," explained survey respondent \#1411800. "All [of the] schools we support with volunteers tell us that the children work much harder, enjoy their lessons more and the teachers are motivated when there is a volunteer around."

Others expressed positive opinions of hosting international volunteers but explained that it often depended on how many they were hosting (fewer appeared to be better for the respondents who mentioned this factor), how long the volunteer stayed, and/or how well the organization recruited and selected the volunteer. "We have had very good ones 
and a couple of very bad ones...It is a mixed bag," wrote survey respondent \#1391344. Survey respondent \#1440184 explained, "It is worthwhile, but we need very few and each for a long period," while survey respondent \#1451143 offered, "Absolutely! But, the longer volunteers stay, the better. The more edcuated [sic] they are on community issues, the better." Survey respondent \#1394601 wrote:

Yes - but with careful selection of who. We hope to make it more worthwhile in the future by reviewing our volunteer projects -making sure there is better recruitment for those who 'fit the bill', especially people who are travelling to our region anyway, and so whose accommodation we don't have to solve.

Finally, survey respondent $\# 1575025$ offered the following personal explanation for why international volunteers are worth their investment of time, resources, and energy: "It would be pretty dull around [the volunteer site] without the international volunteers to entertain us. But sometimes they can drive you nuts."

\section{How host organizations might benefit more.}

While one of the primary goals of the survey was to capture how host organizations currently perceive the benefits and challenges of engaging international volunteers, respondents were also asked if they had any specific suggestions for how to improve future volunteer-host organization relationships and exchanges: "In your opinion, how might organizations like yours benefit more from working with international volunteers?" In response, respondents offered 23 different types of suggestions. However, many survey respondents skipped this question or provided answers that were unclear, meaning that these 23 types of suggestions were provided by only $34.3 \%$ of the total sample. As a result, almost every category was suggested by less than $5 \%$ of the total group. In 
addition, $7.3 \%$ of respondents offered suggestions that were specific to their individual organizations; these answers were captured in a category called "Other."

Suggestions submitted by respondents fell generally into three categories: international volunteer qualities, volunteer management infrastructure, and financial support. In the first category of volunteer qualities, respondents offered suggestions such as international volunteers staying longer (mentioned by $5.2 \%$ of respondents) and staying engaged even after returning home; $4.4 \%$ of respondents noted that international volunteers could stay involved after returning home, continuing to assist with such tasks as fundraising, advocacy, and promoting the volunteer program. As survey respondent \#1506483 suggested, "Greater benefits would come as a result of continued partnership between volunteer and host organization after placement and the volunteer's continued advocacy on our behalf upon returning home."

Respondents also mentioned international volunteers having more realistic expectations of what they will, should, and can do (2.4\%), taking their commitment seriously and following through on their promises (2.0\%), and arriving and staying openminded about, as well as prepared for, cultural differences $(0.8 \%)$. As survey respondent \#1391575 explained:

Globally the world has a very strange view of development work. People want to come and feel like they 'make a difference' Like it is all about them - this utterly selfish need to feel like you have tried to make things better, even though it's a tokenistic gesture and really a holiday. We would benefit if volunteers arrived understanding that actually they are the ones who will learn from this experience, they are the ones who will gain - what they have to offer, much of the time, is little more than money!!

Lastly, survey respondents mentioned needing an even higher quality of international volunteers, including receiving more skilled international volunteers $(2.4 \%)$ and more 
international volunteers with local language fluency $(1.2 \%)$. Survey respondent \#1507247 wrote:

We need better quality volunteers... business people, internet [sic] marketing, distribution. (Poor) [local] people don't need to learn how to grow lettuce or peanuts more efficiently, basically keeping them in poverty and waiting on charity - displacing the family structure and lowering the status of the parents/breadwinner in the eyes of the children and the children think it's normal to wait on charity from people who don't look like them or even speak their language. To eradicate poverty, in my opinion, helping the working class make more money on their own is a better way to go. They are already motivated to work and easily understand the benefits of working with other people to sell their products overseas or to a wider market, locally.

The second category of responses - volunteer management infrastructure elicited an even broader range of suggestions. Almost all of these related to what host organizations themselves could do proactively to gain even more from hosting international volunteers, including developing more stringent application/screening processes to improve matches with volunteers (mentioned by $5.2 \%$ of respondents), helping to ensure that international volunteers receive advance training and/or arrive better prepared to begin the work (4.8\%), developing clear tasks, projects, and roles including detailed project descriptions - for international volunteers (3.2\%), improving communications with volunteers before arrival (2.4\%), seeking greater continuity of international volunteers, including fewer gaps between them (2.4\%), developing and communicating clear policies, guidelines, and expectations for and to volunteers (including trainings and orientations) $(2.0 \%)$, having an overall more structured/supported international volunteer program $(2.0 \%)$, receiving even more international volunteers $(2.0 \%)$, dedicating more time and/or staff to managing international volunteers and the volunteer program (1.6\%), and having better access to 
training and volunteer management resources for hosting international volunteers,

perhaps including - as was suggested by one respondent - joint or shared training

sessions $(1.2 \%)$.

Survey respondent \#1505421 explained:

I feel that more time needs to be taken with selecting appropriate volunteers and ensuring that their skills can be translated. More in depth communication should be performed between volunteer manager and prospective volunteers prior to recruitment, and specific tasks should be allocated to those volunteers who are staying for a short period of time. Communication needs to be enhanced between local staff and volunteers, and local staff feel [sic] empowered to discuss issues and problems with volunteers. Volunteers should be made to understand from the beginning that they are required to adapt to local conditions, whilst also working to improve upon current situation [sic].

Survey respondent \#1510109 shared:

There is a specific infrastructure required in the organisation to be able to effectively work with international volunteers. 1) Someone needs to be focussed [sic] upon recruitment of suitable volunteers, effectively managing the expectations of the volunteers pre-arrival. 2) Someone needs to be available full time at the project to take of [sic] and address the needs of the volunteers. 3) Finally, someone needs to provide training/guidance for the volunteer work, so that the volunteers are made to feel useful and appreciate the contribution they are making to the project. These are typically full-time jobs for 3 people, if you have a reasonable turnover of 10-30 volunteers per month. There are many forms of project [sic] that can benefit from the additional hands and income that this number of regular volunteers can generate.

The third category of responses related primarily to financial factors and included the following four suggestions: 1) International volunteers secure or raise funds for all or part of their expenses abroad $(3.6 \%) ; 2$ ) International volunteers assist with local, national, and international fundraising efforts $(1.6 \%) ; 3)$ Host organizations receive financial support for hosting volunteers (grants, donations, fees, etc.) (1.6\%); and 4) Host organizations receive more support from governments in host and/or volunteer home countries (1.6\%). As survey respondent \#1391221 explained, one thing that would help 
host organizations benefit more from international volunteers is "financial grants to enable us to properly care for our international volunteers - they pay for their own visas and flights, the placements pay for board and lodging and weekly allowances but we have problems locating funding to provide the essential care and mentoring."

\section{Host Organization Characteristics and Opinions by Geography}

While responses overall were received from individuals and organizations in seven different global regions, two regions in particular - Africa and Asia - were particularly well represented. With access to data from these two good-sized yet culturally, politically, and economically diverse - both internally and comparatively geographic subsamples, an opportunity arose to see if any potential geographical differences in characteristics or perspectives might exist. After isolating responses from host organizations in these two regions, characteristics and opinions were then compared between these two groups and with the overall sample. This section of the chapter highlights those areas where responses from individuals in Africa and Asia differed significantly either from each other and/or from the overall sample.

\section{Host organization characteristics.}

As the two largest groups within the overall sample, responses from individuals and organizations in Africa and Asia often mirrored those of the total dataset. However, there were several areas where potentially significant differences emerged.

One, for example, was the characteristic of faith affiliation. Compared to the overall sample, where only $14.5 \%$ reported a faith affiliation, $25.0 \%$ of respondents in Africa reported the same. Indeed, of the 35 respondents indicating a faith affiliation, 21 of them $-60 \%$ of the total - were located in Africa. 
Another area of contrast was the age of the international volunteer program, where a greater proportion $-61.6 \%$ as opposed to $50.4 \%$ in the overall sample - of African organizations and a smaller proportion $-42.0 \%$ - of Asian organizations reported beginning to host international volunteers within the past five years. Similarly, while $78.3 \%$ of the overall sample began hosting international volunteers within the past decade, this figure was higher for African organizations (84.8\%) and lower for Asian organizations (75.3\%).

In terms of volunteer management infrastructure, one difference between organizations in Africa and Asia and the overall sample emerged around having paid staff provide some level of supervision or management: in nearly every category involving paid staff, organizations in Africa and Asia reported lower percentages of adoption. For example, the percentage of respondents reporting one staff volunteer coordinator was $16.0 \%$ for the overall sample, yet just $13.6 \%$ for respondents in Asia and $10.2 \%$ for respondents in Africa. Conversely, respondents in Asia reported higher percentages of volunteers managing other volunteers ( $16.9 \%$ vs. $10.8 \%$ of the overall sample) and international volunteers managing themselves ( $10.2 \%$ vs. $6.6 \%$ of the overall sample).

Regarding recruitment methods, a greater proportion of African organizations reported partnering with organizations like universities and a lesser proportion reported recruitment via their own website, Facebook, Idealist.org, other websites, and other social media. Conversely, a greater proportion of Asian organizations reported using Idealist.org, other websites, partner organizations like universities, and word of mouth, while a lesser proportion reported recruiting via their own website, emails, Facebook, and other social media. And while $20 \%$ of the overall sample reported that international 
volunteers found their organization independently, this figure was significantly lower for organizations in Africa, where only $12.7 \%$ reported receiving independent volunteers. Also, respondents in both Africa and Asia reported higher percentages that had international volunteers placed with them by partner volunteer-sending organizations: while only $13.4 \%$ of the overall sample indicated this recruitment method, $18.6 \%$ of African and $14.1 \%$ of Asian organizations reported the same.

Regarding prerequisites for an individual to volunteer with a responding organization, there were again a few areas where African and Asian organizations differed from the overall sample. Specifically, a greater proportion of African and Asian organizations reported requiring a certain level of education $-54.8 \%$ for Africa and $54.7 \%$ for Asia as compared to $46.9 \%$ in the overall sample; at the same time, lower percentages of respondents in both regions reported requirements such as volunteers being a certain age and having local language abilities (this latter characteristic was especially pronounced among Asia respondents, where only $14.1 \%$ required local language skills as compared to $24.3 \%$ of the overall sample).

There were also a few areas where the two regions varied in their responses. For example, while Asian organizations reported a higher proportion of respondents requiring specific skill sets $-57.8 \%$ vs. $51.3 \%$ for the overall sample - a greater proportion of African organizations $-17.2 \%$ vs. $11.9 \%$ in the overall sample - reported having no requirements at all.

While responses to the number of international volunteers hosted by respondents in Africa and Asia were similarly proportioned to the overall sample, they did tend to skew more heavily towards the lower end of the scale; for example, where $56.5 \%$ of the 
overall sample reported hosting fewer than 10 international volunteers in $2010,60.0 \%$ of African organizations and $64.7 \%$ of Asian organizations reported the same. Respondents in Asia and, especially, Africa also reported hosting higher proportions of older international volunteers; for example, higher percentages of African organizations reported engaging international volunteers in the age groups of thirties, forties, fifties, sixties, seventies and older, and all ages, while also reporting lower percentages of volunteers in their twenties and younger. Comparatively, Asian organizations reported a slightly higher percentage of volunteers under the age of twenty $-23.2 \%$ as compared to $17.2 \%$ in the overall sample and $12.1 \%$ among African organizations - as well as slightly higher percentages of volunteers in their thirties and seventies and older, yet lower percentages of volunteers in their twenties, forties, fifties, sixties, and all ages.

Additional differences between respondents in the overall sample, Africa, and Asia emerged when comparing the types of service projects commonly offered to international volunteers (Table 14). For example, while medical care appeared in the top five most frequently mentioned types of service for African organizations (14.3\% cited it), only $1.6 \%$ of Asian organizations listed the same. Similarly, while only $6.1 \%$ of African organizations mentioned marketing/communications tasks, over two-times as many $-14.8 \%$ - of Asian organizations cited this as a common project for international volunteers. And while only $3.6 \%$ of the overall sample and $1.0 \%$ of African organizations mentioned writing and/or editing projects, $8.2 \%$ of Asian organizations cited this type of service role.

Respondents in Africa also reported higher adoption percentages of methods for determining projects for international volunteers such as creating projects based on 
organizational needs $(77.0 \%$ vs. $72.2 \%$ of the overall sample and $60.9 \%$ of organizations in Asia) and based on community feedback or needs ( $77.0 \%$ vs. $59.8 \%$ of the overall sample and $42.0 \%$ of organizations in Asia); conversely, organizations in Asia reported consistently lower adoption percentages of these methods than either organizations in Africa or the overall sample.

Table 14

Percentage of Respondents Citing Common Types of Projects Done by International Volunteers ${ }^{\text {a }}$

Type of Project

Teaching, classroom assistance, tutoring, and/or community education

Construction and/or infrastructure development/improvement (painting, installations, etc.)

Technology tasks (building websites, etc.)

Research, data collection, and reporting

Fundraising and/or grantwriting

Marketing and/or communications

(newsletter, social media, etc.)

Medical care

\begin{tabular}{ccc}
$\begin{array}{c}\text { Overall } \\
\text { Sample }\end{array}$ & Africa & Asia \\
\hline $61.3 \%(1)$ & $68.4 \%(1)$ & $57.4 \%(1)$ \\
& & \\
$17.8 \%(2)$ & $18.4 \%(3)$ & $11.5 \%(5)$
\end{tabular}

$15.6 \%(3) \quad 19.4 \%(2) \quad 16.4 \%(2)$

$12.4 \%(4) \quad 7.1 \% \quad 13.1 \%(4)$

$10.7 \%(5) \quad 13.3 \%(5) \quad 6.6 \%$

$8.9 \% \quad 6.1 \% \quad 14.8 \%(3)$

$7.6 \% \quad 14.3 \%(4) \quad 1.6 \%$

Notes: ${ }^{\mathrm{a}}$ Rank within top five most frequently mentioned types of projects per sample is indicated in parentheses.

Respondents in the overall sample, Africa, and Asia reported nearly equivalent proportions of offering training to their international volunteers and also shared similar response proportions to types of training identified. However, one area where a difference did emerge was in providing materials prior to a volunteer's arrival; while $5.8 \%$ of the overall sample and $6.1 \%$ of respondents in Asia offered this type of training, 
only 2.8\% of respondents in Africa offered the same. However, a slightly higher proportion of respondents in Africa $-49.3 \%$ as compared to $45.9 \%$ of the overall sample and $42.9 \%$ of organizations in Asia - reported providing materials, orientation, and/or training upon a volunteer's arrival.

The final characteristic for comparison was revenue generation. While $48.0 \%$ of the overall sample reported receiving some kind of funding from hosting international volunteers, a higher proportion of African organizations (57.3\%) and lower proportion of Asian organizations (39.6\%) reported the same. Similar proportions also applied to respondents receiving fees from volunteers and/or funding from partner organizations, with $40.4 \%$ of African organizations and $31.7 \%$ of Asian organizations receiving fees (as opposed to $37.1 \%$ of the overall sample) and $16.9 \%$ of African organizations and $7.9 \%$ of Asian organizations receiving funding from partner organizations (as opposed to $10.9 \%$ of the overall sample).

\section{Host organization opinions.}

In terms of motivations, international volunteers contributing needed skills, languages, and perspectives was the most frequently suggested by respondents both within the overall sample and the subsamples of Africa and Asia. However, respondents in Africa and Asia reported higher percentages of agreement with this motivation $54.0 \%$ in Africa and $51.7 \%$ in Asia vs. $43.2 \%$ within the overall sample.

Other differences in motivation were more region-specific. For example, a higher percentage of respondents in Asia cited the motivation of international volunteers being committed and/or effective (10.0\% as compared to $5.2 \%$ in the overall sample and $2.3 \%$ in Africa), while a lower percentage of respondents in Asia cited seeking international 
volunteers to help raise awareness of the organization and/or issue individually and internationally (6.7\% vs. $11.7 \%$ of the overall sample and $17.2 \%$ of respondents in Africa) and to fill gaps and leverage staff capacity ( $13.3 \%$ vs. $25.4 \%$ of the overall sample and $26.4 \%$ of respondents in Africa). Similarly, a higher percentage of respondents in Africa reported seeking international volunteers to raise awareness of the organization and/or issue (17.2\% vs. $11.7 \%$ of the overall sample and $6.7 \%$ of respondents in Asia), to contribute financial resources, assist with fundraising, and/or become donors $(19.5 \%$ vs. $14.6 \%$ of the overall sample and $10.0 \%$ of respondents in Asia), and to train staff and help expand staff capacity ( $16.1 \%$ vs. $10.8 \%$ of the overall sample and $11.7 \%$ of respondents in Asia), while a lower percentage of respondents in Africa reported being motivated to respond to international volunteer requests and/or fill a need for international volunteer opportunities $(3.4 \%$ vs. $8.5 \%$ of the overall sample and 8.3\% of respondents in Asia).

While a majority of respondents in each of the overall, Africa, and Asia samples did agree or strongly agree with most of the potential benefits statements in the survey, respondents in Africa were generally more enthusiastic and respondents in Asia generally less enthusiastic in their agreement. For example, while the statement that international volunteers "contribute needed skills" was strongly agreed with by $53.7 \%$ of the overall sample, "strongly agree" was selected by $73.0 \%$ of respondents in Africa and $47.2 \%$ in Asia. However, when these responses were combined with the answer option "agree," these differences between samples were largely muted.

When asked to indicate agreement with the idea that international volunteers "bring international attention to our work," the percentage of respondents agreeing or 
strongly agreeing was $90.7 \%$ in the Africa sample, $79.2 \%$ in the overall sample, and $67.2 \%$ in the Asia sample. Indeed, for nearly all of the benefits statements in the survey including those related to potential financial benefits of hosting international volunteers the pattern of agreement was either that all three samples agreed/strongly agreed at roughly the same rate (albeit almost always with more Africa respondents selecting "strongly agree" and more Asia respondents selecting "agree") or the agreed/strongly agreed rate was higher for respondents in Africa and lower for respondents in Asia, with responses from the overall sample falling somewhere in between.

In terms of most important benefits, the most frequently suggested was that international volunteers "contribute needed skills, languages, ideas, energy, and perspectives"; this was suggested by $55.2 \%$ of the overall sample, $53.6 \%$ of respondents in Africa, and $70.3 \%$ of respondents in Asia. The rest of the top five cited by these three samples included international volunteers providing opportunities for cross-cultural connections, learning, and understanding for international volunteers and the community; contributing financial resources, assisting with fundraising, and/or becoming donors; helping to raise awareness of the organization and/or issue individually and internationally; training staff and helping to expand staff capacity; and becoming advocates upon return home.

A few additional patterns emerged between the overall sample and respondents in Africa and Asia. First, there were a handful of most important benefits that were suggested in roughly equal proportion by respondents in Asia and the overall sample but in significantly different percentages by respondents in Africa; for example, almost twice as many respondents in Africa suggested the most important benefit that international 
volunteers "open doors and/or improve relations with other organizations." Also, only $1.2 \%$ of respondents in Africa suggested that international volunteers "can be beneficial, inspiring, and/or serve as role models for the organization and community" (as compared to $7.1 \%$ of the overall sample and $7.8 \%$ of respondents in Asia). Similarly, more respondents in Asia than Africa and the overall sample suggested that some of the most important benefits are where international volunteers "contribute needed skills, languages, ideas, energy, and perspectives," and "can train staff and help to expand staff capacity," while only one-third as many respondents in Asia suggested that international volunteers "provide more people to get our work done."

A third pattern mirrored one identified in the potential benefits question, specifically where higher percentages of respondents in Africa suggested an important benefit than respondents in Asia, with the response rate from the overall sample again falling in between; this occurred with the following suggested most important benefits: international volunteers "help to raise awareness of organization and/or issue individually and internationally" (over twice the percentage of Africa respondents suggested this as being a most important benefit than Asia respondents), "bring credibility and respect to our work" (only $1.6 \%$ of respondents in Asia suggested this as compared to $5.2 \%$ of the overall sample and $9.5 \%$ of respondents in Africa), "are committed and effective" (again the percentage of respondents in the overall and Africa samples were twice and almost three times, respectively, as high as the percentage among respondents in Asia), "contribute financial resources, assist with fundraising, and/or become donors" $(32.1 \%$ of respondents in Africa reported this benefit, as compared to $24.3 \%$ of the overall sample and $10.9 \%$ of respondents in Asia), "become advocates upon return home" $(15.7 \%$ of the 
overall sample suggested this, with $21.4 \%$ of respondents in Africa and $9.4 \%$ of respondents in Asia suggesting the same), and "are inexpensive" (5.2\% of the overall sample suggested this, with twice the percentage of respondents in Africa and no respondents at all in Asia reporting the same).

For all but one of the suggested challenges of hosting international volunteers, respondents in Africa reported lower levels of agreement and/or higher levels of disagreement than respondents in Asia and the overall sample. For example, when asked to offer their level of agreement with the statement that international volunteers "require a lot of training," $34.0 \%$ agreed or strongly agreed, as compared to $42.9 \%$ of the overall sample and $47.1 \%$ of respondents in Asia; at the same time, $31.8 \%$ of the overall sample and $34.3 \%$ of respondents in Asia disagreed or strongly disagreed with this statement while $38.0 \%$ of Africa respondents reported the same. However, for several of the statements where a majority of respondents did agree or strongly agree with the challenge listed, respondents in Africa reported stronger and higher levels of agreement. For example, asked whether international volunteers "can be difficult to find," $71.5 \%$ of respondents in Africa agreed or strongly agreed as compared to $57.2 \%$ of the overall sample and $49.3 \%$ of respondents in Asia.

Respondents in Asia reported higher percentages of agreement and/or lower percentages of disagreement than the overall sample and respondents in Africa for eight of the 13 statements; for example, $47.2 \%$ of respondents in Asia agreed or strongly agreed that international volunteers "require a lot of training," as compared to $42.9 \%$ of the overall sample and $34.0 \%$ of respondents in Africa. Similarly, $11.5 \%$ of respondents in Asia agreed or strongly agreed that international volunteers "are not effective" (as 
compared to $6.3 \%$ of the overall sample and $4.1 \%$ of respondents in Africa) while $68.1 \%$ of respondents in Asia disagreed or strongly disagreed $(74.3 \%$ of the overall sample and $77.1 \%$ of respondents in Africa) with the same statement. Similar to respondents in Africa, for those statements that were agreed or strongly agreed with by $50 \%$ or more individuals, respondents in Asia reported lower levels of agreement and higher levels of disagreement. One example is international volunteers "can be difficult to find"; this statement was agreed or strongly agreed with by $71.5 \%$ of respondents in Africa, $57.2 \%$ of the overall sample and $49.3 \%$ of respondents in Asia while the corresponding levels of disagreement with the statement were $26.7 \%$ among respondents in Asia, $23.6 \%$ in the overall sample, and $13.2 \%$ among respondents in Africa.

Compared to the most frequently mentioned most important benefits, the most frequently mentioned most important challenges were decidedly more diverse. In fact, only three of the most important challenges cited by respondents were in the top five most frequently mentioned for all three samples: international volunteers having difficulty accepting, adjusting, and/or adhering to local cultural /professional norms; international volunteers having unrealistic expectations about what they can or should accomplish and/or how things should be done; and international volunteers being unmotivated and/or unreliable. The rest of those mentioned in the top five were unique to one or two of the sample groups. For example, international volunteers not having language abilities needed was in the top five most frequently mentioned most important challenges for respondents in the overall sample and Africa, but not Asia. Most important challenges that were among the top five most frequently mentioned only by respondents in Africa included international volunteers having difficulty with local 
accommodations, food, transportation, climate, etc.; international volunteers being difficult to find; and international volunteers being expensive. Two most important challenges were in the top five most frequently mentioned by respondents in Asia but not the overall sample or Africa: international volunteers requiring precautions for health and physical safety and security and international volunteers being difficult to assess, vet, and/or match from afar. Finally, international volunteers requiring a lot of supervision and assistance was among the top five most frequently mentioned most important challenges in the overall sample but was not among the top five most frequently mentioned for respondents in either Africa or Asia.

On a statement by statement basis, there were several instances where a greater percentage of respondents in Asia than respondents in Africa and the overall sample suggested a challenge as being the most important; for example, almost twice as high a percentage of respondents in Asia than respondents in Africa suggested that international volunteers "may not have the language abilities needed" (20.0\% vs. $11.4 \%$, with $15.5 \%$ of the overall sample suggesting the same). Similarly, $30.0 \%$ of respondents in Asia suggested that one of the most important challenges was that international volunteers "can have unrealistic expectations about what they can or should accomplish and/or how things should be done," as compared to $21.4 \%$ of the overall sample and $19.0 \%$ of respondents in Africa. And while the actual percentage was low for all three samples, it was interesting to learn that $8.0 \%$ of respondents in Asia felt that one of the most important challenges was the difficulty of assessing, vetting, and/or matching international volunteers from afar, especially given that only $4.8 \%$ of the overall sample and none of the respondents in Africa suggested the same. 
Lastly, there were five most important challenges suggested by a greater percentage of respondents in Africa than the other two samples: international volunteers "can be difficult to find," "can require accommodations, transportation, meals, etc. that are difficult to find or very different from local standards," "can be unmotivated and/or unreliable," "can be expensive," and "can have difficulty with local accommodations, food, transportation, climate, etc.” On this latter statement, respondents in Africa reported this in much higher numbers than the other two samples, with $17.7 \%$ citing this as a most important challenge as compared to only $10.7 \%$ of the overall sample and $4.0 \%$ of respondents in Asia.

Responses to the two questions exploring satisfaction with international volunteers - "In your opinion, based on your answers above, do the benefits of hosting international volunteers outweigh the challenges?" and "Overall, do you think that it is worthwhile for your organization to host international volunteers?" - were next explored and found to be largely consistent with the other benefits and challenges statements reviewed above: while all three samples reported overwhelmingly that international volunteers provided more benefits than challenges, the percentages that selected this answer option was higher for respondents in Africa (96.0\%) and lower for respondents in Asia (91.3\%) than the overall sample (94.2\%). Similarly, where $88.0 \%$ of the overall sample chose the answer option "yes" in answer to "Overall, do you think that it is worthwhile for your organization to host international volunteers?" - and a combined $98.0 \%$ chose "yes" or "yes, but/if..." - an even higher percentage of respondents in Africa chose yes (96.5\%), with 100\% choosing "yes" or "yes, but/if..." while a lower 
percentage of respondents in Asia chose yes (84.5\%), with $96.6 \%$ choosing "yes" or "yes, but if..."

The final collection of answers to compare between these two regions and the overall sample was how host organizations might benefit more from hosting international volunteers. While this question was answered by relatively few respondents (including only 32 individuals in Africa and 20 individuals in Asia) and is therefore nowhere near representative of the sample, there were two suggestions that demonstrated additional potential differences between the two regions. Specifically, the suggestions that host organizations "develop more stringent application/screening processes to improve matches with volunteers" and "develop and communicate clear policies, guidelines, and expectations for and to volunteers (including trainings and orientations)" were offered by $35.0 \%$ and $20.0 \%$ of the respondents in Asia who answered this question, yet were suggested by no respondents in Africa.

\section{Host Organization Characteristics and Opinions by Recruitment Type}

As was discussed in Chapter 3, one concern related to self-selection bias was that, given that it was expected that many respondents would receive the survey via Idealist.org - meaning that those respondents represented organizations that either actively recruited international volunteers or, at a minimum, made the decision to create an English-language profile on an international website - survey responses may have then been skewed by those who actively sought international volunteers as compared to those who received them through less pro-active methods. Indeed, when survey respondents were asked whether they actively recruited international volunteers, nearly half responded that they did. To test whether this group of nearly half of all respondents 
may have skewed overall survey results, the data was separated and statistics run again, both for those organizations that responded that they do actively recruit international volunteers as well as for those that indicated that they did not actively recruit international volunteers.

What was discovered was that, while skewing did appear to have taken place in many cases, it occurred in both directions. For example, a comparison of all survey data variables found that 69 were skewed at least in part by those respondents that do actively recruit international volunteers, 68 were skewed at least in part by those respondents that do not actively recruit international volunteers, and 50 variables were relatively even between the two groups. However, a further look at the data to identify those instances where the difference between the overall sample and one or both of the two subgroups was at least $5 \%$ demonstrated that these examples of skewing appeared to be minor in the vast majority of cases.

Specifically, for only seven of over 185 variables did the subgroups of respondents that actively or do not actively recruit international volunteers report a value or percentage that was $5.0 \%$ more or less than the overall sample (Table 15). In addition, a few variables demonstrated differences of at least $+/-5.0 \%$ between those that actively recruit international volunteers and those that do not actively recruit international volunteers, but were still within $+/-5.0 \%$ of the overall sample's response to the same question. For example, the most important benefit of hosting international volunteers “International volunteers... contribute needed skills, languages, ideas, energy, and perspectives" was cited by $55.2 \%$ of the overall sample; it was also cited by a slightly 
Table 15

Variables Where Difference Between Overall Sample and Specific Recruitment Type Responses was $+/-5.0 \%$ a

Variable

\begin{tabular}{ccc}
$\begin{array}{c}\text { Overall } \\
\text { Sample }\end{array}$ & $\begin{array}{c}\text { Respondents } \\
\text { That Do } \\
\text { Actively } \\
\text { Recruit }\end{array}$ & $\begin{array}{c}\text { Respondents } \\
\text { That Do Not } \\
\text { Actively } \\
\text { Recruit }\end{array}$ \\
\hline $10.8 \%$ & $\mathbf{1 6 . 8 \%}$ & $5.9 \%$
\end{tabular}

Motivation to Host International Volunteers:

"International volunteers can train staff and

help to expand staff capacity"

Most Important Benefit of Hosting

International Volunteers: "International

volunteers...provide other benefits"

Most Important Challenge of Hosting

International Volunteers: "International

volunteers...can have difficulty with local

accommodations, food, transportation,

climate, etc."

International Service Requirements:

"International volunteers must... be able to

$\begin{array}{lll}14.5 \% & \mathbf{7 . 7 \%} & 19.4 \%\end{array}$

stay for a certain period of time"

International Service Requirements:

$6.2 \%$

$1.0 \%$

$10.8 \%$

"International volunteers must... have

awareness of and/or commitment to issue"

International Service Requirements:

"International volunteers must... provide

$10.7 \%$

$17.5 \%$

$5.6 \%$

references or be recommended"

Type of International Service Project:

"Technology tasks (building website, etc.)"

$12.9 \%$

$19.2 \%$

$8.3 \%$

Notes: ${ }^{\text {a }}$ Response percentages that are $+/-5 \%$ from the overall sample are in bold.

higher percentage $-60.6 \%$ - of those who actively recruit international volunteers as compared to a slightly lower percentage $-50.5 \%$ - of those who do not actively recruit international volunteers. Conversely, the motivation to host international volunteers "Volunteers needed to fill gaps and leverage staff capacity" was cited by $25.4 \%$ of the 
overall sample, as well as by a slightly higher percentage of those who do not actively recruit international volunteers $-28.8 \%$ - and a slightly lower percentage of those who do actively recruit international volunteers $-21.1 \%$.

There was also some mixed skewing within those survey questions that housed more than one answer option; for example, when asked to share how much they agreed or disagreed with a particular benefit statement, respondents were offered six answer options: "strongly agree," “agree," "neutral," "disagree," "strongly disagree," and "not sure." In some cases, more or less than $5.0 \%$ of respondents in one of the two subgroups of recruitment types might have chosen one or two of the answer options while, for the remaining answer options in the question, the difference was less than 5.0\%. An example of this can be seen with the benefit statement "International volunteers...contribute needed skills." The percentage of respondents who chose the answer options "not sure," "strongly disagree," "disagree," and "neutral" were equal or relatively similar. However, larger differences emerged when looking at the percentage of respondents who selected the answer options "agree" and "strongly agree." Specifically, while $37.7 \%$ of the overall sample chose "agree" for this statement, $32.7 \%$ of those who do actively recruit and $42.0 \%$ of those who do not actively recruit chose the same. Similarly, where $53.7 \%$ of the overall sample chose the answer option "strongly agree," a higher percentage of those who do actively recruit $-62.8 \%$ - and a lower percentage of those who do not actively recruit $-45.8 \%$ - selected the same answer.

Overall though, answers reported by those who actively recruit international volunteers, those who do not actively recruit international volunteers, and the overall sample were largely similar. Two examples of this are the variables used in this study to 
represent satisfaction with international volunteers: comparing benefits to challenges and whether international volunteers were considered to be worthwhile. In response to the question "In your opinion, based on your answers above, do the benefits of hosting international volunteers outweigh the challenges?", $94.2 \%$ of the overall sample chose the answer option "Yes, I think international volunteers generally provide more benefits than challenges for our organization"; this answer was also chosen by $94.5 \%$ of those who actively recruit international volunteers and $93.9 \%$ of those who do not actively recruit international volunteers. Similarly, while $99.0 \%$ of the overall sample chose the answer options "Yes" or "Yes, but/if..." in response to the question "Overall, do you think that it is worthwhile for your organization to host international volunteers?", $100 \%$ of those who do actively recruit and $98.3 \%$ of those who do not actively recruit selected the same.

\section{Statistically Significant Relationships}

Given the exploratory nature of this study and the general lack of existing information on the target audience, the primary goal of this study was to gather data on host organization characteristics and opinions. However, this study also offered an opportunity to apply initial statistical analysis to the data in order to identify if and what existing relationships might also exist between these factors. This section of the dissertation shares the results of this quantitative analysis.

As was discussed in the section on Research Methodology, because survey data was identified as categorical and non-parametrical in nature, the most appropriate test for exploring potential significant relationships was determined to be Pearson's chi-square. While chi-square does not allow identification of a causal nature nor direction of 
relationships, it does offer a baseline - again, something that is missing from current research on the field of international service, especially host organizations - of potential significant relationships between host organization characteristics and reported opinions on the benefits and challenges of hosting international volunteers.

Tests were conducted to identify significant relationships among study variables using three methods. First, answers to questions regarding host organization characteristics and opinions were tested with respondent answers to the question of whether the benefits of hosting international volunteers outweighed the challenges. Second, answers to questions regarding host organization characteristics and opinions were tested with respondent answers to the question of whether it was worthwhile to host international volunteers. Third, the twelve hypothesized relationships between volunteer program characteristics and satisfaction with engaging international volunteers that I'd developed were explored. For all three types of analysis, tests were run of both the overall sample as well as the three areas of focus typologies that were affiliated with at least twenty or more respondents each: Community Development, Education, and Environment.

\section{Comparing benefits to challenges.}

Did relationships exist between 1) whether a respondent believed the benefits of hosting international volunteers to outweigh the challenges and 2) characteristics of their organization/international volunteer program? What about with perceived benefits and challenges? To explore answers to these questions, respondent answers to "In your opinion, based on your answers above, do the benefits outweigh the challenges?" were 
used as the dependent variable and reported host organization characteristics and opinions were used as the independent variables.

In total, 22 significant relationships were identified in this area of inquiry (Table 16); eight of these relationships were related to host organization characteristics - for example, area of focus, age of international volunteers, revenue generation, etc. - and 14 were related to perceived benefits and challenges.

Table 16

\section{Statistically Significant Relationships (Dependent Variable: Benefits Outweighing Challenges)}

Independent Variable

Benefits of Hosting International Volunteers: "International volunteers...become advocates upon return home"

Challenges of Hosting International Volunteers: "International volunteers...require a lot of supervision"

Challenges of Hosting International Volunteers: "International volunteers...require a lot of training"

Most Important Benefits of Hosting International Volunteers: "International volunteers...can make the volunteer program more sustainable by staying for longer periods of time and/or volunteering more hours per day"

Most Important Benefits of Hosting International Volunteers: "International volunteers... do not provide benefits (benefits are primarily to the volunteers themselves)"

Most Important Challenges of Hosting International Volunteers: "International volunteers...can require resources or tools that are unavailable or too expensive"

Type of International Service Project: "Senior care"

Age of International Volunteers: "70s"

International Service Requirements: "Yes, in most cases, international volunteers must... be qualified in some other way (please specify below)" $.000^{\mathrm{b}}$

$.000^{\mathrm{b}}$

Significance at $<.05$

$$
.000^{\mathrm{b}}
$$

$.000^{\mathrm{b}}$

$.000^{\mathrm{b}}$

$.000^{\mathrm{a}, \mathrm{b}}$

$.000^{\mathrm{a}, \mathrm{b}}$

$.007^{\mathrm{a}, \mathrm{b}}$

$.007^{\mathrm{a}, \mathrm{b}}$ 
Benefits of Hosting International Volunteers: "International

Benefits of Hosting International Volunteers: "International

Volunteers: "International volunteers...can be unmotivated and/or unreliable"

Area of Focus

Challenges of Hosting International Volunteers: "International

Benefits of Hosting International Volunteers: "International

"International volunteers...open doors and/or improve relations with other organizations"

Best Recruitment Methods: "Emails"

Revenue Generation: "No, we do not receive any money from

Most Important Benefits of Hosting International Volunteers:

"International volunteers...help to raise awareness of organization and/or issue individually and internationally"

Most Important Challenges of Hosting International Volunteers: "International volunteers...can be or feel underutilized, sometimes leading to frustration"

Notes: ${ }^{\text {a }}$ This relationship was also significant at $<.05$ according to Fisher's Exact Test (actual test value may vary). ${ }^{\mathrm{b}}$ More than $20 \%$ of cells in this test had an expected cell count of less than five.

When comparing these dependent and independent variables within the three area of focus typologies, additional significant relationships were discovered. Specifically, 22 relationships were identified among Community Development respondents and 15 relationships among Education respondents (Tables 17 and 18); no statistics were 
available for Environment respondents as the dependent variable in this data set was a

constant.

Table 17

Statistically Significant Relationships for Community Development Organizations (Dependent Variable: Benefits Outweighing Challenges)

Independent Variable

Benefits of Hosting International Volunteers: "International volunteers...are inexpensive"

Benefits of Hosting International Volunteers: "International volunteers...become advocates upon return home"

Benefits of Hosting International Volunteers: "International volunteers...become financial donors"

Benefits of Hosting International Volunteers: "International volunteers...bring credibility to our work"

Benefits of Hosting International Volunteers: "International volunteers...bring international attention to our work"

Benefits of Hosting International Volunteers: "International volunteers...generate revenue for our organization"

Best Recruitment Methods: "Other Websites"

Challenges of Hosting International Volunteers: "International volunteers...can be difficult to find"

Challenges of Hosting International Volunteers: "International volunteers...can be expensive"

Country

Most Important Challenges of Hosting International Volunteers: "International Volunteers...can be untrustworthy"

Type of International Service Project: "Cooking and/or food preparation"

Type of International Service Project: "Senior Care"

Most Important Benefits of Hosting International Volunteers: "International volunteers... open doors and/or improve relations

\begin{tabular}{c}
$\begin{array}{c}\text { Significance } \\
\text { at }<.05\end{array}$ \\
\hline $.000^{\mathrm{b}}$ \\
$.000^{\mathrm{b}}$ \\
$.000^{\mathrm{b}}$ \\
$.000^{\mathrm{b}}$ \\
$.000^{\mathrm{b}}$ \\
$.000^{\mathrm{b}}$ \\
$.000^{\mathrm{b}}$ \\
$.000^{\mathrm{b}}$ \\
$.000^{\mathrm{a}, \mathrm{b}}$ \\
$.002^{\mathrm{b}}$ \\
$.000^{\mathrm{a}, \mathrm{b}}$ \\
\end{tabular}


with other organizations"

Training Type: "Training available as needed after arrival" $\quad .005^{\mathrm{b}}$

Most Important Challenges of Hosting International Volunteers: $\quad .006^{\mathrm{b}}$

"International volunteers...can be unmotivated and/or unreliable"

Volunteer Management: "More than one non-volunteer $\quad .006^{\mathrm{b}}$

coordinator staff person responsible"

Benefits of Hosting International Volunteers: "International $\quad .013^{\mathrm{b}}$

volunteers... provide an opportunity for local people to learn more

about other nations and cultures"

Challenges of Hosting International Volunteers: "International $\quad .021^{\mathrm{b}}$

volunteers... may not have the skills needed"

Most Important Benefits of Hosting International Volunteers: $\quad .021^{\mathrm{b}}$

"International volunteers... provide more people to get our work done"

Challenges of Hosting International Volunteers: "International $\quad .034^{\mathrm{b}}$ volunteers...distract staff and local volunteers from the work"

Faith Affiliation $\quad .039^{\mathrm{b}}$

Notes: ${ }^{\mathrm{a}}$ This relationship was also significant according to Fisher's Exact Test. ${ }^{\mathrm{b}}$ More than $20 \%$ of cells in this test had an expected cell count of less than five.

Table 18

Statistically Significant Relationships for Education Organizations (Dependent Variable: Benefits Outweighing Challenges)

Independent Variable

Benefits of Hosting International Volunteers: "International volunteers...become advocates upon return home"

Most Important Challenges of Hosting International Volunteers: "International volunteers...can require resources or tools that are unavailable or too expensive"

Most Important Benefits of Hosting International Volunteers: "International volunteers...open doors and/or improve relations with other organizations"

Best Recruitment Methods: "Emails"
Significance

$\frac{\text { at }<.05}{.000^{\mathrm{b}}}$

$.000^{\mathrm{b}}$

$.001^{\mathrm{b}}$

$.004^{\mathrm{b}}$ 
Faith Affiliation

$.004^{\mathrm{a}, \mathrm{b}}$

International Service Requirements: "International volunteers

$.005^{\mathrm{b}}$

must...be qualified in some other way (please specify below)"

Most Important Challenges of Hosting International Volunteers: $\quad .006^{\mathrm{b}}$

"International volunteers...can be difficult to find"

Age of International Volunteers: "20s" $\quad .009^{\mathrm{a}, \mathrm{b}}$

Challenges of Hosting International Volunteers: "International $\quad .021^{\mathrm{b}}$

volunteers...require a lot of training"

Age of International Volunteers: "60s" $\quad .033^{\mathrm{b}}$

Motivation to Host International Volunteers: "Other reasons" $.033^{\text {b }}$

Most Important Benefits of Hosting International Volunteers: $\quad .036^{\mathrm{b}}$

"International volunteers... are inexpensive"

Challenges of Hosting International Volunteers: "International $\quad .038^{\mathrm{a}, \mathrm{b}}$

volunteers...are not always welcome in our community"

Age of International Volunteers: "70s and older" $\quad .039^{\text {b }}$

Revenue Generation: "No, we do not receive any money from $\quad .049^{\text {b }}$ hosting international volunteers"

Notes: ${ }^{\mathrm{a}}$ This relationship was also significant according to Fisher's Exact Test. ${ }^{\mathrm{b}}$ More than $20 \%$ of cells in this test had an expected cell count of less than five.

\section{Is hosting international volunteers worthwhile?}

To explore whether any relationships existed between host organization characteristics/opinions and whether a respondent believed hosting international volunteers to be worthwhile, the question "Overall, do you think that it is worthwhile for your organization to host international volunteers?" was used as the dependent variable and respondent organization characteristics and opinions were used as the independent variables.

Here 20 significant relationships were identified, the majority of which with motivations and perceived benefits and challenges (Table 19). The five significant 
relationships with host organization characteristics were with specific types and models of volunteer management, service project types, training methods offered, and the age of international volunteers engaged.

Table 19

Statistically Significant Relationships (Dependent Variable: Whether Hosting International Volunteers is Worthwhile)

Independent Variable

Benefits of Hosting International Volunteers: "International volunteers... are inexpensive"

Benefits of Hosting International Volunteers: "International volunteers...generate revenue for our organization"

Benefits of Hosting International Volunteers: "International volunteers...provide a new viewpoint or perspective"

Challenges of Hosting International Volunteers: "International volunteers...are expensive"

Challenges of Hosting International Volunteers: "International volunteers...are not always welcome in our community"

Challenges of Hosting International Volunteers: "International volunteers...can be difficult to find"

Most Important Benefits of Hosting International Volunteers: "International volunteers...help to make our programs more interesting to the population served"

Motivation to Host International Volunteers: "International volunteers can make the program more sustainable"

Challenges of Hosting International Volunteers: "International volunteers...are not effective"

Benefits of Hosting International Volunteers: "International volunteers...become financial donors"

Challenges of Hosting International Volunteers: "International volunteers...take the place of local jobs"

Challenges of Hosting International Volunteers: "International volunteers...take the place of local volunteers"
Significance at $<.05$

$.000^{\mathrm{b}}$

$.000^{\mathrm{b}}$

$.000^{\mathrm{b}}$

$.000^{\mathrm{b}}$

$.000^{\mathrm{b}}$

$.000^{\mathrm{b}}$

$.000^{\mathrm{b}}$

$.000^{\mathrm{b}}$

$.001^{\mathrm{b}}$

$.002^{\mathrm{b}}$

$.004^{\mathrm{b}}$

$.005^{\mathrm{b}}$ 
Type of International Service Project: "Childcare and/or $\quad .006^{\mathrm{b}}$ playing with kids"

Volunteer Management: “One non-volunteer coordinator staff $\quad .009^{\mathrm{b}}$ person responsible"

Motivation to Host International Volunteers: "Volunteers $\quad .017^{\mathrm{b}}$

needed to fill gaps and leverage staff capacity"

Most Important Challenges of Hosting International

$.026^{\mathrm{b}}$

Volunteers: "International volunteers...can require

precautions for health and physical safety and security"

Challenges of Hosting International Volunteers: "International

$.028^{\mathrm{b}}$

volunteers...distract staff and local volunteers from the work"

Training Type: "Materials provided before they arrive" $\quad .029^{\mathrm{b}}$

Age of International Volunteers: "70s and older" $.040^{\mathrm{b}}$

Type of International Service Project: "Leading or managing $\quad .047^{\mathrm{b}}$ organizational projects and programs"

Notes: ${ }^{a}$ This relationship was also significant at $<.05$ according to Fisher's Exact Test (actual test value may vary). ${ }^{\mathrm{b}}$ More than $20 \%$ of cells in this test had an expected cell count of less than five.

While no significant relationships were discovered among Community

Development respondents (this was due to all respondents in this group responding that it was generally worthwhile to engage international volunteers, thus making the dependent variable a constant), several relationships were identified among the subsamples of Education and Environment respondents (Tables 20 and 21). Specifically, there were eight significant relationships among Education respondents and ten significant relationships among Environment respondents; for both groups, approximately half of these significant relationships were related to motivations, benefits, and challenges and the other half to host organization characteristics. 
Table 20

Statistically Significant Relationships for Education Organizations (Dependent Variable: Whether Hosting International Volunteers is Worthwhile)

Independent Variable

Significance

Benefits of Hosting International Volunteers: "International at $<.05$ volunteers...provide a new viewpoint or perspective" $.000^{\mathrm{b}}$

Most Important Benefits of Hosting International Volunteers:

$.000^{\mathrm{b}}$ "International volunteers...help to make our programs more interesting to the population served"

Benefits of Hosting International Volunteers: "International $.001^{\mathrm{b}}$ volunteers...bring international attention to our work"

Age of International Volunteers: "70s and older" $\quad .004^{\mathrm{b}}$

Type of International Service Project: "Childcare and/or playing with $\quad .005^{\mathrm{b}}$ kids"

Training Type: "Other or unspecified type of training and/or orientation $\quad .008^{\mathrm{b}}$ provided or offered after arrival"

Type of International Service Project: "Leading or managing $\quad .010^{\mathrm{b}}$ organizational projects and programs"

Benefits of Hosting International Volunteers: "International $\quad .013^{\text {b }}$ volunteers...help our economy by spending money locally"

Notes: ${ }^{a}$ This relationship was also significant according to Fisher's Exact Test. ${ }^{\mathrm{b}}$ More than $20 \%$ of cells in this test had an expected cell count of less than five.

\section{Table 21}

Statistically Significant Relationships for Environment Organizations (Dependent Variable: Whether Hosting International Volunteers is Worthwhile)

Independent Variable

Most Important Challenges of Hosting International Volunteers: "International volunteers...can be unmotivated and/or unreliable"

Most Important Challenges of Hosting International Volunteers: "International volunteers...can require precautions for health and physical safety and security"
Significance

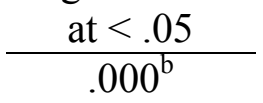

$.000^{\mathrm{b}}$ 
Training Type: "Materials provided before they arrive" $\quad .000^{\mathrm{b}}$

Most Important Benefits of Hosting International Volunteers: $.005^{\mathrm{b}}$

"International volunteers...provide more people to get our work done"

Age of International Volunteers: "20s" $\quad .009^{\mathrm{b}}$

Motivation to Host International Volunteers: "International volunteers $\quad .009^{\mathrm{b}}$

can make the program more sustainable"

Volunteer Management: "One non-volunteer coordinator staff person $\quad .025^{\mathrm{b}}$

responsible"

Challenges of Hosting International Volunteers: "International $\quad .030^{\mathrm{b}}$

volunteers...don't stay long enough"

Benefits of Hosting International Volunteers: "International $\quad .034^{\text {b }}$

volunteers...provide a new viewpoint or perspective"

Age of International Volunteer Program $\quad .041^{\mathrm{b}}$

Notes: ${ }^{a}$ This relationship was also significant according to Fisher's Exact Test. ${ }^{\mathrm{b}}$ More than $20 \%$ of cells in this test had an expected cell count of less than five.

\section{Testing hypotheses.}

The next step in the analysis process was to test the relationship hypotheses I'd created in order to help answer guiding research questions (see Table 1). For each of these tests, respondent answers to survey questions \#4 - comparing benefits to challenges - and \#5 - whether hosting international volunteers is worthwhile - were used as the dependent variables.

\section{Determining fit.}

The first hypothesis concerned the process for determining the fit of an international volunteer within a host organization. Sherraden, Lough, and McBride (2008) cited the matching process - determining the fit of a volunteer for an organization based on both individual and organizational goals and objectives - as potentially being "a key to predicting outcomes" (p. 399). Similarly, McBride, Sherraden, and Lough (2007) 
raised concerns that, where there was not attention paid to appropriately matching international volunteers, the result could be volunteers being placed in unsatisfying roles and projects and host organizations and communities not being most effectively served. Based on these findings, I hypothesized that those host organizations that reported using a matching process for international volunteers would report more positive perceptions of international volunteers.

This hypothesis was tested using as the independent variables those answers relevant to volunteer matching that were received in response to survey question \#14"Do you have any requirements for accepting an international volunteer?" However, no significant relationships were discovered between these variables and comparing benefits to challenges or considering hosting an international volunteer to be worthwhile.

\section{Length of international service.}

While scholars like Laleman et al (2007) have explored the benefits of longerterm service, the hypothesis for whether a relationship existed between positive perceptions of international volunteers and the length of international service was based largely on anecdotal evidence from peers of the author in the fields of domestic and international service. As was explained by many of these colleagues in these fields, one longer-term volunteer often requires less supervision and training than multiple shortterm volunteers doing the same work. Given this, I hypothesized that where an international volunteer stayed longer, therefore assumedly requiring less hands-on support, there might also be more positive perceptions of hosting them.

To test this idea, answers to survey question \#17: "How long do international volunteers serve with your organization?" were used as the independent variable. Again, 
no significant relationships were identified within either the overall sample or the subset samples of Community Development, Education, and Environment respondents.

\section{Number of international volunteers.}

The third hypothesis was designed to explore if a relationship existed between positive perceptions of hosting international volunteers and the number of international volunteers engaged in the past year. However, I was generally unsure what, if any, effect hosting more or fewer international volunteers might have on perceptions of them.

This hypothesis was tested using answers to survey question \#15: "Approximately how many international volunteers did you host in 2010?" as the independent variable. Again though, no significant relationships were identified within either the overall sample or the subsets of Community Development, Education, and Environment respondents.

\section{Age of international volunteers.}

The fourth hypothesis explored potential relationships between perceptions of hosting international volunteers and the age of international volunteers. While older volunteers might offer an organization more relevant skills and experiences than a younger volunteer, a younger volunteer might be more open to new ways of doing things and/or a wider variety of potential tasks. Again though, with no current data to support these theories, I was unsure what results to expect from the data.

This hypothesis was tested using respondent answers to survey question \#16 "How old are most of your international volunteers?" - as the independent variables. In this case, eight significant relationships were identified.

Within the overall survey sample, significant relationships were discovered between comparing benefits to challenges and two age groups of international volunteers: 
international volunteers in their 60's (.011) and in their 70's and older (.007); both of these relationships were also deemed significant via Fisher's Exact Test. There was also a significant relationship between whether hosting international volunteers was worthwhile and hosting international volunteers in their 70's and older (.040).

Among Education respondents, a relationship was discovered between comparing benefits to challenges and hosting international volunteers in their 20's (.009 - this relationship was also significant via Fisher's Exact Test), 60's (.033), and 70's and older (.039); there was also again a significant relationship between whether hosting international volunteers was worthwhile and hosting international volunteers in their 70's and older (.004).

Finally, among Environment respondents, a significant relationship was identified between respondent opinions on whether hosting international volunteers was worthwhile and hosting international volunteers in their 20's (.009).

\section{Partner organizations.}

McBride, Sherraden, and Lough (2007) found that where local organizations partnered with volunteer-sending organizations to determine how volunteers were engaged, more effective programs were developed. Based on this, it is possible that those partnerships where host organizations had a significant voice in planning and implementation might result in more positive perceptions of international volunteers. At the same time, those host organizations that had no little to no voice in whether and/or how to engage international volunteers might harbor more negative overall perceptions.

To test these ideas, independent variables drawn from the answer options for four survey questions were used: $\# 1$ "Why did your organization decide to host international 
volunteers?" (the relevant answer option was "International volunteers were provided by [a] partner organization"), \#11 "How are international volunteers managed at your organization?" (“Partner organization [is] responsible”), \#12 “How does your organization get most of your international volunteers?" (all answer options), \#13 "If your organization does actively seek out international volunteers, which recruitment methods have been the most successful?" ("Partner organizations (including universities)"), \#19 “How does your organization generally determine projects for international volunteers?” (“Projects for international volunteers... are suggested or proposed by our partner organizations"), \#20 "Does your organization offer training to international volunteers?" ("Partner organization [is] responsible for training and/or orientation"), and \#21 "Does your organization receive or earn any money from hosting international volunteers?" ("Yes, we receive funding from a partner organization for hosting international volunteers"). However, despite testing several independent variables, no significant relationships were discovered, either within the overall sample or the subset samples of Community Development, Education, and Environment respondents.

\section{Recruitment methods.}

While it was unclear what, if any, effect how an international volunteer connects with a host organization might have on positive or negative perceptions, it is possible that a relationship could in fact exist. To explore this, answers to survey questions \#12 "How does your organization get most of your international volunteers?" and \#13 "If your organization does actively seek out international volunteers, which recruitment methods have been the most successful?" were used as the independent variables. 
In exploring this hypothesis, three significant relationships were discovered. Within the overall sample, a significant relationship was identified between comparing benefits to challenges and selecting "emails" as being one of the most effective recruitment tools (.037). This relationship was also discovered between these two variables among Education respondents (.004). In addition, among Community Development respondents, a significant relationship -.000 - was identified between comparing benefits to challenges and identifying "other websites" as being one of the most effective recruitment tools (note: those websites that were listed specifically by respondents - for example, the host organization's own website, Facebook, Idealist.org, GoAbroad.com, and other social media websites - were coded as their own answer categories and thus not included in "other websites").

\section{Revenue generation.}

It was unclear what, if any, effect revenue generated by hosting international volunteers might have on host organization perceptions. On one hand, if program fees or other revenue generated by international volunteers had a significant impact on an organization's financial well-being, then one might expect perceptions to be more positive. However, several scholars have also explored concerns over the costs of hosting international volunteers (Erdenechimeg, et al., 2005; Laleman, et al., 2007; McBride, et al., 2007; Sherraden, et al., 2008), so it was feasible that where costs appeared to be greater than revenue received, a more negative perception could be formed.

To test these ideas, answers to the survey question \#21 "Does your organization receive or earn any money from hosting international volunteers?" were used as the 
independent variable. Here two significant relationships were discovered between comparing benefits to challenges and selecting the answer option "No, we do not receive any money from hosting international volunteers": one within the overall sample (.038) and the other among Education respondents (.049).

\section{International volunteer skills.}

While there is still considerable debate over how effective skill transfer via international service may be, many scholars have explored the pros and cons of engaging skilled vs. general international volunteers (Keesbury, 2003; Lewis, 2005; Rockcliffe, 2005; Sherraden, et al., 2005; Laleman, et al., 2007; Sherraden, et al. 2008). Thus far, the consensus appears to be that skilled volunteers may have overall greater impact (although the type and measures of impact are still largely open to debate). Similarly, while I was unaware of any current research on what if any impact language ability might have on the efficacy of an international volunteer, it is possible that those volunteers with greater fluency in one or more of the local languages might be more effective and therefore fuel more positive perceptions from host organizations.

To test this hypothesis, several answer options from survey question \#14 "Do you have any requirements for accepting an international volunteer?" were used as the independent variables: international volunteers, in most cases, must 1) "have specific skills (for example, they must be qualified to provide medical care)", 2) "have a certain level of education", 3) "be able to speak one or more local languages", 4) "have relevant certifications per field", and 5) "have experience working with children or young people." However no significant relationships were discovered among these variables. 


\section{Staff input.}

Sherraden, Lough, and McBride (2008) found that where organizations played an active role in determining community needs and crafting appropriate volunteer roles and projects, more effective international service was likely to occur. These same authors found in 2007 that where local organizations collaborated with volunteer-sending organizations to determine how international volunteers were engaged, more effective programs were developed (McBride, et al, 2007). Based on this evidence, I hypothesized that more organizational control over determining projects for international volunteers might also minimize concerns over international volunteers replacing local jobs.

To test this, two answer options from survey question \#19 "How does your organization generally determine projects for international volunteers?" were used as the independent variables: "Projects for international volunteers... are created by our staff based on what our organization needs" and "Projects for international volunteers... are created by our staff based on community feedback and what our community needs." However, no significant relationships were discovered between the variables.

\section{Training methods.}

Several scholars have cited the importance of adequate training for international volunteers (Lewis, 2005; Laleman, et al., 2007; McBride, et al., 2007; Sherraden, et al., 2008). Based on these findings, I hypothesized that those volunteers who received and/or had access to training might be more effective, leading to a more positive organizational perception (note, however, that without assessing the effectiveness of available trainings, I suspected that this would likely be a speculative conclusion.) 
Using answers to survey question \#20 "Does your organization offer training to international volunteers? If so, please share what your training is like" as the independent variables, five significant relationships were identified within the data. In the overall sample, two relationships were discovered: one between benefits outweighing challenges and whether an organization offers some kind of training to their international volunteers (.010 - this relationship was also significant according to Fisher's Exact Test) and another between whether hosting international volunteers was considered to be worthwhile and providing materials to international volunteers before their arrival (.029); this relationship was also significant among Environment respondents (.000). Two additional significant relationships were found within the other area of focus subgroups: 1) among Community Development respondents between comparing benefits to challenges and offering training as needed after volunteer arrival (.005), and 2) among Education respondents between whether it is worthwhile to host international volunteers and providing other or unspecified types of training and/or orientation after volunteer $\operatorname{arrival}(.008)$.

\section{Volunteer management infrastructure.}

Research on domestic volunteer management has demonstrated that more effective volunteer engagement occurs where there is a dedicated paid volunteer management staff position (Urban Institute, 2004). Similarly, Sherraden, Lough, and McBride (2008) found that where international organizations engaged in effective volunteer management practices such as determining appropriate projects, selecting volunteers, and providing supervision, a more collaborative model of volunteers serving with community members emerged, potentially resulting in more positive perceptions of 
international volunteers overall. With this evidence in mind, I hypothesized that where a host organization had paid staff people managing the international volunteer program, perceptions of international volunteers would be more positive.

To test this hypothesis, coded answers to survey question \#11 "How are international volunteers managed at your organization?" were used as the independent variables. In total, three significant relationships were discovered, one in the overall sample between whether hosting international volunteers was considered to be worthwhile and having "one non-volunteer coordinator staff person responsible" for managing international volunteers (.009); this was also significant among Environment respondents (.025). In addition, among Community Development respondents, a significant relationship was found between comparing benefits to challenges and having "more than one non-volunteer coordinator staff person responsible" (.006).

\section{Age of international volunteer program.}

For the final hypothesis, I suspected that the more experience an organization had with international volunteers - in theory, allowing them time to develop and strengthen their international engagement program and practices - the more positive their perceptions would be of international volunteers. To test this conjecture, answers to survey question \#10 "In what year did your organization begin hosting international volunteers?" served as the independent variable. Here one significant relationship was identified among Environment respondents between whether it is worthwhile to host international volunteers and the age of the international volunteer program (.041). 


\section{Responses to Follow-Up Questions}

Based on initial analysis of the survey data, five follow-up questions were developed to garner more in-depth explanations and opinions from study participants (see Appendix D for the full list of questions). These were then emailed to the 165 survey respondents who shared their email address with permission to be contacted with additional questions. Of the 165 potential follow-up question respondents, $31-$ or $18.8 \%$ - provided answers in response to this email.

\section{Engaging local volunteers.}

The first follow-up question asked respondents to share whether they also recruited local volunteers. Overall, 22 individuals $-71 \%$ of follow-up question respondents - indicated that their organization engaged local volunteers in addition to international volunteers.

Three additional questions were then asked of those who replied yes. First, they were asked to share what they believed were the benefits of engaging local volunteers; the most commonly cited benefit - mentioned by approximately one-third of those that reported engaging local volunteers - was developing local volunteer skills and overall community capacity. As follow-up questions respondent \#1009 explained, local volunteers "motivate and animate an intert [sic] community. Unemployment is high and youth do not have any work experience and volunteering teaches them skills and they are less socially excluded." Additional benefits cited included such things as increasing the long-term sustainability of the volunteer program, demonstrating local investment in and contributions to the community, and local volunteers having local language fluency as well as local knowledge, cultural awareness, and understanding of local needs and issues. 
The second question for those that also engaged local volunteers concerned potential challenges of this activity. Among the 20 respondents that answered this question, the most frequently mentioned challenge (25.0\%) was different cultural understandings of volunteerism; as follow-up questions respondent \#1009 wrote, "Often I hear comments [from local volunteers] such as 'why should I work for free."” The next most frequently mentioned challenges - cited by $15 \%$ of those that responded to this question - were local volunteers being less available due to personal or professional obligations and local citizens being unable to afford to volunteer. Additional challenges mentioned included issues with local labor laws, scheduling logistics, language differences, a feeling of inequality between local and international volunteers, a different local work ethic, and inappropriate interactions between local and international volunteers in the past. Overall, $15 \%$ of those who answered this question stated that they had not in fact experienced any challenges while engaging local volunteers.

The third question for those that also engaged local volunteers was "How do the benefits and challenges of local volunteers compare to the benefits and challenges of international volunteers?" Two of the 18 respondents who answered this question responded that local volunteers were generally better for their organization, while two others stated that international volunteers were generally more beneficial. However, onethird of respondents identified benefits and challenges with both local and international volunteers. As follow-up questions respondent \#1023 wrote, "Local volunteers understand the local context better than international volunteers but they are often less educated and experienced. They also often have different expectations (such as payment etc)." Almost half of respondents $-44.4 \%$ - to this question stated that local volunteers 
were easier to work with, citing such benefits as not requiring assistance with things like housing and visas, having more local knowledge and language fluency, being less expensive, and being easier to screen and train in-person. Another respondent mentioned that local volunteers were often considered by local citizens to be more worthy of trust than foreign volunteers. Other respondents cited the benefits of hosting international volunteers, including such things as being able to volunteer for more time and over a longer period, bringing different skills and perspectives, serving as spokespeople and advocates upon return home, and serving as a source of interest and excitement for both the organization and people being served in the community. In addition, as follow-up questions respondent \#1009 explained, engaging both local and international volunteers can help to change perceptions of service as well as leverage local service efforts:

[The respondent's country] has a history of people helping one another but it has not been called volunteerism. It is a new concept here and people are suspiscious [sic]. There has been progress over time. When my organization started inviting international volunteers the local community was suspicious and convinced that the volunteers were paid. Now over time they have realized that volunteers contribute to their community and also have begun volunteering more.

Finally, those respondents who indicated that they do not currently engage local volunteers were asked "why not?" The most frequent response to this question was that local citizens were largely uninterested in volunteering (often due to a lack of time or financial incentive). One respondent stated that their organization was not opposed to hosting local volunteers; rather, it had just not happened yet. Other respondents indicated that they did not have the capacity to take on local volunteers as well as international volunteers. One respondent cited a lack of enough volunteer opportunities to also engage locals while another remarked that their organizational engagement structure was 
explicitly focused on international volunteers. Follow-up questions respondent \#1014

offered the following explanation:

To be blunt, international volunteers are an excellent income-generating resource. Local volunteers do not pay a fee and it takes an immense amount of resources to train a short-term local volunteer. We would rather hire a local resource to be a part of our full-time team as the investment we make in training will pay off at the end of the day.

\section{Keeping former international volunteers involved.}

The second follow-up question for participating survey respondents explored whether their organizations kept former international volunteers involved after their return home and how this might contribute to their organizational capacity and networking. Here, an overwhelming majority of follow-up respondents $-90.3 \%-$ indicated that they do indeed stay connected with former volunteers.

The first question for those who reported staying connected to their former volunteers was "How do they stay involved?" Among methods used to communicate with former volunteers, the most frequently mentioned were, in order, Facebook, email, Twitter, and host organization websites, listservs, newsletters, and events. Several different types of roles and activities for former international volunteers were also mentioned by respondents, including assisting with fundraising, returning as international volunteers in the future, becoming donors, helping to recruit new international volunteers, and raising awareness.

Other respondents cited examples of former international volunteers staying involved as volunteers from their home countries, including serving as board members and trustees, creating films and documentaries, and assisting with marketing, graphic design, newsletters, translations, website design, and specific volunteer management 
tasks like updating materials for and performing reference checks on incoming volunteers. It was also noted that some former international volunteers, upon return to volunteer with the host organization, served as project managers. Several respondents mentioned that their relationships with former international volunteers were akin to friendships while others cited that staying connected with former volunteers helped to boost the morale of staff. As follow-up questions respondent \#1009 stated, "working in a problematic postwar community you often face resistance and hostility and international volunteer [sic] sometimes remind us of the importance to keep doing this work."

The second question for those that reported staying connected with former international volunteers was "What are the benefits in keeping former international volunteers involved?" Most of the answers submitted mirrored those of the previous question, with a few additionally mentioned benefits emerging such as adding credibility to the organization, serving as a social support network, helping to acclimate new volunteers, and contributing to good public relations. On this latter point, follow-up questions respondent \#1028 offered the following: "[International volunteer] experiences and stories are a powerful testimony to the organization's work."

When those that stay connected with their former international volunteers were asked about potential challenges, the most frequently mentioned - by approximately onequarter of these respondents - was losing touch with former international volunteers as they find jobs and/or re-enter their busy lives upon return home. As follow-up questions respondent \#1006 remarked, "Distance and time tends to decrease enthusiasm." The next most frequently mentioned challenges were, in order, keeping up regular communications, coming up with ways to keep former international volunteers involved, 
and a lack of resources - for example, a formal communications database - to keep them engaged. Interestingly, almost one-fifth of these respondents stated that they had experienced no challenges at all.

Of those follow-up respondents who do not currently keep former international volunteers involved, three individuals indicated that they were in fact interested in doing so, while a fourth - follow-up questions respondent \#1017 - stated that "the work required on our part to engage former international volunteers would not be worth the effort." When asked how they would like to keep former international volunteers involved, suggestions included keeping them informed via such tools as Facebook and newsletters, engaging them as advocates and connectors upon return home, and discussing and potentially continuing work on the project they'd contributed to during their time in-country.

When these respondents were asked what they thought the benefits might be for keeping international volunteers involved, suggestions included fundraising and building friendships. In addition, as follow-up questions respondent \#1029 explained:

Former volunteers already know and understand the nature and terrain of the project and community they had [sic] worked in, and so can better get involve [sic] with either the organization or the community, suggesting new recommendations, involve [sic] in the planning of new projects, connecting new volunteers and donors and even making personal contributions towards a particular aspect in the community they had lived in.

Regarding potential challenges, the responses from those who do not stay connected to former international volunteers mirrored those of the respondents that do stay connected with their former international volunteers, including keeping them interested in the work of the organization, differing urgencies in terms of 
communications, and former international volunteers becoming busy with their own lives upon return home. One respondent also mentioned that some of their former international volunteers sometimes spread negative impressions of the host organization and host community upon their return home.

\section{Preparing international volunteers.}

The third follow-up question addressed two concerns cited by survey respondents: that international volunteers often have difficulty culturally adjusting to local personal and professional ways of doing things, and that they often arrive with unrealistic expectations for what they can accomplish during their time abroad. Here, follow-up respondents were asked whether they felt that host organizations could help to prepare international volunteers before they arrive and, if so, how.

Overall, 30 of the 31 follow-up question respondents answered this question. While there were few who explicitly answered yes or no to this question, overwhelmingly the sentiment was that there were indeed things that host organizations could do to better prepare their incoming international volunteers.

The most frequently suggested method for this, mentioned by one-third of respondents, was sending information about the organization, the volunteer role, and the community to incoming volunteers in advance; suggested methods and structures for sharing this information included project overviews, volunteer job descriptions, guides, handouts, videos, and pre-departure orientation sessions. Follow-up questions respondent \#1011 explained:

We have a series of online 'handouts' that we send to volunteers during their preparation process. First is travel info and a packing list, then an intro to their project and housing, and eventually, cultural info, tips for working with children, 
ideas about what to do on the weekends, and suggested items to have friends and family donate to support the volunteer's work. By spacing out these materials, the volunteer is not inundated and has time to absorb the info. In addition to handouts, once a volunteer is confirmed, we also introduce them to current and incoming volunteers via email and facebook [sic]. We have a facebook [sic] page that shares info and pix [sic] and so that helps them to see the day to day life of our volunteers.

One-fifth of respondents recommended conducting interviews, having a rigorous application and matching process, and/or providing orientations before departure as well. Additional suggestions included connecting incoming volunteers with current or former international volunteers, connecting potential volunteers with staff members, providing clear information on the organization's website, and partnering new volunteers with current volunteers upon arrival.

Finally, the need for discussing and establishing realistic expectations was mentioned by over one-quarter of respondents. Follow-up questions respondent \#1005 explained:

Make sure that correspondence is clear, defined and accurate and get a written response from teh [sic] volunteers of their skills, what they wish to achieve for themselves whilst they are volunteering. this [sic] then can be used in dialogue when times get tough or they change their minds.

\section{Ideal volunteer management.}

In an effort to provide further clarification to survey respondent's answers regarding their volunteer management processes, the fourth follow-up question asked respondents to describe their ideal model for managing international volunteers at their organization. Again, 30 of the 31 follow-up question respondents answered this question.

Over half of these respondents stated that they have or would like to have a volunteer coordinator on staff. Follow-up questions respondent \#1007 wrote: 
I think if organizations really want to benefit from volunteers, they should treat volunteers serious [sic] and they should have a person in charge of this. If the number of volunteers is not very big, such role [sic] can be delegated to one of the existing staff members. They should, however, be properly trained and see volunteering as a good way to benefit the organization by highly qualified or less qualified people without a need to pay them.

Additional models mentioned included having multiple staff responsible for and/or assisting with volunteer management, offering more intensive staff support of international volunteers overall, having a staff mix of local and international individuals, providing cultural and language orientations, offering pre-service training, recruiting locals to provide guidance to international volunteers, and engaging experienced volunteers as coordinators.

Overall, $15 \%$ of respondents stated that they were happy with their current model for volunteer management. Still others were pleased with particular components of their current system. As follow-up questions respondent \#1013 explained, "We involve former volunteers in the pre-departure orientation and that works very well because new recruits hear what it is really like from people who have been out and been [sic] volunteers. This preparatory orientation is extremely important."

When asked "What are the main obstacles to achieving this ideal?," almost onethird of respondents cited financial barriers to funding their ideal volunteer management structure. One-fifth also cited not having enough time while just under one-fifth were concerned about having enough and/or recruiting appropriate staff. Additional challenges mentioned were language barriers and cultural differences. Finally, three respondents indicated that they were not experiencing any obstacles to their current management system. 


\section{Local languages.}

The fifth and final follow-up question asked respondents whether their organization required international volunteers to speak one or more local languages. Among the 31 follow-up respondents, $22.6 \%$ indicated that they do, for at least some if not all international volunteer roles, require language abilities, either of a local language or a common second language like English or Spanish.

Those who responded "yes" to this question were then asked if this requirement made it easier or more difficult for them to recruit appropriate international volunteers. Overall, none of the respondents cited this as being a barrier to recruitment; as follow-up questions respondent \#1016 explained, "It does not make [recruitment] more difficult. Most of the people who show interest towards the program already have a language skill or are in the process of learning the language. All of them know its importance."

Those who indicated that they do not have a language requirement were then asked to explore whether this willingness to accept anyone regardless of language skills creates challenges for their organization. Of the 18 respondents who answered this question, $77.8 \%$ responded that this did not create challenges for the organization. In addition, many cited that knowing a common second language like English or Spanish was in fact more important than knowing a local language. As follow-up questions respondent \#1008 wrote: "It would be impossible to find volunteers who already speak the numerous local languages our partner organizations speak. Since we only require a short-term commitment (3 months) it's also impossible to train people." Follow-up questions respondent \#1007 wrote: "I would say that it is more important for the staff to know good English than for volunteers to know the local language!" Other respondents 
stated that, while local language abilities weren't required - and didn't necessarily create challenges - host organizations did encourage international volunteers to learn them; follow-up questions respondent \#1028 explained:

people [sic] who speak the local language can do a lot more and can build stronger relationships with the local people, but volunteers who don't speak the language can still accomplish a lot. Because many segments of the population here speak English anyways, volunteers do not require any translation to reach these people. Other projects, such as working with small children, do not really require language for a volunteer to be effective.

Finally, a second question was asked of those that stated that they did not have local language requirements, designed to explore how they address any challenges they've experienced from accepting international volunteers regardless of language ability. Strategies mentioned to minimize these challenges included providing a translator, pairing international volunteers with fluent staff members and volunteers, offering language classes, encouraging volunteers to seek language training, recruiting volunteers with existing language abilities, and being supportive and patient.

\section{Responses from Organizations That Do Not Host International Volunteers}

While the audience for participation in this study was those organizations that currently host international volunteers, I was also curious why an organization might not host international volunteers. To explore this idea as well as to assist with establishing eligibility for participation, the following question was asked in a preliminary section of the survey: "Does your organization currently host international volunteers? By host, we mean that your organization recruits or accepts volunteers from other countries to work on local projects with your organization." Those respondents who chose the answer "Yes" proceeded to the survey; those who chose the answer "No" were directed to a page 
with the following text: "Unfortunately if your organization does not currently host international volunteers, then it does not qualify to participate in this study. Before you go though, we'd love to hear why you do not host international volunteers. Thank you!" In total, 22 individuals responded "No" to this question and were directed to the secondary page; of these 22,18 shared reasons for why they do not currently host international volunteers.

The most frequently cited reason - by $27.8 \%$ of these respondents - was due to financial barriers. As respondent $\# 1416778$ wrote, "We are a small organization which is working on self funding and for this reason we cannot afford to host international volunteers." Other reasons included lacking such things as staff capacity, available volunteer projects, a clear understanding of volunteerism, and ties with international sources and partner organizations; in addition, one respondent stated that they simply didn't need them.

While three respondents reported that they were not currently structured to host international volunteers (two of these were volunteer-sending organizations and one a for-profit company), over one-fifth of those respondents that did not currently host international volunteers also reported that they would, in fact, like to. 


\section{Chapter 5: Conclusions}

\section{Research Summary}

I embarked on this dissertation in an effort to learn more about how and why organizations around the globe host and engage international volunteers. What I received through the course of my research was a new body of data on the disparate and shared practices, infrastructures, and opinions of nearly 250 individuals and organizations in at least 57 countries. In an effort to summarize the findings contained within this research, I will here revisit each of this study's central guiding questions:

1. What are the primary motivations for an organization to seek and/or accept international volunteers?

2. What are the primary perceived benefits of engaging international volunteers?

3. What are the primary perceived challenges of engaging international volunteers?

4. Do statistically significant relationships exist between an organization's area of focus and their perceived benefits of, perceived challenges of, and satisfaction with engaging international volunteers? Specifically, are there variations in perceptions among organizations doing different kinds of charitable work?

5. Do statistically significant relationships exist between an organization's volunteer program characteristics and their perceived benefits of, perceived challenges of, and satisfaction with engaging international volunteers?

The first guiding research question - "What are the primary motivations for an organization to seek and/or accept international volunteers? - was designed to explore the initial "why" of hosting international volunteers. What reasons, perceptions, anticipated rewards did host organizations have in mind when they embarked on this venture? In 
order to garner respondents' opinions on this matter, I asked them this question directly in the survey.

Responses to my query exposed a broad and varied spectrum of potential motivations for hosting international volunteers. These ranged from direct benefits to the organization, like contributing needed skills and leveraging staff capacity, to extending benefits to the greater community and international volunteers themselves, e.g. providing opportunities for cross-cultural interaction and personal/professional development.

While many of the motivations identified by respondents corresponded with anticipated potential benefits for host organizations, I also discovered some unexpected attributes in the data. For example, I did not expect that, for several respondents, international volunteers would be sought for such seemingly large and ambitious goals as increasing organizational and community diversity, demonstrating organizational commitment to international values, and/or serving as sources of inspiration, both for their organization and the greater community. It was also an unexpected discovery that only around $7 \%$ of respondents decided to host international volunteers less out of an internal demand for them and more as a response to a supply of international volunteers seeking the opportunity to serve; given increasing levels of individual interest in international service (as evidenced in this study's literature review), I expected that this percentage would be higher. Similarly, I was surprised to learn that only $12.5 \%$ of host organizations decided to engage international volunteers primarily for financial gain; based on anecdotal data from practitioners and peers in the field, I again expected this percentage to be higher. 
My second guiding research question - "What are the primary perceived benefits of engaging international volunteers?" - also afforded some interesting results. First, I was surprised by how strongly respondents agreed with the potential benefits suggested in the survey; over half of all survey respondents agreed or strongly agreed with all but three of the benefits statements posited. I was also once again surprised to see how little financial gain appeared to contribute to benefits experienced by host organizations; indeed, of the five answer options where more than $10 \%$ of respondents disagreed or strongly disagreed with a suggested benefit, four were related to financial benefits that could be gained by hosting international volunteers. However, at the same time, the potential for financial gain was still viewed quite positively, as over one-fifth of respondents suggested that it was one of the most important benefits of hosting international volunteers. In fact, the potential for international volunteers to contribute financial resources, assist with fundraising, and/or become donors was the third most frequently suggested response to the question "What do you think are the most important benefits of hosting international volunteers?"

The opportunity for respondents to write in their answers to this latter question also provided insight into some additional, unanticipated benefits experienced by hosting organizations. For example, I was intrigued to learn that international volunteers sometimes helped to make the programs and services offered by host organizations more interesting to local populations served. Also, it was interesting to discover that an increased organizational credibility because of, as well as sheer interest in, international volunteers could help to improve relations and/or open doors to partnerships with other local and international entities. 
The third guiding research question - "What are the primary perceived challenges of engaging international volunteers?" - was explored, similar to the second guiding research question, using two survey questions, the first a list of statements with a Likert Scale response structure and the second an open text box. However, in contrast to the question regarding potential benefits, where a majority of respondents agreed or strongly agreed with all but three of the suggested statements, a majority of respondents agreed or strongly agreed with only four of the 13 statements regarding potential challenges. Indeed, a majority of respondents disagreed or strongly disagreed with just under half of all suggested challenges.

Given that a strong critique of international service is its ability to intentionally or unintentionally disengage local actors - a legitimate concern for those seeking to prevent international volunteering from serving as a form of modern-day colonialism - I was intrigued to learn that three-quarters of respondents disagreed or strongly disagreed that international volunteers take the place of local jobs and local volunteers. It was also interesting to see how the potential challenge statements elicited more mixed responses than the potential benefits statements; for example, for eight of the 13 potential challenge statements, between one-fifth and one-third of respondents chose the answer options of "neutral" or "not sure." However, discovering more about the ambiguity behind these responses is a charge for future research.

When respondents were asked to suggest the most important challenges of hosting international volunteers, two challenges rose to the top of the list: the first that many international volunteers have difficulty accepting, adjusting to, and/or adhering to local cultural and/or professional norms and, the second, that international volunteers can have 
unrealistic expectations about what they can or should accomplish and/or how things should be done. While I did anticipate that some version of these challenges might present itself in the data - I'd included the somewhat related challenge of volunteers being accustomed to different ways of doing things as a statement in the potential challenges question - the frequency with which this challenge was cited, as well as the frustration expressed due to international volunteers' occasional if not frequent inability to adjust to local realities, was a surprise.

Another unanticipated yet clearly relevant challenge suggested by respondents, particularly those in Africa, was related to the difficulties international volunteers sometimes have with local living conditions - from housing to food to transportation norms - and the impact these struggles have on hosting organizations. Again, my interest was peaked but my ability to further explore the impacts of these challenges limited by the scope of this study.

I explored the fourth guiding research question - "Do statistically significant relationships exist between an organization's area of focus and their perceived benefits of, perceived challenges of, and satisfaction with engaging international volunteers?" using data from the three area of focus typologies that were affiliated with at least twenty respondents each: Community Development, Education, and Environment. For each of these typologies, I sought to identify relationships between respondents' reported satisfaction with international volunteers (as measured through the two survey questions asking respondents to compare benefits to challenges and assess whether hosting international volunteers was worthwhile) and host organization characteristics and opinions. 
Among Community Development respondents, I identified 22 significant relationships where the dependent variable was comparing benefits to challenges (Table 16) and zero significant relationships where the dependent variable was whether hosting international volunteers was considered to be worthwhile (this latter result was due to all respondents in this group responding that it was generally worthwhile to engage international volunteers, thus making the dependent variable a constant). Of these, fourteen relationships were found to be significant only within this subsample, between comparing benefits to challenges and 1) Country, 2) Type of International Service Project: "Cooking and/or food preparation", 3) Volunteer Management: "More than one non-volunteer coordinator staff person responsible”, 4) Best Recruitment Methods: "Other Websites", 5) Training Type: "Training available as needed after arrival”, 6) Benefits of Hosting International Volunteers: "International volunteers... provide an opportunity for local people to learn more about other nations and cultures", 7) Benefits of Hosting International Volunteers: "International volunteers...bring credibility to our work", 8) Benefits of Hosting International Volunteers: "International volunteers...are inexpensive", 9) Challenges of Hosting International Volunteers: "International volunteers...can be difficult to find", 10) Challenges of Hosting International Volunteers: "International volunteers...can be expensive", 11) Challenges of Hosting International Volunteers: "International volunteers... may not have the skills needed", 12) Challenges of Hosting International Volunteers: "International volunteers...distract staff and local volunteers from the work", 13) Most Important Benefits of Hosting International Volunteers: "International volunteers...provide more people to get our work done", and 
14) Most Important Challenges of Hosting International Volunteers: "International Volunteers...can be untrustworthy."

Where the typology was Education, 15 significant relationships were identified where the dependent variable was comparing benefits to challenges (Table 17) and eight significant relationships where the dependent variable was whether hosting international volunteers was worthwhile (Table 19). However, only seven of these relationships were unique to Education respondents (given the size of this subsample, it is perhaps not surprising that so many of the significant relationships identified here were also significant for the overall sample). These included four relationships with comparing benefits and challenges -1 ) the "other reasons" motivation to host international volunteers, 2) the age of international volunteers: 20s, 3) the most important benefits statement "International volunteers... are inexpensive, and 4) the most important challenges statement "International volunteers...can be difficult to find" - and with whether hosting international volunteers was considered to be worthwhile -1 ) the benefit of hosting international volunteers "international volunteers...bring international attention to our work," 2) the benefit "international volunteers...help our economy by spending money locally," and 3) the training type "Other or unspecified type of training and/or orientation provided or offered after arrival."

The smallest number of significant relationships was discovered among Environment respondents; this was not too surprising though given that this was also a relatively small subsample. However, of the ten significant relationships for this subgroup (Table 20), all where the dependent variable was whether hosting international volunteers was considered to be worthwhile (there were no significant relationships with 
comparing benefits to challenges as the dependent variable in this data set was a constant), six relationships were unique to Environment respondents:1) the age of the international volunteer program, 2) the age of international volunteers: “20s", 3) the benefit that "International volunteers...provide a new viewpoint or perspective," 4) the challenge that "International volunteers...don't stay long enough," 5) the most important benefit that "International volunteers...provide more people to get our work done", and 6) the most important challenge that "International volunteers...can be unmotivated and/or unreliable.”

Additional research is required to fully extrapolate from these findings exactly why and what differences exist between specific areas of focus and reported satisfaction with international volunteers. However, even within these limited samples, there were clearly some very real differences between respondents in specific areas of focus and the overall sample, evidenced in part by the number of relationships found to be unique to each typology. Looking forward, these findings on the differences and similarities among host organizations and areas of focus may ultimately serve best as an introduction to this line of study, inspiring future, more in-depth research into the topic.

To shape exploration of my fifth and final guiding research question - "Do statistically significant relationships exist between an organization's volunteer program characteristics and their perceived benefits of, perceived challenges of, and satisfaction with engaging international volunteers?" - I developed a series of hypothesized relationships (Table 1) and then tested each to identify any significant relationships. In total, I identified significant relationships with 22 variables related to these hypotheses, eight within the overall sample and 14 within specific areas of focus (Table 22). 
Table 22

Statistically Significant Relationships Identified via the Twelve Hypotheses

\begin{tabular}{|c|c|c|c|c|}
\hline $\begin{array}{l}\text { Hypothesis } \\
\text { Title }\end{array}$ & Dependent Variable & Independent Variable & Sample & $\begin{array}{l}\text { Sig. at } \\
<.05\end{array}$ \\
\hline $\begin{array}{l}\text { Age of } \\
\text { International } \\
\text { Volunteer } \\
\text { Program }\end{array}$ & $\begin{array}{l}\text { Whether Hosting } \\
\text { International } \\
\text { Volunteers is } \\
\text { Worthwhile }\end{array}$ & $\begin{array}{l}\text { Age of International } \\
\text { Volunteer Program }\end{array}$ & Environment & $.041^{\mathrm{b}}$ \\
\hline $\begin{array}{l}\text { Age of } \\
\text { International } \\
\text { Volunteers }\end{array}$ & $\begin{array}{l}\text { Comparing Benefits } \\
\text { to Challenges }\end{array}$ & $\begin{array}{l}\text { Age of International } \\
\text { Volunteers: "20s" }\end{array}$ & Education & $.009^{\mathrm{a}}$ \\
\hline $\begin{array}{l}\text { Age of } \\
\text { International } \\
\text { Volunteers }\end{array}$ & $\begin{array}{l}\text { Whether Hosting } \\
\text { International } \\
\text { Volunteers is } \\
\text { Worthwhile }\end{array}$ & $\begin{array}{l}\text { Age of International } \\
\text { Volunteers: "20s" }\end{array}$ & Environment & $.009^{\mathrm{b}}$ \\
\hline $\begin{array}{l}\text { Age of } \\
\text { International } \\
\text { Volunteers }\end{array}$ & $\begin{array}{l}\text { Comparing Benefits } \\
\text { to Challenges }\end{array}$ & $\begin{array}{l}\text { Age of International } \\
\text { Volunteers: "60s" }\end{array}$ & $\begin{array}{l}\text { Overall / } \\
\text { Education }\end{array}$ & $\begin{array}{l}.011^{\mathrm{a}} \\
/ .033^{\mathrm{b}}\end{array}$ \\
\hline $\begin{array}{l}\text { Age of } \\
\text { International } \\
\text { Volunteers }\end{array}$ & $\begin{array}{l}\text { Comparing Benefits } \\
\text { to Challenges }\end{array}$ & $\begin{array}{l}\text { Age of International } \\
\text { Volunteers: "70s and } \\
\text { older" }\end{array}$ & $\begin{array}{l}\text { Overall / } \\
\text { Education }\end{array}$ & $\begin{array}{l}.007^{\mathrm{a}} \\
/ .039^{\mathrm{b}}\end{array}$ \\
\hline $\begin{array}{l}\text { Age of } \\
\text { International } \\
\text { Volunteers }\end{array}$ & $\begin{array}{l}\text { Whether Hosting } \\
\text { International } \\
\text { Volunteers is } \\
\text { Worthwhile }\end{array}$ & $\begin{array}{l}\text { Age of International } \\
\text { Volunteers: "70s and } \\
\text { older" }\end{array}$ & $\begin{array}{l}\text { Overall / } \\
\text { Education }\end{array}$ & $\begin{array}{l}.040^{\mathrm{b}} \\
/ .004^{\mathrm{b}}\end{array}$ \\
\hline $\begin{array}{l}\text { Recruitment } \\
\text { Methods }\end{array}$ & $\begin{array}{l}\text { Comparing Benefits } \\
\text { to Challenges }\end{array}$ & $\begin{array}{l}\text { Best Recruitment } \\
\text { Method: "Emails" }\end{array}$ & $\begin{array}{l}\text { Overall / } \\
\text { Education }\end{array}$ & $\begin{array}{l}.037^{\mathrm{b}} \\
/ .004^{\mathrm{b}}\end{array}$ \\
\hline $\begin{array}{l}\text { Recruitment } \\
\text { Methods }\end{array}$ & $\begin{array}{l}\text { Comparing Benefits } \\
\text { to Challenges }\end{array}$ & $\begin{array}{l}\text { Best Recruitment } \\
\text { Method: "Other } \\
\text { Websites" }\end{array}$ & $\begin{array}{l}\text { Community } \\
\text { Development }\end{array}$ & $.000^{\mathrm{b}}$ \\
\hline $\begin{array}{l}\text { Revenue } \\
\text { Generation }\end{array}$ & $\begin{array}{l}\text { Comparing Benefits } \\
\text { to Challenges }\end{array}$ & $\begin{array}{l}\text { Revenue Generation: } \\
\text { "No, we do not receive } \\
\text { any money from hosting } \\
\text { international volunteers" }\end{array}$ & $\begin{array}{l}\text { Overall / } \\
\text { Education }\end{array}$ & $\begin{array}{l}.038^{\mathrm{b}} \\
/ .049^{\mathrm{b}}\end{array}$ \\
\hline $\begin{array}{l}\text { Training } \\
\text { Methods }\end{array}$ & $\begin{array}{l}\text { Comparing Benefits } \\
\text { to Challenges }\end{array}$ & Training & Overall & $.010^{\mathrm{a}, \mathrm{b}}$ \\
\hline
\end{tabular}




\begin{tabular}{|c|c|c|c|c|}
\hline $\begin{array}{l}\text { Training } \\
\text { Methods }\end{array}$ & $\begin{array}{l}\text { Whether Hosting } \\
\text { International } \\
\text { Volunteers is } \\
\text { Worthwhile }\end{array}$ & $\begin{array}{l}\text { Training Type: } \\
\text { "Materials provided } \\
\text { before they arrive" }\end{array}$ & $\begin{array}{l}\text { Overall / } \\
\text { Environment }\end{array}$ & $\begin{array}{l}.029^{\mathrm{b}} \\
/ .000^{\mathrm{b}}\end{array}$ \\
\hline $\begin{array}{l}\text { Training } \\
\text { Methods }\end{array}$ & $\begin{array}{l}\text { Comparing Benefits } \\
\text { to Challenges }\end{array}$ & $\begin{array}{l}\text { Training Type: "Training } \\
\text { available as needed after } \\
\text { arrival" }\end{array}$ & $\begin{array}{l}\text { Community } \\
\text { Development }\end{array}$ & $.005^{\mathrm{b}}$ \\
\hline $\begin{array}{l}\text { Training } \\
\text { Methods }\end{array}$ & $\begin{array}{l}\text { Whether Hosting } \\
\text { International } \\
\text { Volunteers is } \\
\text { Worthwhile }\end{array}$ & $\begin{array}{l}\text { Training Type: "Other or } \\
\text { unspecified type of } \\
\text { training and/or } \\
\text { orientation provided or } \\
\text { offered after arrival" }\end{array}$ & Education & $.008^{\mathrm{b}}$ \\
\hline $\begin{array}{l}\text { Volunteer } \\
\text { Management } \\
\text { Infrastructure }\end{array}$ & $\begin{array}{l}\text { Whether Hosting } \\
\text { International } \\
\text { Volunteers is } \\
\text { Worthwhile }\end{array}$ & $\begin{array}{l}\text { Volunteer Management: } \\
\text { "One non-volunteer } \\
\text { coordinator staff person } \\
\text { responsible" }\end{array}$ & $\begin{array}{l}\text { Overall / } \\
\text { Environment }\end{array}$ & $\begin{array}{l}.009^{\mathrm{b}} \\
/ .025^{\mathrm{b}}\end{array}$ \\
\hline $\begin{array}{l}\text { Volunteer } \\
\text { Management } \\
\text { Infrastructure }\end{array}$ & $\begin{array}{l}\text { Comparing Benefits } \\
\text { to Challenges }\end{array}$ & $\begin{array}{l}\text { Volunteer Management: } \\
\text { "More than one non- } \\
\text { volunteer coordinator } \\
\text { staff person responsible" }\end{array}$ & $\begin{array}{l}\text { Community } \\
\text { Development }\end{array}$ & $.006^{\mathrm{b}}$ \\
\hline
\end{tabular}

Overall, I proposed twelve different hypotheses. For eight of these, I offered descriptions of the relationships I expected to find; for the remaining four, I was unsure whether a relationship would even in fact exist. However, while I suspect that - given the overwhelmingly positive responses to the dependent variable questions of comparing benefits to challenges and whether hosting international volunteers was worthwhile these identified relationships are likely positive in nature (for example, I suspect that those organizations engaging volunteers in their 60 s and 70 s and/or offering training also reported more positive levels of satisfaction with their international volunteers, perhaps because these variables may serve as possible indicators of more structured, formalized 
international volunteer engagement programs), I simply can't be certain using only chisquare to assess them. Instead, I hope that each of these discoveries will serve as starting points for future lines of inquiry, ideally using more robust measures of association to identify strength, direction, and causality within these relationships.

\section{Theoretical Contributions}

Acknowledging the relevant theoretical foundations established in Chapter 2, I will now discuss this study's findings as they contribute to existing theory, specifically how this study builds on and expands the field's understanding of international volunteer engagement in relationship to organizational capacity and social capital.

\section{Organizational capacity.}

As was outlined in Chapter 2, several scholars have cited the potential of international volunteers to increase or otherwise enhance organizational capacity by lending new skills and perspectives, providing training to local staff and volunteers as well as facilitating other methods of skill and knowledge transfer, offering opportunities for host organizations to become more internationally and culturally competent, and even simply providing more people to do the work at hand (UNV, 2001; Keesbury, 2003; Randel et al., 2004; Lewis, 2005; Sherraden et al., 2006; Laleman et al., 2007; Plewes and Stuart, 2007; Sherraden et al., 2008; Lough, McBride, Sherraden, \& O'Hara, 2011). Would respondents to this study reinforce these findings by reporting similar benefits to their organizational capacity?

Overall, it does appear that these pre-existing theories were reinforced by the results of this study. For example, this dissertation gathered significant evidence that host organizations are in fact seeking international volunteers to contribute, lend, and - 
ideally - transfer skills and expertise to local organizations and communities. Indeed, the most frequently cited motivation for hosting international volunteers - mentioned by $43.2 \%$ of survey respondents - was that international volunteers could contribute needed skills, languages, and perspectives, while the third most frequently cited motivation mentioned by over one-quarter of survey respondents - was that volunteers were needed to help fill gaps and leverage staff capacity. In addition, just over 10\% of respondents cited a motivation as being the possibility that "international volunteers can train staff and help to expand staff capacity."

Similarly, over half of survey respondents also agreed or strongly agreed with potential benefits statements related to building organizational capacity, including that international volunteers "contribute needed skills" (91.4\%), "provide a new viewpoint or perspective" (89.1\%), "provide more people to get our work done" $(77.7 \%)$, and "generate revenue for our organization" (51.5\%); an additional $48.1 \%$ agreed or strongly agreed that international volunteers "help us attract local volunteers." When asked what the most important benefits of hosting international volunteers might be, the most frequently reported response - according to $55.2 \%$ of respondents - was that international volunteers could contribute needed skills, languages, ideas, energy, and perspectives. Additional most important benefits mentioned by respondents included training staff and helping to develop staff capacity (cited by 18.6\%) and providing more people to get work done (cited by $15.7 \%$ ). Overall, whether it was by simply increasing the number of people available for completing specific tasks or engaging individuals with desired skill sets (from both local and international communities), this study supports the theory that 
hosting international volunteers can be a legitimate way to build and/or leverage organizational capacity.

At the same time though, it is important to note some interesting results that emerged from the potential challenges statements related to organizational capacity. Specifically, while a majority of respondents disagreed or strongly disagreed with most of the challenge statements related to organizational capacity, a few statements in particular drew a majority response of agreement, where international volunteers "require a lot of supervision" (50.0\% agreed or strongly agreed) and "may not have the language abilities needed" (53.8\% agreed or strongly agreed). While this suggests that some international volunteers may help to build organizational capacity just as others seemingly tax it, it does appear that - for this sample of respondents- that the balance was largely positive; for example, when asked to weigh in on the statement that international volunteers "distract staff and local volunteers from the work," 53.8\% disagreed or strongly disagreed. In addition, even those statements where a majority agreed that international volunteers require significant resources, a large proportion of respondents also disagreed; one example of this is international volunteers requiring "a lot of supervision": while $50.0 \%$ agreed or strongly agreed with this statement, over onequarter disagreed or strongly disagreed with the same. In short, it would appear that international volunteers can potentially increase organizational capacity but may also serve as a drain on organizational time and resources; further research is required to determine the variables and circumstances in which these one or both of these outcomes might occur. 
An additional area where findings in this dissertation appear to both support and be supported by previously discovered evidence is in terms of statistically significant relationships. When variables in this study were tested to identify potential relationships between perceived satisfaction with hosting international volunteers and host organization characteristics and opinions, 12 relationships relevant to organizational capacity were found to be significant within the overall sample (Table 23), with additional relationships also found to be significant within area of focus subgroups also tested. While the strength, direction, and causality of these relationships is unknown due to the limitations of chi-square, it does highlight several areas where additional connections between hosting international volunteers and either increasing or decreasing organizational capacity may exist.

Table 23

Statistically Significant Relationships Related to Organizational Capacity

Dependent Independent Variable

Variable

Whether

Hosting is

Worthwhile

Whether

Hosting is

Worthwhile

Benefits

Outweighing

Challenges

Benefits

Outweighing Challenges organization" perspective"
Significance at $<.05$

Benefits of Hosting International Volunteers: $\quad .000^{\mathrm{b}}$

"International volunteers...generate revenue for our

Benefits of Hosting International Volunteers:

$.000^{\mathrm{b}}$

"International volunteers...provide a new viewpoint or

Challenges of Hosting International Volunteers:

$.000^{\mathrm{b}}$

"International volunteers...require a lot of supervision"

Challenges of Hosting International Volunteers:

$.000^{\mathrm{b}}$ 


\begin{tabular}{|c|c|c|}
\hline $\begin{array}{l}\text { Benefits } \\
\text { Outweighing } \\
\text { Challenges }\end{array}$ & $\begin{array}{l}\text { Most Important Benefits of Hosting International } \\
\text { Volunteers: "International volunteers...can make the } \\
\text { volunteer program more sustainable by staying for longer } \\
\text { periods of time and/or volunteering more hours per day" }\end{array}$ & $.000^{\mathrm{a}, \mathrm{b}}$ \\
\hline $\begin{array}{l}\text { Benefits } \\
\text { Outweighing } \\
\text { Challenges }\end{array}$ & $\begin{array}{l}\text { Most Important Benefits of Hosting International } \\
\text { Volunteers: "International volunteers...do not provide } \\
\text { benefits (benefits are primarily to the volunteers } \\
\text { themselves)" }\end{array}$ & $.000^{\mathrm{a}, \mathrm{b}}$ \\
\hline $\begin{array}{l}\text { Benefits } \\
\text { Outweighing } \\
\text { Challenges }\end{array}$ & $\begin{array}{l}\text { Most Important Challenges of Hosting International } \\
\text { Volunteers: "International volunteers...can require } \\
\text { resources or tools that are unavailable or too expensive" }\end{array}$ & $.000^{\mathrm{b}}$ \\
\hline $\begin{array}{l}\text { Whether } \\
\text { Hosting is } \\
\text { Worthwhile }\end{array}$ & $\begin{array}{l}\text { Motivation to Host International Volunteers: } \\
\text { "International volunteers can make the program more } \\
\text { sustainable" }\end{array}$ & $.000^{\mathrm{b}}$ \\
\hline $\begin{array}{l}\text { Benefits } \\
\text { Outweighing } \\
\text { Challenges } \\
\text { Whether } \\
\text { Hosting is } \\
\text { Worthwhile }\end{array}$ & $\begin{array}{l}\text { Benefits of Hosting International Volunteers: } \\
\text { "International volunteers...generate revenue for our } \\
\text { organization" } \\
\text { Motivation to Host International Volunteers: "Volunteers } \\
\text { needed to fill gaps and leverage staff capacity" }\end{array}$ & $.012^{\mathrm{b}}$ \\
\hline $\begin{array}{l}\text { Whether } \\
\text { Hosting is } \\
\text { Worthwhile }\end{array}$ & $\begin{array}{l}\text { Challenges of Hosting International Volunteers: } \\
\text { "International volunteers...distract staff and local } \\
\text { volunteers from the work" }\end{array}$ & $.028^{\mathrm{b}}$ \\
\hline $\begin{array}{l}\text { Benefits } \\
\text { Outweighing } \\
\text { Challenges }\end{array}$ & $\begin{array}{l}\text { Revenue Generation: "No, we do not receive any money } \\
\text { from hosting international volunteers" }\end{array}$ & $.038^{\mathrm{b}}$ \\
\hline
\end{tabular}

Notes: ${ }^{a}$ This relationship was also significant at $<.05$ according to Fisher's Exact Test (actual test value may vary). ${ }^{\mathrm{b}}$ More than $20 \%$ of cells in this test had an expected cell count of less than five.

One more seemingly significant area where host organization capacity may potentially be expanded by engaging international volunteers relates specifically to fundraising and resource development. As reported by several organizations responding to this study, many former international volunteers return home and continue to assist with fundraising efforts by linking the host organization to potential funders and organizations abroad, helping to spread the word on their mission and available volunteer 
roles, and/or becoming donors themselves. As a phenomenon that could be defined as both organizational capacity development and one of the benefits of the second theoretical foundation presented here - social capital - this topic provides a natural bridge to examine this study's theoretical contributions using this second lens.

\section{Social capital.}

Based on the research of Schneider and other scholars, I posit that there are two key outcomes related to international volunteer engagement and organizational social capital that serve as a foundation for the issues explored in this paper: 1) greater bridging ties between the host organization and global communities, networks, and organizations (including potential donors, funders, partner organizations and future volunteers) and 2) perceived greater trust in the organization due to the engagement of international volunteers (aka symbolic capital). Again, these theories appear to be reinforced by the findings in this study.

For example, while the first and third most frequently cited motivations for hosting international volunteers were related to organizational capacity, the second most frequently cited - by $31.0 \%$ of respondents - was a motivation to host international volunteers because of the opportunities they present for cross-cultural connections, learning, and understanding; this was also the second most frequently cited most important benefit of hosting international volunteers. In addition, the fourth most frequently cited motivation - cited by $14.6 \%$ of respondents - was that international volunteers could potentially contribute financial resources, assist with fundraising, and/or become donors. Additional motivations cited by respondents included "international volunteers help to raise awareness of organization and/or issue individually and 
internationally" (cited by 11.7\%), "international volunteers support local efforts and encourage local involvement/volunteerism" (cited by 4.7\%) and "international volunteers lend credibility and respect to the work" $(2.3 \%)$.

Additional most important benefits mentioned by respondents that are relevant to social capital included an introduction - especially for local young people - to new role models and other personal and professional possibilities, international volunteers making programs and classes more interesting for local participants, international volunteers helping to raise awareness of the organization and/or the organization's mission, international volunteers bringing credibility and respect to the organization's work, international volunteers supporting local efforts by promoting volunteerism and/or attracting local volunteers, and international volunteers helping to open doors and/or improve relations with other organizations. Respondents also cited such most important benefits as international volunteers becoming advocates upon return home, friendships forming between international volunteers and community members that are often sustained beyond the term of service, and the potential for international volunteers to contribute financial resources, assist with fundraising and/or become donors (the latter was the third most frequently cited most important benefit, mentioned by nearly onequarter of respondents.)

Similarly, over half of survey respondents also agreed or strongly agreed with potential benefits statements related to social capital, including that international volunteers "provide an opportunity for local people to learn more about other nations and cultures" (88.0\%), "bring international attention to our work" (79.2\%), "become advocates upon return home" (76.2\%), and "bring credibility to our work" (70.4\%). In 
addition, just under half of respondents agreed or strongly agreed that international volunteers can become financial donors.

A second relationship between international volunteer engagement and organizational social capital that is potentially relevant to this study is the ability of international volunteers to help host organizations build or develop greater trust from local community members, organizations, and decision makers (Keesbury, 2003; Randel et al., 2004; Ihlen, 2007). As Randel et al explained (2004, p. 13), "volunteers are often more trusted by local communities than government...A volunteer can help build trust between local communities and local government. This trust is a form of social capital drawing on it makes implementing programmes easier." This can be considered a type of symbolic capital, as defined by Bourdieu (as cited in Ihlen, 2007, p. 272) as "a reputation for competence and an image of respectability and honorability."

While this study focused on and thus is largely limited to organizational outcomes and experiences, it is also possible that the types of international volunteer engagement reported contributed to greater community social capital as well. This has been identified as a positive outcome of international service by several scholars of international service and, based on some of the perceptions of responding organizational representatives, it appears as though survey respondents have witnessed some of the elements of greater community social capital being developed as well, from an increased level of local volunteer engagement (perhaps due to the appeal of volunteering alongside an international colleague and/or international volunteers demonstrating civic engagement opportunities), new opportunities for bridging ties to be established between and among local individuals and communities, greater human capital (for example, professional 
skills) developed by local volunteers, a broader world lens and greater intercultural competence (as well as potentially decreased racism) within the community, and international networks established between local and international citizens, including providing role models and potential personal/professional contacts for young people, perhaps especially important for youth located in isolated or homogenized communities (Randel et al., 2004; Lewis, 2005; McBride et al., 2007; Plewes \& Stuart, 2007; Sherraden et al., 2008; Lough et al., 2011). Taken a step further, as explained by Randel et al (2004):

International volunteers working in developing countries by their very presence reinforce some of the key elements of social capital within communities. They also help to build awareness of a citizenship beyond community and indeed country - so if social capital can be said to exist beyond local communities, - if there is such a thing as global social capital (which the authors think there is!), volunteer sending has the potential to be a significant catalyst for it. (p. 12).

However, exploring these theories requires more in-depth research, beyond the scope of this paper, to identify if and how community and/or global social capital might be influenced by the engagement of international volunteers.

Again, this dissertation appears to support and be supported by previously identified findings in terms of statistically significant relationships among variables. Here, seven relationships related to social capital were found to be significant within the overall sample (Table 24), with additional relationships also significant within area of focus subgroups. Again though, lacking data on the strength, direction, and causality of these relationships, these findings primarily highlight areas where additional connections between hosting international volunteers and social capital may in fact exist. 
Table 24

Statistically Significant Relationships Related to Social Capital

Dependent Independent Variable Significance

Variable $\quad$ at $<.05$

Benefits $\quad$ Benefits of Hosting International Volunteers: $\quad .000^{\mathrm{b}}$

Outweighing "International volunteers...become advocates upon return

Challenges home"

Whether Most Important Benefits of Hosting International $\quad .000^{\mathrm{b}}$

Hosting is Volunteers: "International volunteers...help to make our

Worthwhile programs more interesting to the population served"

Whether $\quad$ Benefits of Hosting International Volunteers: $\quad .002^{\mathrm{b}}$

Hosting is "International volunteers...become financial donors"

Worthwhile

Benefits Benefits of Hosting International Volunteers:

Outweighing "International volunteers...become financial donors"

Challenges

Benefits Benefits of Hosting International Volunteers:

$.025^{\mathrm{b}}$

Outweighing "International volunteers...bring international attention to

Challenges our work"

Benefits Most Important Benefits of Hosting International

$.025^{\mathrm{b}}$

Outweighing Volunteers: "International volunteers...open doors and/or

Challenges improve relations with other organizations"

Benefits Most Important Benefits of Hosting International

Outweighing Volunteers: "International volunteers...help to raise

Challenges awareness of organization and/or issue individually and internationally"

Notes: ${ }^{\text {a }}$ This relationship was also significant at $<.05$ according to Fisher's Exact Test (actual test value may vary). ${ }^{\mathrm{b}}$ More than $20 \%$ of cells in this test had an expected cell count of less than five.

Respondents to this study's follow-up questions also reported several ways in

which they foster their international networks by staying in touch with former

international volunteers, with many of the reported methods and outcomes mirroring

those mentioned by other scholars in similar research; for example, several respondents

reported former international volunteers staying involved as volunteers from their home 
countries, assisting with outreach and volunteer management tasks from abroad, returning as future volunteers, and developing what are essentially ongoing friendships with staff and local residents. When asked what they believed the benefits might be of staying in touch with international volunteers, follow-up question respondents cited such things as adding credibility to the organization, serving as a social support network, helping to acclimate new volunteers, and contributing to good public relations.

\section{Additional foundational evidence.}

Finally, while not necessarily falling within the two pre-established theoretical families of organizational or social capital theory, several additional conclusions were identified as providing supporting evidence for the findings in this paper. The following sections explore these discoveries.

\section{Overall satisfaction with hosting international volunteers.}

Lough et al (2011, p. 125) found that host organization respondents to their recent survey reported "positive perceptions of [international volunteers]. In fact, the most frequently mentioned outcome was 'general satisfaction' with volunteers.” This was also reflected in this paper's findings as over half of all survey respondents agreed or strongly agreed with all but three of the benefits I'd posited. Respondents also overwhelmingly agreed that the benefits of hosting international volunteers outweighed the challenges and that it was generally worthwhile to host international volunteers.

\section{Challenges of hosting international volunteers.}

Lough et al (2011) also heard from host organizations that had experienced challenges with international volunteers having unrealistic expectations or challenging and/or adjusting to local cultural, social, political, and economic norms. Again, this was 
reflected in this paper's findings as well when respondents were asked to share what they believed to be the most important challenges of hosting international volunteers: the two challenges that rose to the top of the list were 1) many international volunteers have difficulty accepting, adjusting to, and/or adhering to local cultural and/or professional norms and 2) that international volunteers can have unrealistic expectations about what they can or should accomplish and/or how things should be done. While I did anticipate that some version of this challenge might present itself in the data - indeed, I'd included the somewhat related challenge of volunteers being accustomed to different ways of doing things as a statement in the potential challenges question, with which $56.4 \%$ of respondents agreed or strongly disagreed - the frequency with which this challenge was cited, as well as the frustration expressed due to international volunteers' occasional if not frequent inability to adjust to local realities, was surprising. However, comparing these results with those of Lough et al's recent study, it is perhaps simply further evidence that this is indeed one of the primary challenges of hosting international volunteers.

\section{International volunteer management practices.}

This study also offers a new look at existing practices and models for hosting international volunteers. For example, responding organizations offered insight into a number of internal volunteer management practices, providing evidence for the importance of such intake mechanisms as applications, interviews, and pre/on arrival trainings (a finding which further strengthens and expands upon the conclusions of such scholars as McBride et al (2007) and Sherraden et al (2008), the latter of whom determined the matching process to be a critical step for successful international 
volunteer engagement). While some data did already exist on these types of international volunteer management practices, what information we had was very limited in scope and primarily to just volunteer-sending organizations.

\section{Financial investment.}

Several responding organizations also commented on the financial investment made (and often lack of revenue received) for hosting international volunteers, confirming the assertion that there are real costs associated with this activity, many of which are largely borne by the host organization itself (albeit, in some cases, this is offset by volunteer and/or placement organization fees). This again further confirms the findings of McBride et al (2007) who concluded that, even with evidence that host and volunteer-sending organizations often share program costs, engaging international volunteers can still result in a significant investment of time and resources for host organizations.

\section{Host organization characteristics.}

Host organization characteristics reported by respondents - typical project types, the prevalence of international volunteer requirements, etc. - also mirrored several international service models and characteristics described in the current literature; however, again it is worth noting that this pre-existing data had thus far been drawn largely from volunteers and volunteer-sending entities. With the findings presented in this study, we now have further evidence for the prevalence of these models, infrastructures, and characteristics in the field, as reported by practitioners themselves. 


\section{Engaging local actors.}

At the same time, this study reinforces the importance of engaging local actors in the international engagement process. Indeed a strong critique of international service throughout the field is its potential to intentionally or unintentionally disengage local actors - a legitimate concern for those seeking to prevent international volunteering from serving as a form of modern-day colonialism. For example, one of Lewis's (2005) concerns was the exclusion of local actors from the community development process. Similarly, McBride et al (2007) stated that where local organizations and community members actively collaborated with international volunteer-sending organizations again, those entities that coordinate international volunteerism projects and/or serve as a bridge between interested volunteers and foreign host communities - to determine how international volunteers are engaged, more effective programs, both for the volunteers and their hosts, were developed and implemented. The authors also found partnerships between local and international volunteers to be central to community capacity development; these local-international volunteer collaborations were shown to be effective for assessing community need as they helped to ensure that international volunteer roles and projects were wanted and needed by the local community and did not intentionally or unintentionally replace jobs or volunteer roles that could have effectively been filled by local citizens.

With these findings in mind, I was especially interested to learn that over threequarters of this study's respondents disagreed or strongly disagreed that international volunteers take the place of local jobs or local volunteers. I was also intrigued by $59.8 \%$ of respondents reporting that "projects for international volunteers are created by our staff 
based on community feedback and what our community needs". Overall, it appears that many of this study's respondents do involve the community in the decision-making process as well as have an interest in engaging local citizens more fully as volunteers. While further research is necessary to confirm whether the opinions expressed by these respondents is in fact representative of the larger population, this study does appear to support the assertion that the desire to partner more with local individuals and entities exists among host organizations as well.

\section{Research Significance}

Having rooted this study's findings in, as well as discussed how it makes new contributions to, existing theoretical foundations, I will now outline how this research contributes to the field's broader knowledge of international volunteerism and service.

First, by offering a baseline understanding of organizational motivations for and perceived benefits and challenges of engaging international volunteers, this study significantly adds to the growing literature on international civic service, especially the slim body of existing knowledge on host organization impacts, practices and motivations. Indeed, with the exception of a small handful of previously existing studies and the recently published paper by Lough et al in 2011, this dissertation serves as one of the first ever comprehensive explorations of host organization practices, perceptions, and motivations. This new data will help to determine future lines of inquiry into this population as well as potentially offer practical suggestions and models to individual practitioners in the field.

This research also contributes to the broader theoretical foundation on the benefits and value of engaging international volunteers, especially as they relate to organizational 
capacity and social capital. One example of this is the benefits reported by survey participants, ranging from direct benefits to the organization, like contributing needed skills and leveraging staff capacity, to extending benefits to the greater community and international volunteers themselves, e.g. providing opportunities for cross-cultural interaction and personal/professional development. In fact, when I revisited the sixteen categories of motivations I'd identified from open-ended survey responses - this time using a lens of primary beneficiary - it emerged that almost two-thirds of the motivations suggested by respondents directly benefitted the organization; by comparison, onequarter primarily benefitted the community while one-fifth primarily benefitted the volunteer. From an organizational capacity standpoint, this suggests that many if not most responding organizations sought to host international volunteers intentionally, with an eye towards the potential benefits for their organization, rather than simply in response to outside demands or influence.

Another significant contribution is further evidence to suggest that hosting international volunteers can help to build organizational, as well as potentially community, social capital. Indeed, many responding organizations cited motivations and benefits that went beyond the immediate hands-on work a single volunteer could complete while in-country; these included such things as helping to increase trust and perceived organizational credibility, opening doors to new partnerships with potential local and international organizations and funders, and building and strengthening ties with organizational supporters -advocates, volunteers, donors, etc. - again both within the local community and around the globe. 
Overall, a vast majority of responding organizations reported that they as an organization, as well as the community they served, received real tangible and intangible benefits from the engagement of international volunteers. And while real challenges were also highlighted - many of them reflective of concerns expressed in the literature such as the need to more fully engage local actors -host organization respondents consistently emphasized the benefits of international service, overwhelmingly stating that the benefits of hosting international volunteers outweighed the challenges, that it was on the whole worth it for their organization to serve as a host of foreign volunteers. These findings, rooted in existing theory and evidence yet based on a new body of data drawn from a newly heard voice central to the field of international service, are a significant contribution to our understanding of international volunteerism and service, both overall as a phenomenon as well as how it relates to the potential development of organizational capacity and social capital around the globe.

\section{Limitations}

While the preceding sections of this chapter have offered evidence for the significance of this study's findings to the field of international volunteer engagement, it is also critical that we review the limitations of this research in order to most accurately interpret and apply a realistic lens. In total, three types of limitations have been identified that may potentially skew, obscure, or otherwise alter the findings of this study.

\section{Sampling limitations.}

The first and most significant type of limitation is related to sampling. Specifically, as an exploratory study of a largely unmapped population, there were several challenges experienced with determining how - and how much - data to collect. 
For example, given that there is no existing database of all international host organizations, it was impossible to predetermine an ideal response rate much less to ensure that the sample was in fact representative of the overall field. This was then exacerbated by an inability to determine exactly how many organizations (as opposed to organizational representatives) received the survey link from Idealist.org and/or the snowball sampling method.

Another sampling limitation concerned language barriers. While efforts were made to minimize challenges with language by specifically seeking out participants on English-language listservs and websites, there was no guarantee that the person responding to the survey would have sufficient language proficiency to respond. In future studies, in order to collect an even broader array of responses as well to potentially offset this challenge, an ideal solution might be to offer the survey in additional languages, for example, Spanish and French; this may help to facilitate an even higher response rate, especially from organizations located in Latin and South America as well as throughout Africa where these languages may be spoken more frequently and broadly than English.

There is also significant concern that self-selection bias may have skewed responses from those who responded to the survey. For example, it is possible that those who have had more positive experiences with international volunteers might be motivated to share their insights via the survey while those who have had largely negative interactions may simply lack interest in responding. Alternatively, an argument could be made that those who have had negative experiences might be grateful for the forum in which to express their frustrations, thus encouraging a higher response rate among those 
with more negative experiences than positive. Whether one or both of these phenomena occurred though is impossible to determine.

Another concern related to self-selection was that survey responses may have been skewed by those who actively sought international volunteers as compared to those who received them through less pro-active methods. Indeed, when survey respondents were asked whether they actively recruited international volunteers, nearly half responded that they in fact did. While this was perhaps less than might have been expected, it was still a concern that this group of nearly half of all respondents may have skewed overall survey responses. To test this, the data was separated and statistics were run again, both for those organizations that responded that they do actively recruit international volunteers as well as for those that indicated that they did not actively recruit international volunteers.

What I discovered was that little significant skewing appears to have taken place and, where it did, it occurred in both directions. Overall, for only seven of over 185 variables was the difference between responses received from the overall sample and one or both of these subgroups of respondents $+/-5.0 \%$. Instead, for the vast majority of variables, the differences between answers provided by those who do actively recruit international volunteers, those who do not actively recruit international volunteers, and the overall sample were largely minimal.

Given that no clear pattern of influence emerged from the data as well as, where skewing does appear to have occurred, it was driven by both types of organizations those that actively recruit and those that don't - and at what appear to be relatively minor levels of intensity, I determined that the influence self-selecting organizations that do 
actively recruit international volunteers may have had on the overall data and findings was likely minimal.

While few definitive answers were discovered to set concerns to rest regarding these potential sampling challenges, perhaps the larger overall concern is simply the relatively small set of responses received. While 248 responses is a good start to learning more about this unstudied field, it is almost certainly not representative by any definition. Thus it is perhaps best to view the findings discovered here as they were intended: an exploratory (albeit guarded) glimpse into the opinions and practices of a largely unknown population.

\section{Survey design limitations.}

The second type of limitation experienced relates to how survey questions were designed and structured. With no pre-existing baseline data from which to determine such things as appropriate multiple choice answer options, as well as concerns about language proficiency, the decision was made to offer several open-ended questions to allow respondents to explain their answers in open-ended formats. While in many cases this strategy worked as planned, there were a handful of instances where the open-ended nature of the question led primarily to confusion or ambiguity. A prime example of this was the question regarding the volunteer management infrastructure supporting international volunteers at the host organization; here I discovered that categorizing and comparing responses proved to be a very challenging task due to ambiguous, oft difficult to understand responses. However, while the data collected in this survey may be limited in its ability to effectively categorize and compare these reported models for managing international volunteers, perhaps the greatest benefit of asking this question was simply 
gathering the range of responses; these should ideally help to inform the crafting of more accurate multiple choice questions in future surveys, providing opportunities for easier, less ambiguous quantitative analysis of the topic.

A second challenge related to question design and structure was experienced when analyzing follow-up question responses. Specifically, because follow-up question responses could not be tied back to survey responses - and no identifying details were collected from follow-up question respondents - there was no way to tie specific responses to, nor explore potential relationships with, other organizational perceptions and/or characteristics. While this was done intentionally to protect the anonymity of survey respondents, it did deprive follow-up question responses from the context that might have been afforded were they linked to respondents' previously submitted survey responses.

The third challenge related to question design was the limitation of not being able to ask every question I wanted to ask. While this is a common lamentation of the researcher - weighing the balance between asking comprehensive questions and not asking so many questions as to deter responses - not being able to gather all available data from a population without a baseline meant that many characteristics, practices, and other information remains simply unknown. One particularly frustrating example of this is the lack of information about the type and overall structure of responding organizations; for example, history and age, scope or scale, size and type of staffing, budget and funding information, etc. This data would have been very useful, for example, to explore if differences of perspective or practice exist between organizations that are primarily serving local needs vs. those that serve a national population or 
between organizations that have a very small local staff vs. one with a large multinational employee base. However, once again, these are questions designated to future studies.

\section{Analysis limitations.}

The third category of limitations relates primarily to statistical analysis, specifically chi-square. While limiting quantitative analysis only to chi-square - a necessity given the nature of the data - was already a significant challenge, a second concern emerged once analysis had begun.

Specifically, there were many cases where SPSS software identified a significant relationship that was then invalidated by a violation of chi-square assumptions; this occurred where an expected cell count of less than five was considered to be invalid by SPSS yet several of the cells in my data had counts of less than five. In addition, there were also cases in which one or more cells contained zero responses. In these cases, the cells were treated both by the researcher and SPSS as sampling zeros and thus, given the size of the overall sample and the nature of sampling vs. structural zeros, were determined to not invalidate overall chi-square and Fisher's Exact Test results.

I suspect that there were two primary reasons for these challenges. First, many of the survey questions were structured as open-ended responses. This was again done both to facilitate ease of answering for those respondents where English was their second (or even possibly third or fourth) language as well as to allow respondents to offer answers that weren't listed in a multiple choice question structure (again, an especially important feature given the lack of foundational data on host organization perspectives and opinions). However, due to the sheer breadth of answers received via these open-ended survey questions, a broad range of answer categories for each was developed and, in 
many cases, this meant that some answer categories received response frequencies of fewer than five.

Second, there were overwhelmingly positive responses to the two questions that served as the dependent variables for identifying significant relationships: 1) comparing benefits to challenges and 2) whether hosting international volunteers was worthwhile. For example, in response to the first of these two questions, $94.2 \%$ of respondents answered "Yes, I think international volunteers generally provide more benefits than challenges for our organization." This means that only $5.8 \%$ of respondents chose the answer option "No, I think international volunteers generally create more challenges than benefits for our organization" or skipped the question. When answers to this question were then used as the dependent variable for comparison with independent variables particularly those independent variables with multiple answer options - it meant that this $5.8 \%$ of respondents was then spread across multiple independent variable answer options, increasing the likelihood of several cells having fewer than five responses each.

While Cochran's rule, which states that chi-square is a valid metric for identifying significant relationships among variables where no more than $20 \%$ of the cells have expected values of between one and five, is the standard rule of thumb for many researchers using chi-square, according to Delucchi (1993), several scholars have also questioned whether it is in fact too conservative. For example, in a 1978 study of employing chi-square in $2 \times 2$ tables, Camilli and Hopkins "found that expected values as low as one or two were acceptable when the total sample size was greater than 20 " (Delucchi, 1993, p. 300). Similarly, when consulting with Dr. Jason Newsom at Portland State University regarding recommended strategies for addressing this issue in my 
research, he advised that "the regular chi-square should be robust even with expected values as low as 1 or 2" (personal communication, November 3, 2011). However, while Delucchi, similar to Newsom, concluded that chi-square could potentially be used where expected values were much lower than Cochran's parameters, he still recommended using Cochran's rule as a reasonable and accepted foundation for valid measurement. Where this metric was unavailable, he suggested instead employing exact tests (although he also provided a caveat that there was some degree of controversy regarding the validity of these tests as well).

In an attempt to strike a balance between these varying recommendations, I presented my findings in this paper using two lenses: specifically, I reported all relationships that were significant according to chi-square, using footnotes to indicate those tests where a) more than $20 \%$ of cells had an expected count of less than five and/or b) relationships were found to also be significant using Fisher's Exact Test (where available).

My hope is that, for those scholars who might question the validity of these findings based on differing opinions on acceptable expected cell counts, including these potentially contested findings in this study will provide a baseline of data from which future researchers can identify new lines of more focused inquiry as well as craft more appropriate multiple choice answer options, ideally facilitating a less ambiguous data collection and analysis process down the road.

\section{Implications for Host Organizations}

With these limitations in mind, we can then turn attention to how this study might have implications for staff and volunteers of current and potential host organizations. 
Indeed, as one who regularly collaborates with individuals and organizations in the field of international service, I was particularly interested in finding ways to translate the findings of this study into practical applications for practitioners in the field. I suspect that much of this translation will likely take place once these results have been shared with those who do this work on a day-to-day basis; a primary interest in garnering information on the perceptions and practices of host organizations from the organizations themselves was to learn directly from the source. In the interim, however, I have identified eleven implications for organizations that currently or are considering hosting international volunteers.

First, based on the perceived and experienced benefits and challenges reported herein, organizations that are considering hosting international volunteers should have a more accurate range of potential benefits and challenges to consider, helping them to make a more informed decision. For example, if an organization believes that the primary benefit from hosting international volunteers will be financial gain, the findings in this paper may provide them with a more realistic picture that places revenue generation further down the list of both received and realistic benefits.

Similarly, a second potential implication for current or potential host organizations is the finding that many of the benefits that can be derived from hosting international volunteers may take time to realize. For example, while respondents reported several benefits that could be directly experienced in real-time while hosting an international volunteer (for example, engaging a skilled volunteer directly in a task while they are in-country), evidence collected here also suggests that many of the benefits gained from hosting international volunteers are accumulated collectively over the course 
of engaging multiple volunteers. Many respondents cited important benefits that were accrued only after an international volunteer had already returned home, including former volunteers becoming advocates, raising awareness, helping with fundraising, assisting with volunteer recruitment, staying involved as remote volunteers, and becoming donors. Another example of this is greater organizational visibility and credibility, both within the local community and internationally, due to affiliation with international volunteers.

For those organizations considering an international volunteer program, evidence cited in this paper suggests that they might also consider starting with a small, individualized effort; almost two-thirds of respondents reported hosting fewer than 10 international volunteers in 2010 yet over $90 \%$ indicated that they believed the benefits to outweigh the challenges. It can therefore perhaps be surmised that having a larger international volunteer program does not necessarily increase how beneficial it will be to the host organization.

For both future and current host organizations, there is also a clear emphasis on the need for a strategic intake process. For almost every area of focus, at least half of respondents reported requiring an application from their international volunteers. The need for more stringent application, interview, and matching procedures was also cited by several respondents, both as being a current challenge as well as being important components of an ideal international volunteer management model. Similarly, several respondents qualified their answers by stating that the benefits gleaned from engaging international volunteers were linked to how well the volunteer fit with the organization; a clear application and matching process would provide host organizations with additional 
tools and information with which to identify appropriate, potentially more effective international volunteers for their organization.

For those organizations that are seeking to actively recruit international volunteers, this dissertation provides new data on and examples of effective recruitment strategies, including the potential benefits of an informative website and relationships with partner organizations. These findings are especially important for those organizations that seek volunteers with specific skill sets as this study found that the most commonly identified recruitment method for finding these types of volunteers was partnerships with organizations like universities, faith groups, and volunteer-sending organizations.

Based on responses received via both the survey and follow-up questions, both current and potential host organizations should also seek to establish realistic expectations for and with their international volunteers before they embark, as well as prepare for a potentially steep learning - and cultural adjustment - curve upon arrival. Respondents cited these issues as being among the most significant challenges experienced by host organizations. However, they also suggested that these challenges could be minimized using such methods as implementing a formal application/interview process, providing orientation and/or other preparatory materials before a volunteer arrives, and pairing incoming volunteers with experienced current and former volunteers, staff, and local community members.

Along this same vein, this study also identified training as a significant component of an effective international volunteer program. Almost $80 \%$ of respondents reported offering some type of training to their international volunteers. In addition, 
significant relationships were identified between offering training and reported levels of satisfaction with hosting international volunteers. Whether training is offered before and/or upon arrival, it is clear that this is an important step in the international volunteer engagement process.

This dissertation provides new data on and examples of potential structures for international volunteer programs - from staffing and types of service projects to the processes of determining projects and pros and cons of having stricter or more open service requirements. While no clear formulas were developed for a "best" type of international volunteer program structure, many suggested practices and models were identified that can potentially be emulated by other host organizations perhaps to similar result. This includes a list of suggestions respondents provided for helping host organizations benefit even more from engaging international volunteers.

While this study only brushed the surface in terms of identifying geographic and area of focus differences and similarities among host organizations, it is clear that these variations do exist. Therefore while this research offers a broad global snapshot of potential international volunteer hosting models and practices, an even richer, perhaps even more appropriate source might be found via peer host organizations in one's own region, country, and/or mission or cause area.

Based on existing data identified during the literature review as well as responses received via follow-up questions, it is also clear that there is an important role for local volunteers, both as standalone actors and as partners with international volunteers. While further research is needed to fully understand the strengths and potential leveraging 
effects local volunteers might have for host organizations, it is clear that host organizations should at least consider whether and/or how they might be engaged.

Finally, it was interesting to discover that even though fewer than half of respondents reported receiving any type of financial benefit from hosting international volunteers, almost $95 \%$ believed that the benefits of hosting international volunteers outweighed the challenges and almost $100 \%$ agreed that it is generally worthwhile for their organization to host international volunteers. While the question remains whether these responses are representative of the entire field given the limitations of this study, especially the potential for self-selection and sampling biases, from the responses collected here, it appears that there are in fact many benefits - for the host organization, the community, and volunteers themselves - that can be gleaned from facilitating international service and, despite the many challenges and costs that can often accompany this activity, it appears to be ultimately worth it in the vast majority of cases.

\section{Suggestions for Future Research}

By seeking the opinions of host organizations as well as identifying significant relationships between host organization characteristics and opinions, the analysis outlined in this dissertation helps to form a foundation for future studies of both relationship strength/causality and potential new gaps and unanswered questions. Indeed, as one of the first ever studies of host organization perspectives and practices, one of the primary ways the data and findings in this dissertation should perhaps be used is to determine what new and expanded lines of inquiry should be explored. While many if not most of these research questions will be crafted by fellow researchers and academics in the field, here are several suggestions for consideration. 
First, while a broad cross-section of respondents were engaged in this study, there are still significant gaps in the knowledge base. Specifically, given the popularity of international service in these regions - and the relatively low numbers of respondents from these regions represented in this paper - it is important to gather further data from host organizations in Central and South America. Similarly, further data is needed from various typologies of host organizations, for example, additional areas of focus, models of international service (from short-term group projects to long-term remote or online roles), and types of international volunteers engaged (youth volunteers, skilled professionals, faith groups, etc.).

For example, given that this study's tests for statistical significance were limited to chi-square and Fisher's Exact Test, it was difficult to extrapolate from these findings exactly why and what differences might exist between specific areas of focus and reported satisfaction with international volunteers. However, even within these limited samples, there were clearly some very real differences between respondents in specific areas of focus and the overall sample, evidenced in part by the number of relationships found to be unique to each subgroup. These findings on the differences and similarities among host organizations and areas of focus may ultimately serve best as an introduction to this line of study, inspiring future, more in-depth research into the topic. Similarly, several significant relationships were discovered between the age of international volunteers hosted and perceived satisfaction with hosting international volunteers; further research should delve more into this topic to discover if and how this might play out in a larger or more targeted sample. 
Further research is also needed to more fully explore geographic differences and similarities among host organizations. For example, how might identified differences and similarities change when the scale is reduced from region to country; how might the perceptions and characteristics of host organizations in Thailand and Cambodia differ from those in Japan and South Korea? Additional research and more focused inquiry is needed to more accurately identify and understand these factors.

Given that a majority of the responding organizations in this study have relatively young international volunteer programs, it is critical that data also be gathered from older, more established programs - both to provide a baseline for those organizations as well as to offer comparative data via a lens of historical experience.

Similarly, there is also a general need for even more data - both qualitative and quantitative - on the volunteer management infrastructures supporting international volunteers. Overall, a more comprehensive snapshot and nuanced understanding of these management models - staffing, intake, matching, supervision, retention, recognition, communications, evaluation, and especially training - needs to be captured and explored so that the field has an even more accurate picture of relevant management processes, from the recruitment of international volunteers to their continued engagement upon return home.

The topic of international volunteer skills appears to be another rich vein to mine. For example, while over $91 \%$ of respondents agreed or strongly agreed that international volunteers provide needed skills and perspectives, over one-quarter of respondents chose the answer options "neutral" or "not sure" when asked whether they agreed that international volunteers were effective. Similar uncertainty was expressed when asked to 
agree or disagree with the statement that international volunteers "may not have the skills needed"; here, $41.1 \%$ agreed or strongly agreed while $34.5 \%$ disagreed or strongly disagreed. Are these responses contingent upon the type of skill being considered? The length of time the volunteer can stay? The organization's capacity to recruit and retain skilled international volunteers for sufficient periods of time? With ample evidence suggesting that skills are an important factor in effective volunteer engagement, but few answers shedding focused light on the nuances of engaging skilled international volunteers, understanding the disparity between these reported perceptions and opinions is even more critical.

Another area where there was a multitude of mixed responses was regarding potential challenges of engaging international volunteers. Indeed, for eight of the 13 potential challenge statements in the survey, between one-fifth and one-third of respondents chose the answer options of "neutral" or "not sure." Learning more about the challenges of hosting - the situations in which they occur, the factors that might influence a challenge being perceived as more or less relevant - is an important area for future research.

Given the challenges experienced with translating open-ended responses into concrete answer categories, the data in this study was not as amenable to statistical analysis as was intended. However, this study should provide baseline data and clarity for future researchers to design more informed multiple choice questions for future surveys, ideally allowing for clearer explorations of statistical significance and new opportunities to run more robust tests such as analysis of variance and regression analysis on then-parametric data. For example, to explore the fifth guiding research question, I 
proposed and tested twelve different hypotheses; for eight of these, I offered descriptions of the relationships I expected to find; for the remaining four, I was unsure whether a relationship would even in fact exist. And while I suspect that - given the overwhelmingly positive responses to the dependent variable questions of comparing benefits to challenges and whether hosting international volunteers was worthwhile these identified relationships are likely positive in nature (for example, I suspect that those organizations engaging volunteers in their $60 \mathrm{~s}$ and $70 \mathrm{~s}$ and/or offering training also reported more positive levels of satisfaction with their international volunteers, perhaps because these variables may serve as possible indicators of more structured, formalized international volunteer engagement programs), I simply can't be certain using only chisquare to assess them. Instead, I hope that each of these discoveries will serve as starting points for future lines of inquiry, ideally using more robust measures of association to identify strength, direction, and causality within these relationships. Similarly, and again using more robust tools and measures, additional analysis should also be done to further explore the relationships between host organization characteristics, opinions, and perceived satisfaction with hosting international volunteers, especially regarding the strength, direction, and causality of these relationships.

Future studies should also apply an even more qualitative lens to this overall topic as well, perhaps in the form of in-depth case studies or longitudinal analysis. The stories told and examples shared via survey quotes and follow-up questions were insightful, but a qualitative design would allow for an even more comprehensive glimpse into the experiences of host organizations around the globe. 
Future studies should also spend more time on the topic of revenue generation and the costs of hosting international volunteers. A significant relationship was identified in this study's data between perceived satisfaction with hosting international volunteers and not receiving any funding to host them; many respondents also indicated that the potential for international volunteers to generate revenue was a significant motivation and/or potential benefit. However, without more robust tools than chi-square, the strength, direction, and/or causality of these relationships is still unknown. Future research should more fully explore if and what impact receiving funding to cover the costs of hosting international volunteers (as well as potentially other organizational needs) might have on organizational opinions.

Again based both on existing literature and responses received via follow-up questions, further research is also needed to understand the current and potential benefits and challenges, including possible leveraging effects, of engaging local volunteers, both as individual community actors as well as potential partners with international volunteers. This dissertation merely brushed the surface on this topic, one deserving of further and more intensive exploration by future scholars.

Finally, given the exploratory nature of and accompanying broad range of questions asked during the data collection for this study, it was significantly limited in its ability to focus specifically on how hosting international volunteers might relate to the theoretical foundations of organizational capacity and social capital. For example, were this study wholly focused on exploring contributions to organizational theory, additional questions would need to be asked to determine how the hosting organization is structured, staffed, and funded. The field of organizational theory is large and diverse, and it is 
highly likely that additional concepts within organizational theory could also potentially be applied to studies of international host organizations; however, the data collected on organizational characteristics and structural elements for this study were simply too limited to explore organizational theory concepts beyond capacity development. Therefore, future studies should turn a much more focused eye to these foundations, exploring in more depth how these theories apply to the organizational motivations, benefits, and challenges of hosting international volunteers. 


\section{References}

Action Without Borders (2010). Idealist.org. Retrieved from http://www.idealist.org.

Anheier, H. K. \& Salamon, L.M. (1999). Volunteering in Cross-National Perspective: Initial Comparisons. Law and Contemporary Problems 62(4): 43-65.

Arai, S. M. (2000). Typology of Volunteers for a Changing Sociopolitical Context: The Impact on Social Capital, Citizenship and Civil Society. Loisir et sociâetâe. Society and Leisure 23(Part 2): 327-352.

Baron, S., et al., Eds. (2000). Social Capital: Critical Perspectives. Oxford; New York, Oxford University Press.

Brooks, A. C. (2003). Religious Faith and Charitable Giving. Policy Review (121): 39-50.

Brown, E. (1999). Assessing the Value of Volunteer Activity. Nonprofit and Voluntary Sector Quarterly 28(1): 3-17.

Brown, E. \& Ferris, J.M. (2002). The Impacts of Human Capital, Social Capital, and Religious Attendance on Charitable Giving and Volunteering. Association for Research on Nonprofit Organizations and Voluntary Action.

Brudney, J. L. (1990). Expanding the Government-by-Proxy Construct: Volunteers in the Delivery of Public Services. Nonprofit and Voluntary Sector Quarterly 19: 315328.

Brudney, J.L. \& Gazley, B. (2002). Testing the Conventional Wisdom Regarding Volunteer Programs: A Longitudinal Analysis of the Service Corps of Retired Executives and the U.S. Small Business Administration. Nonprofit and Voluntary Sector Quarterly 31: 525-548.

Brudney, J.L. \& Kellough, J.E. (2000). Volunteers in State Government: Involvement, Management, and Benefits. Nonprofit and Voluntary Sector Quarterly 29: 111130. 
Campbell, L.M. \& Smith, C. (2006). What Makes Them Pay? Values of Volunteer Tourists Working for Sea Turtle Conservation. Environmental Management 38 (1): 84-98.

Clary, E.G., Synder, M., Ridge, R.D., Copeland, J., Stukas, A.H., Haugen, J., \& Miene, P. (1998). Understanding and Assessing the Motivations of Volunteers: A Functional Approach. Journal of Personality and Social Psychology 74(6): 15161530 .

Davis Smith, J. (2004). Civic Service in Western Europe. Nonprofit and Voluntary Sector Quarterly 33: 64S-78S.

de Raad, A. (2003). Volunteerism, at the Heart of Social Capital. International Meeting on Mobilizing Social Capital and Volunteer Action in Latin America, Santiago de Chile.

Dekker, P. and Uslaner, E.M., Eds. (2001). Social Capital and Participation in Everyday Life. Routledge/ECPR Studies in European Political Science; 23. London; New York, Routledge/ECPR.

Delucchi, K.L. (1993). On the Use and Misuse of Chi-Square. In G. Keren \& C. Lewis (Eds.), A Handbook for Data Analysis in the Behavioral Sciences: Statistical Issues (pp. 295-313). Hillsdale, NJ: Lawrence Erlbaum Associates, Publishers.

Dohn, M.N. \& Dohn, A.L. (2006). Short-Term Medical Teams: What They Do Well . . and Not So Well. Evangelical Missions Quarterly 42(2): 216-224.

Eby, J.W. (1998). Linking Service and Learning: Observations from the ServiceLearning Movement. Mission Focus Annual Review 6: 137-148.

Erdenechimeg, T., Bulganzaya, T., \& Gantumut, R. (2005). Study on the Effects of the National United Nation's Volunteer Program in Mongolia (CSD Research Report 05-06). St. Louis: Washington University, Center for Social Development.

Ferris, E. (2005). Faith-Based and Secular Humanitarian Organizations. International Review of the Red Cross. 87(858): 311-325. 
Fien, J. and Skoien, P. (2002). "I'm Learning...How You Go about Stirring Things Up-in a Consultative Manner": Social Capital and Action Competence in Two Community Catchment Groups. Local Environment 7(3): 269-282.

Friesen. R. (2005). The Long-term Impact of Short-term Missions. Evangelical Missions Quarterly. October 2005: 448-454

Gakushuu.org. (2011). Historical Perspectives on Organizational Theory. Retrieved from http://gakushuu.org/organizations/organizational-theory.

Gamm, L. \& Kassab, C. (1983). Productivity Assessment of Volunteer Programs in Notfor-Profit Human Services Organizations. Nonprofit and Voluntary Sector Quarterly 12: 23-38.

Handy, F. \& Srinivasan, N. (2005). The Demand for Volunteer Labor: A Study of Hospital Volunteers. Nonprofit and Voluntary Sector Quarterly 34: 491-509.

Handy, F., Mook, L., \& Quarter, J. (2008). The Interchangeability of Paid Staff and Volunteers in Nonprofit Organizations. Nonprofit and Voluntary Sector Quarterly 37: 76-92.

Hays, R. A. (2002). Habitat For Humanity: Building Social Capital Through Faith Based Service. Journal of Urban Affairs 24(3): 247-268.

Horton Smith, D. (1994). Determinants of Voluntary Association Participation and Volunteering: A Literature Review. Nonprofit and Voluntary Sector Quarterly 23: 243-263.

Ihlen, Ø. (2007). Building on Bourdieu: A Sociological Grasp of Public Relations. Public Relations Review 33: 269-274.

Independent Sector (2001) Giving and Volunteering in the United States 2001. Independent Sector. Retrieved from http://www.independentsector.org/GandV/s_keyf.htm.

Independent Sector (2009) Independent Sector. Retrieved from http://www.independentsector.org/programs/research/volunteer_time.html. 
Isham, J., Kolodinsky, J., \& Kimberly, G. (2006). The Effects of Volunteering for Nonprofit Organizations on Social Capital Formation: Evidence from a Statewide Survey. Nonprofit and Voluntary Sector Quarterly 35: 367-383.

Jeannotte, M. S. (2003). Singing Alone? The Contribution of Cultural Capital to Social Cohesion and Sustainable Communities. International Journal of Cultural Policy 9(1): 35-49.

Keesbury, J. (2003). The Value of International Volunteerism: A Review of Literature on International Volunteer-Sending Programs. Washington DC: USAID Development Information Services.

Knack, S. (2002). Social Capital and the Quality of Government: Evidence From the States. American Journal of Political Science 46(4): 772-785.

Krabill, J.R. (1998). The Short-term Experience: Current Trends/Future Challenges. Mission Focus Annual Review 6: 125-135.

Lacey, A. \& Ilcan, S. (2006). Voluntary Labor, Responsible Citizenship, and International NGOs. International Journal of Comparative Sociology 47: 34-53.

Laleman, G., Kegels, G., Marchal, B., Van der Roost, D., Bogaert, I., \& Van Damme, W. (2007). The Contribution of International Health Volunteers to the Health Workforce in Sub-Saharan Africa. Human Resources for Health. 5(19): 1-9.

Lewis, David. (2005). Globalisation and International Service: A Development Perspective. The Journal of the Institute for Volunteering Research 7(2): 13-25.

Lough, B.J. (2006). International volunteerism in the United States, 2005 (CSD Working Paper 06-18). St. Louis: Washington University, Center for Social Development.

Lough, B., McBride, A.M., \& Sherraden, M.S. (2007). The Estimated Economic Value of a US Volunteer Abroad (CSD Working Paper 07-29). St. Louis: Washington University, Center for Social Development. 
Lough, B.J., McBride, A.M., \& Sherraden, M.S. (2009). Perceived Effects of International Volunteering: Reports from Alumni (CSD Research Report 09-10). St. Louis: Washington University, Center for Social Development.

Lough, B.J., McBride, A.M., Sherraden, M.S., \& O’Hara, K. (2011). Capacity Building Contributions of Short-Term International Volunteers. Journal of Community Practice 19(2): 120-137.

McBride, A.M. \& Daftary, D. (2005). International Service: History and Forms, Pitfalls and Potential (CSD Working Paper 05-10). St. Louis: Washington University, Center for Social Development.

McBride, A.M. \& Lough, B.J. (2008). Access to International Volunteering (CSD Working Paper 08-30). St. Louis: Washington University, Center for Social Development.

McBride, A.M., Sherraden, M., Benitez, C., \& Johnson, E. (2004). Civic Service Worldwide: Defining a Field, Building a Knowledge Base. Nonprofit and Voluntary Sector Quarterly 33: 8S-21S.

McBride, A.M., Sherraden, M.S., \& Lough, B.J. (2007). Inclusion and Effectiveness in International Volunteering and Service (CSD Perspective 07-13). U.S. Congressional Briefing on Global Service Fellowships.

McGehee, N. G. (2002). Alternative tourism and social movements. Annals of Tourism Research, 29(1), 124-143.

Plewes, B. \& Stuart, R. (2007). Opportunities and Challenges for International Volunteer Co-Operation. International FORUM on Development Service.

Price, B. (2002). Social Capital and Factors Affecting Civic Engagement as Reported by Leaders of Voluntary Associations. The Social Science Journal 39(Part 1): 119128.

Pratt, B. (2002). Volunteerism and Capacity Development. Development Policy Journal 2: 95-117. 
Priest, R. \& Dischinger, T. (n.d.) Are Short-Term Mission Trips the Key to Bridging Inter-Ethnic Conflict? A Research Study of Ethnocentrism. Trinity International University. Retrieved from http://www.tiu.edu/files/divinity/academics/programs/phd/ics/dischinger05.pdf.

Putnam, R. D. (1995). Bowling Alone: America's Declining Social Capital. Journal of Democracy 6(1): 65-78.

Putnam, R. D. (2000). Bowling Alone: The Collapse and Revival of American Community. New York, Simon \& Schuster.

Randel, J., German, T., Cordiero, M., \& Baker, L. (2004). International Volunteering: Trends, Added Value and Social Capital. Somerset, UK: Development Initiatives.

Rieffel, L. (2005). Reaching out: Americans serving overseas. Brookings Institution.

Rockliffe, B. (2005). International Volunteering: An Evolving Paradigm. Voluntary Action 7(2): 35-44.

Schneider, J. (2007). Connections and Disconnections Between Civic Engagement and Social Capital in Community-Based Nonprofits. Nonprofit and Voluntary Sector Quarterly. 36(4): 572-597.

Schneider, J. (2009). Organizational Social Capital and Nonprofits. Nonprofit and Voluntary Sector Quarterly. 38(4): 643-662.

Schuh, R.G. \& Leviton, L.C. (2006). A Framework to Assess the Development and Capacity of Non-Profit Agencies Evaluation and Program Planning. 29: 171-179.

Scott, W.R. \& Davis, G.F. (2007). Organizations and Organizing: Rational, Natural, and Open Systems Perspectives. Upper Saddle River, New Jersey, Pearson Education, Inc.

ServiceLeader. (2009) Why Involve Volunteers? Retrieved from http://www.serviceleader.org/new/managers/2003/04/000063.php. 
Sherraden, M.S., Stringham, J., Sow, S.C. \& McBride, A.M. (2006). The forms and structure of international voluntary service. Voluntas: International Journal of Voluntary and Nonprofit Organizations 17(2): 156-173.

Sherraden, M.S., Lough, B. \& McBride, A.M. (2008). Effects of International Volunteering and Service: Individual and Institutional Predictors. Voluntas: International Journal of Voluntary and Nonprofit Organizations 17: 395-421.

Slate, C.P. (n.d.). Short-Term vs. Long-Term Missions and the Stewardship of Western Missions Money. Missions Resource Network Library. Retrieved from http://www.mrnet.org/library.

Smith, S. R. (1999). Volunteering and Community Service. Law and Contemporary Problems 62(4): 169-176.

Sundeen, R.A. (1990). Citizens Serving Government: The Extent and Distinctiveness of Volunteer Participation in Local Public Agencies Nonprofit and Voluntary Sector Quarterly 19: 329-344.

UN Volunteers. (2001). Caring Cities: Volunteerism in Urban Development and the Role of the United Nations Volunteers Programme.

UN Volunteers. (2002). Volunteerism and Capacity Development.

Unstead-Joss, R. (2008). An Analysis of Volunteer Motivation: Implications for International Development. Voluntary Action: The Journal of the Institute for Volunteering Research 9(1): 3-20.

The Urban Institute. (2004). Volunteer Management Capacity in America's Charities and Congregations: A Briefing Report. Retrieved May 17, 2009, from http://www.urban.org/UploadedPDF/410963_VolunteerManagement.pdf.

van Deth, J. W. (2003). Measuring Social Capital: Orthodoxies and Continuing Controversies. International Journal of Social Research Methodology 6(1): 79-92.

Van Engen, J. (2000). The cost of short-term missions. Other Side 36: 20-23. 
VanRheenen, G. (n.d.). Money and Mi\$\$ion\$ (Revisited): Combating Paternalism. Missions Resource Network Library. Retrieved from http://www.mrnet.org/library.

Vian, T., Feeley, F., MacLeod, W., Richards, S.C., \& McCoy, K. (2007). Measuring the Impact of International Corporate Volunteering: Lessons Learned from the Global Health Fellows Program of Pfizer Corporation Final Report. Boston University School of Public Health, Center for International Health.

Wilson, J. \& Musick, M. (1998). The Contribution of Social Resources to Volunteering. Social Science Quarterly 79(4): 799-814.

Wilson, J. \& Musick, M. (1999). The Effects of Volunteering on the Volunteer. Law and Contemporary Problems 62(4): 141-168.

Wolozin, H. (1975). The Economic Role and Value of Volunteer Work in the United States: An Exploratory Study. Nonprofit and Voluntary Sector Quarterly 4: 23-42. 


\section{Appendix A: Sample Selection of Idealist.org Areas of Focus}

Table A1

Sample Selection of Idealist.org Areas of Focus (as of January 8, 2011)

\begin{tabular}{|c|c|c|c|c|}
\hline Areas of Focus ${ }^{a}$ & $\begin{array}{c}\text { Total Number } \\
\text { of } \\
\text { Organizational } \\
\text { Profiles }\end{array}$ & $\begin{array}{l}\text { Total Number } \\
\text { of Non-U.S.- } \\
\text { Based } \\
\text { Organizational } \\
\text { Profiles }{ }^{b}\end{array}$ & $\begin{array}{l}\text { Total Number } \\
\text { of Volunteer } \\
\text { Opportunities }\end{array}$ & $\begin{array}{c}\text { Total Number } \\
\text { of Non-U.S.- } \\
\text { Based } \\
\text { Volunteer } \\
\text { Opportunities }\end{array}$ \\
\hline Agriculture & 2193 & 876 & 486 & 345 \\
\hline Animals & 2037 & 409 & 338 & 123 \\
\hline Arts & 6994 & 752 & 1197 & 397 \\
\hline $\begin{array}{l}\text { Civic } \\
\text { Engagement }\end{array}$ & 1499 & 185 & 152 & 20 \\
\hline $\begin{array}{l}\text { Community } \\
\text { Development }\end{array}$ & 8735 & 2001 & 2374 & 1035 \\
\hline $\begin{array}{l}\text { Conflict } \\
\text { Resolution }\end{array}$ & 2270 & 618 & 287 & 103 \\
\hline $\begin{array}{l}\text { Crime and } \\
\text { Safety }\end{array}$ & 1515 & 451 & 305 & 153 \\
\hline Disability & 3217 & 732 & 750 & 364 \\
\hline Disaster Relief & 1821 & 612 & 299 & NA \\
\hline $\begin{array}{l}\text { Economic } \\
\text { Development }\end{array}$ & 5367 & 1554 & 1086 & 541 \\
\hline Education & 23726 & 4099 & 3636 & 1253 \\
\hline $\begin{array}{l}\text { Energy } \\
\text { Conservation }\end{array}$ & 2528 & 527 & 341 & 195 \\
\hline Environment & 9608 & 2211 & 1833 & 697 \\
\hline Family & 6612 & 939 & 1426 & 543 \\
\hline $\begin{array}{l}\text { Health and } \\
\text { Medicine }\end{array}$ & 7616 & 1354 & 1335 & 467 \\
\hline $\begin{array}{l}\text { Housing and } \\
\text { Homelessness } \\
\text { Human Rights }\end{array}$ & 3963 & 407 & 739 & 136 \\
\hline $\begin{array}{l}\text { \& Civil } \\
\text { Liberties }\end{array}$ & 4659 & 1236 & 514 & 183 \\
\hline
\end{tabular}




\begin{tabular}{|c|c|c|c|c|}
\hline Human Services & 1476 & 107 & 540 & 79 \\
\hline Immigration & 1542 & 139 & 321 & 28 \\
\hline $\begin{array}{l}\text { International } \\
\text { Cooperation }\end{array}$ & 1618 & 550 & 321 & 135 \\
\hline $\begin{array}{l}\text { International } \\
\text { Relations }\end{array}$ & 1642 & 383 & 453 & 110 \\
\hline $\begin{array}{l}\text { Job and } \\
\text { Workplace }\end{array}$ & 2395 & 407 & 390 & 67 \\
\hline Legal Assistance & 1402 & 202 & 199 & NA \\
\hline LGBT & 1270 & 107 & 111 & NA \\
\hline Media & 3097 & 543 & 807 & 142 \\
\hline Men & 1368 & 226 & 206 & NA \\
\hline Mental Health & 3477 & 402 & 503 & 91 \\
\hline Microcredit & 620 & 257 & 358 & 129 \\
\hline $\begin{array}{l}\text { Networks of } \\
\text { Nonprofits }\end{array}$ & 3929 & 876 & 480 & 151 \\
\hline Philanthropy & 4070 & 827 & 771 & 324 \\
\hline Politics & 1287 & 166 & 157 & NA \\
\hline $\begin{array}{l}\text { Poverty and } \\
\text { Hunger }\end{array}$ & 3956 & 1069 & 1005 & 224 \\
\hline $\begin{array}{l}\text { Race and } \\
\text { Ethnicity }\end{array}$ & 1341 & 144 & 161 & NA \\
\hline $\begin{array}{l}\text { Religion and } \\
\text { Spirituality }\end{array}$ & 2230 & 275 & 107 & NA \\
\hline $\begin{array}{l}\text { Research and } \\
\text { Science }\end{array}$ & 1263 & 243 & 134 & NA \\
\hline Rural & 2541 & 1404 & 748 & 551 \\
\hline $\begin{array}{l}\text { Seniors and } \\
\text { Retirement }\end{array}$ & 1332 & 86 & 334 & 4 \\
\hline Social Enterprise & 1623 & 500 & 374 & 175 \\
\hline $\begin{array}{l}\text { Sports and } \\
\text { Recreation }\end{array}$ & 1684 & 219 & 370 & 88 \\
\hline Technology & 3262 & 905 & 1122 & 363 \\
\hline Urban & 2130 & 302 & 454 & 134 \\
\hline
\end{tabular}


Volunteering

Women

Youth

TOTAL
9101

6475

19159

58612
2158

8027

2016

1716

1146

477

3783

3827

1263

9124

8028

2016

Notes: ${ }^{a}$ Qualifying Areas of Focus (in bold) are those indicated on a minimum of 1,000 non-U.S.-based organizational profiles and/or 300 non-U.S.-based volunteer opportunities. The exceptions to this are International Cooperation and International Relations which were included for their explicitly international focus. ${ }^{b, c}$ Qualifying statistics are in bold. 


\section{Appendix B: Survey Questions}

[Notes in italics and brackets were not included in the survey text]

Engaging Global Service: Organizational Perspectives on the Value of International Volunteers

Good afternoon!

My name is Erin Barnhart, and I am a Ph.D. student at Portland State University in Portland, Oregon, USA. I am beginning a study on international volunteers and would like to invite you to participate.

You are being asked to take part because your organization is a nonprofit/nongovernmental organization or government agency located outside of the United States. I am interested in your opinions on and experiences with international volunteers. I'm collecting this information to help those in the field of international service have a better understanding of how and why organizations around the world engage international volunteers.

If your organization works with international volunteers, you are invited to participate! (Please note that this study is of organizations that host international volunteers rather than volunteer-sending organizations; if your organization is involved in international service but does not physically host them, please consider forwarding this survey on to any partner host organizations.)

To be eligible for participation in this research, your organization should:

1) Be a nonprofit/nongovernmental organization or government agency that is not located in the United States

2) Focus on, do work in, or seek to address one or more of the following cause, issue, or problem areas: Agriculture, Arts, Community Development, Disability Issues, Economic Development, Education, Environment, Family, Health and Medicine, Human Rights and Civil Liberties, International Cooperation, International Relations, Philanthropy, Poverty and Hunger, Rural Issues, Technology, Volunteering, Women, or Youth.

Any staff person or volunteer at your organization over the age of 18 is welcome to respond to this survey although please note that only one person per organization should participate. Ideally, this person should be the person most responsible for managing your international volunteers.

If you decide to participate in this study, you will be asked to answer 22 questions about your organization, your international volunteers, and your opinions on working with 
international volunteers. This survey should take approximately 15-20 minutes to complete.

Participation in this study is entirely voluntary. The survey does not require your name or your organization's name and all responses are confidential. All information will be transferred from this online survey to my personal computer; should you accidentally include information that identifies you or your organization, this will be deleted.

Please note that this research is for my graduate studies and not on behalf of any nonprofit/nongovernmental organization (for example, Action Without Borders/Idealist.org) or government agency. Your decision to participate or not, as well as your responses to my survey, will not in any way affect your relationship with Idealist.org or any other entity. Should you begin the survey but change your mind and decide that you don't want to finish, you are welcome to stop at any time; your responses will not be sent to me until you choose to submit them at the end of the survey.

There is very little to no risk in participation. You may not receive any direct benefit from taking part in this study, but this study may help to increase knowledge about hosting international volunteers, which could potentially help organizations like yours better plan for future hosting of foreign volunteers.

If you have any questions, please email me directly at ebarnha@pdx.edu. If you have concerns or problems with your participation in this study or your rights as a research subject, please contact the Human Subjects Research Review Committee, Office of Research and Sponsored Projects, 600 Unitus Bldg., Portland State University (Phone number is 1-877-480-4400.) Please save or print a copy of this page for your records. This information can also be found at www.volunteerstudy.wordpress.com.

Ready to get started? Because this is a university study, I am required to first request your informed consent to participate. To do so, please read the following three statements:

1. I am 18 years old or older. (If you are not 18 years old or older, please pass this survey along to someone at your organization who is. Thank you!)

2. I am the person responsible or most responsible for managing international volunteers. (If you are not the person responsible or most responsible for this, please pass this survey along to the person who is. Thank you!)

3. I understand that my responses to this survey will be kept confidential and I agree to participate.

If the three statements above are true for you, please click yes:

1. Yes [Note: If they answered Yes to this question, they skipped the next 
page]
2. No [Note: If they answered No to this question, they continued to the next
page (below)]

[Note: Respondents were required to answer this question]

Page Break

[Note: Respondents only saw this page if they selected No on the previous question.

Upon clicking Continue, they were transferred to the Thank You page at the end of the survey.]

If the three statements on the preceding page were not true for you, then unfortunately you are not eligible to participate in this study.

If this is because you are not 18 years old or older, or the person most responsible for managing international volunteers, please consider sending this survey to someone else at your organization who is eligible to respond. Here is the survey link again:

http://volunteerstudy.questionpro.com/.

Thank you for your time! To exit the survey, please click Continue below.

Page Break

[Note: If respondents selected Yes on the first question, they jumped to this page upon clicking Continue.]

Does your organization currently host international volunteers? By host, we mean that your organization recruits or accepts volunteers from other countries to work on local projects with your organization.

1. Yes [Note: If they answered Yes to this question, they skipped the next page]

2. No [Note: If they answered No to this question, they continued to the next page (below)]

[Note: Respondents were required to answer this question]

Page Break

[Note: Respondents only saw this page if they selected No on the previous question. After answering this question, they were transferred to the Thank You page at the end of the survey.]

Unfortunately if your organization does not currently host international volunteers, then it does not qualify to participate in this study. Before you go though, we'd love to hear why you do not host international volunteers. Thank you! 
[Note: If respondents selected Yes to the question re: hosting international volunteers, they jumped to this page upon clicking Continue.]

Thank you! I am looking forward to learning more about your motivations, experiences, and opinions of hosting international volunteers.

First I have 6 questions about your experiences hosting international volunteers...

1. Why did your organization decide to host international volunteers? If you're not sure, please explain why you think the organization decided to host international volunteers.

2. What do you think are the potential benefits of hosting international volunteers?

Please mark how much you agree or disagree with the following statements:

International volunteers. . .

\begin{tabular}{|c|c|c|c|c|c|c|}
\hline & $\begin{array}{c}\text { Strongly } \\
\text { Agree }\end{array}$ & Agree & Neutral & Disagree & \begin{tabular}{|l|} 
Strongly \\
Disagree \\
\end{tabular} & $\begin{array}{l}\text { Not } \\
\text { Sure }\end{array}$ \\
\hline ...contribute needed skills & $\square$ & $\square$ & $\square$ & $\square$ & $\square$ & $\square$ \\
\hline $\begin{array}{l}\text {...provide more people to get our } \\
\text { work done }\end{array}$ & $\square$ & $\square$ & $\square$ & $\square$ & $\square$ & $\square$ \\
\hline $\begin{array}{l}\text {...provide a new viewpoint or } \\
\text { perspective }\end{array}$ & $\square$ & $\square$ & $\square$ & $\square$ & $\square$ & $\square$ \\
\hline $\begin{array}{l}\text {...provide an opportunity for local } \\
\text { people to learn more about other } \\
\text { nations and cultures }\end{array}$ & $\square$ & $\square$ & $\square$ & $\square$ & $\square$ & $\square$ \\
\hline ...help us attract local volunteers & $\square$ & $\square$ & $\square$ & $\square$ & $\square$ & $\square$ \\
\hline $\begin{array}{l}\text {...bring international attention to } \\
\text { our work }\end{array}$ & $\square$ & $\square$ & $\square$ & $\square$ & $\square$ & $\square$ \\
\hline ...bring credibility to our work & $\square$ & $\square$ & $\square$ & $\square$ & $\square$ & $\square$ \\
\hline ...are effective & $\square$ & $\square$ & $\square$ & $\square$ & $\square$ & $\square$ \\
\hline $\begin{array}{l}. . \text { help our economy by spending } \\
\text { money locally }\end{array}$ & $\square$ & $\square$ & $\square$ & $\square$ & $\square$ & $\square$ \\
\hline $\begin{array}{l}. . \text { generate revenue for our } \\
\text { organization }\end{array}$ & $\square$ & $\square$ & $\square$ & $\square$ & $\square$ & $\square$ \\
\hline
\end{tabular}




\begin{tabular}{|l|c|c|c|c|c|c|}
\hline ...become financial donors & $\square$ & $\square$ & $\square$ & $\square$ & $\square$ & $\square$ \\
\hline $\begin{array}{l}\text {...become advocates upon return } \\
\text { home }\end{array}$ & $\square$ & $\square$ & $\square$ & $\square$ & $\square$ & $\square$ \\
\hline ...are inexpensive & $\square$ & $\square$ & $\square$ & $\square$ & $\square$ & $\square$ \\
\hline
\end{tabular}

What do you think are the most important benefits of hosting international volunteers? If possible, please share a specific example of how international volunteers have benefitted your organization.

3. What do you think are the potential challenges of hosting international volunteers? Please mark how much you agree or disagree with the following statements:

International volunteers. . .

\begin{tabular}{|c|c|c|c|c|c|c|}
\hline & $\begin{array}{l}\text { Strongly } \\
\text { Agree }\end{array}$ & Agree & Neutral & Disagree & $\begin{array}{l}\text { Strongly } \\
\text { Disagree }\end{array}$ & Not Sure \\
\hline ...require a lot of training & $\square$ & $\square$ & $\square$ & $\square$ & $\square$ & $\square$ \\
\hline ...require a lot of supervision & $\square$ & $\square$ & $\square$ & $\square$ & $\square$ & $\square$ \\
\hline $\begin{array}{l}\text {...distract staff and local } \\
\text { volunteers from the work }\end{array}$ & $\square$ & $\square$ & $\square$ & $\square$ & $\square$ & $\square$ \\
\hline $\begin{array}{l}\text {... are accustomed to different } \\
\text { ways of doing things }\end{array}$ & $\square$ & $\square$ & $\square$ & $\square$ & $\square$ & $\square$ \\
\hline $\begin{array}{l}\text {... are not always welcome in } \\
\text { our community }\end{array}$ & $\square$ & $\square$ & $\square$ & $\square$ & $\square$ & $\square$ \\
\hline $\begin{array}{l}\text {...may not have the skills } \\
\text { needed }\end{array}$ & $\square$ & $\square$ & $\square$ & $\square$ & $\square$ & $\square$ \\
\hline $\begin{array}{l}\text {...may not have the language } \\
\text { abilities needed }\end{array}$ & $\square$ & $\square$ & $\square$ & $\square$ & $\square$ & $\square$ \\
\hline ...don't stay long enough & $\square$ & $\square$ & $\square$ & $\square$ & $\square$ & $\square$ \\
\hline ...can be difficult to find & $\square$ & $\square$ & $\square$ & $\square$ & $\square$ & $\square$ \\
\hline $\begin{array}{l}\text {...take the place of local } \\
\text { volunteers }\end{array}$ & $\square$ & $\square$ & $\square$ & $\square$ & $\square$ & $\square$ \\
\hline ...take the place of local jobs & $\square$ & $\square$ & $\square$ & $\square$ & $\square$ & $\square$ \\
\hline ...are not effective & $\square$ & $\square$ & $\square$ & $\square$ & $\square$ & $\square$ \\
\hline ...are expensive & $\square$ & $\square$ & $\square$ & $\square$ & $\square$ & $\square$ \\
\hline
\end{tabular}

What do you think are the most important challenges of hosting international volunteers? If possible, please share a specific example of how international volunteers have been challenging for your organization. 
4. In your opinion, based on your answers above, do the benefits of hosting international volunteers outweigh the challenges?

1. Yes, I think international volunteers generally provide more benefits than challenges for our organization.

2. No, I think international volunteers generally create more challenges than benefits for our organization.

Please explain your answer.

5. Overall, do you think that it is worthwhile for your organization to host international volunteers? Please explain why or why not.

6. In your opinion, how might organizations like yours benefit more from working with international volunteers?

Page Break

Thanks! Next, I would like to ask you 8 questions about your organization...

7. Which country, sovereign state, or territory is your organization located in?

8. What is your organization's primary mission, issue, or area of focus? Please choose only one.

1. Agriculture

2. Arts 
3. Community Development

4. Disability Issues

5. Economic Development

6. Education

7. Environment

8. Family

9. Health and Medicine

10. Human Rights and Civil Liberties

11. International Cooperation

12. International Relations

13. Philanthropy

14. Poverty and Hunger

15. Rural Issues

16. Technology

17. Volunteering

18. Women

19. Youth

9. Is your organization affiliated with a faith group or institution like a church, temple, or mosque?

1. Yes

2. No

If yes, what is your organization's affiliation?

10. In what year did your organization begin hosting international volunteers? If you are not sure, please estimate the year.

11. How are international volunteers managed at your organization? For example, you might have one staff person responsible for this, several staff people who do this, one or more volunteers who manage international volunteers, or they may manage themselves.

12. How does your organization get most of your international volunteers? 
Most of our international volunteers. . .

1. ...find us through our recruitment efforts (for example, posting volunteer opportunities on websites like Idealist.org)

2. ...find us on their own (for example, they hear about us from former volunteers)

3. ....are placed with us by a partner volunteer-sending organization

4. ....are placed with us by other kinds of partner organizations (for example, universities, faith groups, etc.)

5. Other

13. If your organization does actively seek out international volunteers, which recruitment methods have been the most successful? For example, it might be your website, partner organizations, Facebook, etc.

14. Do you have any requirements for accepting an international volunteer? If so, please mark all that apply.

Yes, in most cases, international volunteers must. . .

1. ...have specific skills (for example, they must be qualified to provide medical care)

2. ... have a certain level of education

3. ... be a certain age

4. ...be able to speak one or more local languages

5. ...submit an application to volunteer with us

6. ...complete an interview to volunteer with us

7. ... be qualified in some other way (please specify below).

8. No, we do not have any requirements for our international volunteers

Please explain or share examples.

Page Break

Thank you! Finally, I have 8 questions about your international volunteers...

15. Approximately how many international volunteers did you host in 2010 ? 
16. How old are most of your international volunteers? For example, do you usually have international volunteers who are in their 20 s or older volunteers in their 50 s or 60 s?

17. How long do international volunteers serve with your organization?

\begin{tabular}{|c|c|c|c|}
\hline & Rarely or Never & Occasionally & Almost Always \\
\hline 2 weeks or less & $\square$ & $\square$ & $\square$ \\
\hline Between 2 weeks and 1 month & $\square$ & $\square$ & $\square$ \\
\hline 1 to 3 months & $\square$ & $\square$ & $\square$ \\
\hline 3 to 6 months & $\square$ & $\square$ & $\square$ \\
\hline 6 to 12 months & $\square$ & $\square$ & $\square$ \\
\hline Over 1 year & $\square$ & $\square$ & $\square$ \\
\hline
\end{tabular}

18. What are the most common types of projects done by your international volunteers? For example, do they work directly in the community doing things like teaching or construction? Do they help your organization with things like building your website?

19. How does your organization generally determine projects for international volunteers? Please choose all that apply.

Projects for international volunteers. . .

1. ....are created by our staff based on what our organization needs.

2. ....are created by our staff based on community feedback and what our community needs.

3. ....are suggested or proposed by our partner organizations.

4. ....are suggested or proposed by international volunteers themselves.

5. Other

20. Does your organization offer training to international volunteers? If so, please share what your training is like. For example, you might offer in-person training for new international volunteers or written instructions for how to complete various types of projects. 
21. Does your organization receive or earn any money from hosting international volunteers? Please choose all that apply.

1. Yes, international volunteers pay us a fee to volunteer with our organization.

2. Yes, we receive funding from a partner organization for hosting international volunteers.

3. No, we do not receive any money from hosting international volunteers.

4. Other

If your organization does receive funding from hosting international volunteers - either through fees paid by volunteers or from a partner organization - please share an example of how this works.

22. Thank you again for your participation! Is there anything else we should know to better understand how and why your organization hosts international volunteers?

Finally, one last question: Would you be willing to participate in a follow-up phone call? I would like to talk to a few organizations to learn more about how they work with international volunteers. Please note that your responses will remain anonymous. If you would be willing to participate in this follow-up research, please provide your name and email address below. Thank you!

To submit your responses to this survey, please click Submit below. 
Thank you again for your time! Your answers to these questions will help us understand more about how and why organizations worldwide host international volunteers. Again, thank you!

Thank You for completing this survey [Note: This links to the PSU homepage] 


\section{Appendix C: Follow-Up Questions}

1) Many people responded that hosting international volunteers helps them recruit local volunteers. Does your organization also recruit local volunteers?

a. If YES:

i. What are the benefits of local volunteers?

ii. What are the challenges of local volunteers?

iii. How do the benefits and challenges of local volunteers compare to the benefits and challenges of international volunteers?

b. If NO, why not?

2) Many people said it was valuable to keep international volunteers involved even after they return to their home countries. Some respondents said former international volunteers help raise awareness and visibility for the organization abroad. Others said former international volunteers help recruit new international volunteers and donors. Do any of your former international volunteers - those who have now returned to their home countries - stay involved with your organization?

a. If YES:

i. How do they stay involved?

ii. What are the benefits in keeping former international volunteers involved?

iii. What are the challenges of keeping former international volunteers involved?

b. If NO:

i. Are you interested in keeping former international volunteers involved?

ii. How would you like to keep former international volunteers involved?

iii. What do you think the benefits might be for keeping former international volunteers involved?

iv. What do you think the challenges might be for keeping former international volunteers involved?

3) People said that two big challenges in hosting international volunteers include: (1) International volunteers have difficulty culturally adjusting to local personal and professional ways of doing things, and (2) International volunteers arrive with unrealistic expectations for what they can accomplish.

a. Do you think host organizations can help prepare international volunteers before they arrive? If so, how?

4) People identified many different models for managing their international volunteer programs. For example, some have a volunteer coordinator on their staff while others rely on volunteers or a committee to manage international volunteers. 
a. What would your ideal model for managing international volunteers at your organization look like?

b. What are the main obstacles to achieving this ideal?

5) Finally, many people said language is a big challenge. Yet over $75 \%$ said that the ability to speak a local language is not a requirement for volunteering. Does your organization require international volunteers to speak one or more local languages?

a. If YES:

i. Do you think this makes it easier to recruit appropriate international volunteers? Or does it make recruitment more

b. If NO: difficult? Please explain your answer.

i. Does accepting anyone regardless of their language skills create challenges for your organization?

ii. How do you try to address these challenges?

Thank you again! Please remember to email your responses to me at ebarnha@pdx.edu by [Date 7-10 days after email send date]. 


\section{Appendix D: Distribution of Respondent Countries}

Table A2

Responses to Survey Question "Which country, sovereign state, or territory is your organization located in?"

Country/Sovereign State/Territory

Africa (Undesignated)

Botswana

Cameroon

The Gambia

Ghana

Number of Organizations

Kenya

Liberia

Malawi

Senegal

Sierra Leone

Somalia

South Africa

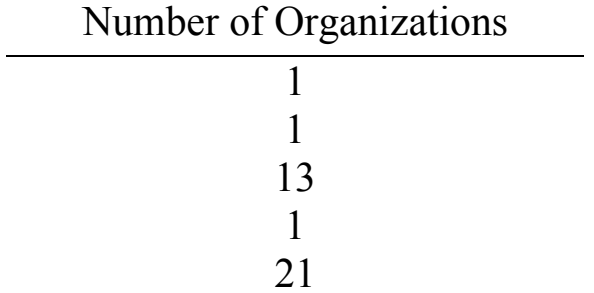

Tanzania

Togo

Uganda

Uganda and South Sudan

TOTAL (AFRICA)

Asia (Undesignated)

103

Bangladesh

Cambodia

India

Indonesia

Israel

Jordan

Kyrgyzstan

Malaysia

Mongolia

Nepal

Pakistan

Palestine/Occupied Palestine Territories

Thailand

Vietnam

Belize 
$\begin{array}{lc}\text { Costa Rica } & 9 \\ \text { Guatemala } & 10 \\ \text { Honduras } & 3 \\ \text { Nicaragua } & 2 \\ \text { TOTAL (CENTRAL AMERICA) } & 25\end{array}$

Croatia 1

Germany 1

Greece $\quad 1$

Italy 2

Lithuania 1

Moldova 2

The Netherlands $\quad 1$

Portugal 1

Romania 2

Spain 1

Switzerland 2

Ukraine 1

United Kingdom

TOTAL (EUROPE) 19

Canada 2

Mexico $\quad 6$

TOTAL (NORTH AMERICA) 8

Australia $\quad 3$

TOTAL (OCEANIA)

Argentina 1

Bolivia 1

Brazil 1

Colombia 1

Ecuador $\quad 4$

Paraguay 2

Peru $\quad 8$

TOTAL (SOUTH AMERICA) 18

$\begin{array}{ll}\text { TOTAL (ALL) } & 248\end{array}$ 